\title{
Development of Extracellular Vesicle Therapeutics: Challenges, Considerations, and Opportunities
}

\section{OPEN ACCESS}

Edited by:

Eduardo Marbán,

Independent Researcher, Los

Angeles, CA, United States

Reviewed by:

Sylwia Bobis-Wozowicz, Jagiellonian University, Poland

Ahmed Gamal Ibrahim, Cedars-Sinai Medical Center, United States

*Correspondence:

David W. Greening

david.greening@baker.edu.au

tORCID:

Bethany Claridge orcid.org/0000-0002-4589-1033 Jonathan Lozano orcid.org/0000-0002-5361-8002

Qi Hui Poh

orcid.org/0000-0003-2620-2834

David W. Greening orcid.org/0000-0001-7516-485X

FThese authors have contributed equally to this work

Specialty section:

This article was submitted to Molecular and Cellular Pathology,

a section of the journal Frontiers in Cell and Developmental

Biology

Received: 01 July 2021

Accepted: 30 July 2021

Published: 20 September 2021

Citation:

Claridge B, Lozano J, Poh QH and Greening DW (2021) Development of Extracellular Vesicle Therapeutics: Challenges,

Considerations, and Opportunities. Front. Cell Dev. Biol. 9:734720. doi: 10.3389/fcell.2021.734720

\author{
Bethany Claridge ${ }^{1,2 \hbar \neq}$, Jonathan Lozano ${ }^{2,3 \hbar \neq}$, Qi Hui Poh ${ }^{1,2 \hbar \neq}$ and David W. Greening ${ }^{1,2,4,5 * t}$
}

1 Department of Biochemistry and Genetics, La Trobe Institute for Molecular Science (LIMS), La Trobe University, Melbourne, VIC, Australia, ${ }^{2}$ Baker Heart and Diabetes Institute, Melbourne, VIC, Australia, ${ }^{3}$ Department of Physiology, Anatomy and Microbiology, La Trobe University, Melbourne, VIC, Australia, ${ }^{4}$ Central Clinical School, Monash University, Melbourne, VIC, Australia, ${ }^{5}$ Baker Department of Cardiometabolic Health, University of Melbourne, Melbourne, VIC, Australia

Extracellular vesicles (EVs) hold great promise as therapeutic modalities due to their endogenous characteristics, however, further bioengineering refinement is required to address clinical and commercial limitations. Clinical applications of EV-based therapeutics are being trialed in immunomodulation, tissue regeneration and recovery, and as delivery vectors for combination therapies. Native/biological EVs possess diverse endogenous properties that offer stability and facilitate crossing of biological barriers for delivery of molecular cargo to cells, acting as a form of intercellular communication to regulate function and phenotype. Moreover, EVs are important components of paracrine signaling in stem/progenitor cell-based therapies, are employed as standalone therapies, and can be used as a drug delivery system. Despite remarkable utility of native/biological EVs, they can be improved using bio/engineering approaches to further therapeutic potential. EVs can be engineered to harbor specific pharmaceutical content, enhance their stability, and modify surface epitopes for improved tropism and targeting to cells and tissues in vivo. Limitations currently challenging the full realization of their therapeutic utility include scalability and standardization of generation, molecular characterization for design and regulation, therapeutic potency assessment, and targeted delivery. The fields' utilization of advanced technologies (imaging, quantitative analyses, multi-omics, labeling/live-cell reporters), and utility of biocompatible natural sources for producing EVs (plants, bacteria, milk) will play an important role in overcoming these limitations. Advancements in EV engineering methodologies and design will facilitate the development of EV-based therapeutics, revolutionizing the current pharmaceutical landscape.

Keywords: extracellular vesicle therapeutics, drug and vector delivery, exosome-based therapeutics, nanomedicine, nanovesicles/microparticles, EV hybrids and mimetics, bioengineering, clincal trials and utility

\section{INTRODUCTION}

Extracellular vesicles (EVs) are nanosized, membranous cell-derived particles with important roles in exchanging molecular information between cells; they have been shown to contain and transfer proteins and nucleic acids (DNA, mRNA, miRNA) to recipient cells, modulating their functional activity through transcriptional and translational regulation (Luga et al., 2012; Xu et al., 2016; Thery et al., 2018; Flaherty et al., 2019; Kalluri and LeBleu, 2020); 
transfer of organelles has also been highlighted by EVs, including mitochondria (Spees et al., 2006), to regulate inflammatory response (Zhang Y. et al., 2021). EVs can be classified by their biogenesis and biophysical/biochemical characteristics. The subtypes include intracellular formed exosomes (50-200 nm) secreted after fusion of multivesicular bodies with the cell surface, microvesicles (100-1,000 nm) formed by outward budding of the plasma membrane, shed midbody remnants released during cytokinesis (200-600 nm), and apoptotic bodies (100-5,000 nm) released during apoptosis (Al-Nedawi et al., 2008; Willms et al., 2016; Xu et al., 2016; van Niel et al., 2018; Jeppesen et al., 2019; Martinez-Greene et al., 2021; Rai et al., 2021). The International Society for EVs (ISEV) recommends the use of "EV" as a broad classifier term for these types of vesicles, due to the difficulty in assigning an EV to a particular biogenesis pathway, and instead recommends classifying EVs by their physical attributes (size, density), their differing biochemical composition, and surface charge (Thery et al., 2018). The nature and relative abundance of EV cargo is selectively determined during EV biogenesis (Palmulli and van Niel, 2018; van Niel et al., 2018; Clancy et al., 2021), and varies according to EV subtype and state/type of the producing cell (Kowal et al., 2016; Xu et al., 2016; Zabeo et al., 2017; Greening and Simpson, 2018; Martin-Jaular et al., 2021). Importantly, EVs, comprising of a lipid membrane and aqueous lumen (Cvjetkovic et al., 2016; Skotland et al., 2019), provide a pathway for the transfer of hydrophobic and hydrophilic components allowing for complex intercellular signaling (Luga et al., 2012; Cossetti et al., 2014; de Couto et al., 2017; Kamerkar et al., 2017; Nabet et al., 2017; Wang and Lu, 2017; Flaherty et al., 2019; Han et al., 2019).

Due to their nanoscale size, stability, biocompatibility, and propensity for cellular uptake, EVs have been recognized as viable vehicles for therapeutic application. Recent studies have highlighted the therapeutic potential of EVs, investigated in clinical trials (phase I/II) for their regenerative capacity (NCT04223622) (Niada et al., 2019), vaccine potential (Gehrmann et al., 2014; Narita et al., 2015; Besse et al., 2016; Coakley et al., 2017; Shehata et al., 2019; Nikfarjam et al., 2020; Andrews et al., 2021), immunotherapeutic activity (Narita et al., 2015; Besse et al., 2016; Chen G. et al., 2018), and application as delivery vectors (NCT01294072). Indeed, pre-clinical and therapeutic applications of EVs across a wide range of pathologies for tissue repair and regeneration are well underway (Table 1). Critically, stem cell-derived EVs can ameliorate the effects of various diseases in the liver (fibrosis, hepatitis, inflammation), brain (stroke), heart (myocardial infarction, contractility), kidney (renal ischemia, stenosis), and immune system [reviewed in Wiklander et al. (2019) and Yin et al. (2019)]. EVs have been shown in various mechanisms to regulate the immune system, enhancing or inhibiting the immune response depending on their parental cell source and of the immune context of the application site (Zhou et al., 2020), demonstrating a potential use in immunotherapy. Indeed, EVs exert specific and potent therapeutic effects on recipient cells because of complex bioactive properties and are an effective and efficient system of cell-cell communication, surmounting biological barriers.

The diverse beneficial effects of seemingly identical entities [i.e., mesenchymal stem cell (MSC)-EVs, bone marrow-derived stem cell (BMDSC)-EVs (Kordelas et al., 2014; de Couto et al., 2017; Xue et al., 2018; Han et al., 2019; Lukomska et al., 2019; Williams A. M. et al., 2019)] suggests a complex repertoire of active cargo (Toh et al., 2018) working synergistically, as opposed to a single molecular component. As such, a global view of EV-based therapeutic action is needed. The biological cargo harbored by EVs, including proteins (Al-Nedawi et al., 2008; Yim et al., 2016; Yuan et al., 2017; Zhang G. et al., 2017; Roefs et al., 2020), nucleic acids (Ratajczak et al., 2006; Liang et al., 2016; Xiao G. Y. et al., 2016; Song et al., 2017; Gu et al., 2018; Shi et al., 2018; Gu Y. Y. et al., 2019; Basalova et al., 2020), and lipids (Lindemann, 1989; Fadok et al., 2000; Gurnani et al., 2004; Yuyama et al., 2014) [reviewed in Greening et al. (2017), Skotland et al. (2019), O'Brien et al. (2020)] (Table 2), greatly influence their clinical potential. The protein and lipid expression of EVs yield insights into their surface receptor mediated interactions with, and effects on recipient cells, including their fusion and uptake (Christianson et al., 2013; Purushothaman et al., 2016; Berenguer et al., 2018), while their genetic landscape sheds light on the EVs' reprogramming potential through regulation of protein expression (Ratajczak et al., 2006; Skog et al., 2008; Abels et al., 2019). Findings from such studies have inspired strategies for EVbased therapeutic development, such as the modification of their contents to perform a specified function for a specific disease phenotype (Table 3) (Al-Nedawi et al., 2008; Hall et al., 2016; Yim et al., 2016; Greening et al., 2017; Yuan et al., 2017; Zhang G. et al., 2017; Chen R. et al., 2019; Shi et al., 2019; Skotland et al., 2019; O'Brien et al., 2020; Roefs et al., 2020). Comprehensive deciphering of EV biochemical and biophysical heterogeneity (Jeppesen et al., 2019), variable composition (Chen et al., 2016; Kowal et al., 2016; Greening et al., 2017; Jeppesen et al., 2019; Martin-Jaular et al., 2021), pharmacokinetic behavior (Gupta et al., 2020), and functional diversity needs to be addressed in order to harness their potential as next generation therapeutics.

Advances and applied technologies which can be used to reproducibly monitor form and function of EVs at molecular and structural levels will be instrumental in future development of EV research knowledge, and therapeutic design and application. Bioinspired engineered EVs/nanovesicles have emerged as an alternative to native EVs to address issues in production, purity, scalability, and economic viability, while maintaining key properties required for in vivo trafficking, biological function, and therapeutic efficiency. Recent advances in bioengineering have allowed the refinement of cargo loading, targeting capacity, and pharmacokinetic properties of EV-based therapeutics, both native and mimetic.

Here, we focus on recent advances in clinical utility of EVs, understanding the molecular complexity of bioactive cargo, avenues for bioengineering, and monitoring the form and function of EVs intended for clinical use. For further discussion on topics not covered in extensive detail here, we direct readers 
to the following recent reviews and position papers (Lener et al., 2015; Reiner et al., 2017; Colao et al., 2018; Pinheiro et al., 2018; Sluijter et al., 2018; Russell et al., 2019; Whitford and Guterstam, 2019; Wiklander et al., 2019; Gandham et al., 2020; Nelson et al., 2020; Pirisinu et al., 2020; Yin et al., 2020; Grangier et al., 2021; Herrmann et al., 2021; Johnson et al., 2021; Ozturk et al., 2021; Sahoo et al., 2021; Suharta et al., 2021).

\section{CURRENT DEVELOPMENTS IN EV-BASED THERAPEUTICS}

Recent years have seen significant development and translation of EV-associated therapeutics, progressing to pre-clinical and clinical studies (Table 1). Further, the capacity of EVs to transfer biological and pharmaceutical molecules to specific tissues and cell types has raised considerable interest in their development as biocompatible drug delivery systems [reviewed in Sluijter et al. (2018); Pirisinu et al. (2020); Herrmann et al. (2021); and Rankin-Turner et al. (2021)]. At present, https://www.clinicaltrials.gov lists 224 studies which include "exosome," 84 with "extracellular vesicle," 9 with "nanocarrier," 4 with "engineered exosome," and 2,101 with "liposome." While a portion of these are diagnostic/biomarker studies, most are clinical trials based on pre-clinical therapeutic success in wound healing (NCT04761562, NCT04281901, and NCT04664738) (Jia et al., 2021; Zhao et al., 2021), heart disease (NCT04327635) (Aday et al., 2021; Hu S. et al., 2021), COVID-19 (NCT04657458, NCT04493242, NCT04276987, NCT04747574, NCT04389385, and NCT04969172) (Mitrani et al., 2021), infectious disease (NCT01478347, NCT01717638, and NCT04350138), diabetes (NCT02138331), stroke (NCT03384433), arthritis (NCT04223622), and drug delivery (NCT01294072, NCT02889822, and NCT04217096). While classified as EV therapies, such studies are more often comprised of a variety of secreted components (i.e., secretome containing soluble factors and EVs) than purified EVs (Table 1). Various terminology is used in the field (Thery et al., 2018), including "extracellular vesicles," “exosomes," "secretomes," "nanoparticles," or components "enriched in extracellular vesicles." Regardless of terminology or composition, these therapies utilize the functional capacity EVs/secreted components have to mediate a recipient-cell response through the delivery of cargo including siRNAs (Shtam et al., 2013), miRNAs (Li L. et al., 2019), proteins (Garaeva et al., 2021), small molecule drugs (Tian et al., 2014), and molecular toolkits (Ye et al., 2020; Luo et al., 2021; Yao X. et al., 2021).

\section{Immunomodulation}

Extracellular vesicles hold the potential for potent immunomodulation, both in eliciting and suppressing immune response (Zhou et al., 2020). EVs share structural similarities to viruses and recent findings demonstrate that viruses exploit mechanisms associated with EV uptake and release (Feng et al., 2013; Altan-Bonnet, 2016; van Dongen et al., 2016; Urbanelli et al., 2019). Previously, the ground-breaking application of EVs in anti-tumor immunotherapy (Zitvogel et al., 1998) led to two clinical trials where EVs activated patient immune response against tumor antigens (Escudier et al., 2005; Morse et al., 2005). Since then, refinements in EV production and modification have led to successful reduction in tumor size in various pre-clinical models (Lee et al., 2012; Mahaweni et al., 2013; Rao et al., 2016; Cheng et al., 2021) and additional clinical trials exploiting their immunomodulatory capabilities to target various cancer types (NCT01550523, NCT01159288, and NCT02507583) (Besse et al., 2016; Andrews et al., 2021). The use of EVs as antigen vehicles is an approach still under development (Cheng et al., 2021; Hu S. et al., 2021), but does represent the most successful translated application. The FDA approved Bexsero bacterial outer membrane vesicle (OMV)-containing meningococcal vaccine is administered to protect against meningococcal group B (Gorringe and Pajon, 2012). This vaccine exploits the complexity of bacterial OMVs to boost immunogenicity of multi-component formulas over those without OMVs (Gorringe and Pajon, 2012). Anti-viral EV-based vaccines are also in development (Sabanovic et al., 2021), with pre-clinical success against COVID-19 (Polak et al., 2020), influenza H1N1 (Rappazzo et al., 2016; Watkins et al., 2017; Shehata et al., 2019), influenza H3N2 (Watkins et al., 2017), and MERS-CoV (Shehata et al., 2019). In addition to immune-priming, EV therapeutics hold the potential for deactivation and suppression of over-active immune responses. Indeed, although results have yet to be released, a clinical trial is underway examining the therapeutic effect of MSC-derived EVs in the autoimmune disease Type I diabetes (NCT02138331). Pre-clinical success in the treatment of sepsis (Song et al., 2017), inflammatory bowel disease (Yang et al., 2015; Mao et al., 2017), and multiple sclerosis (Casella et al., 2018; Laso-Garcia et al., 2018) suggests EV-mediated treatment of inflammatory and autoimmune disorders (Coakley et al., 2017; Sharma et al., 2017; Fujita et al., 2018; Xu H. et al., 2019; Goodman and Davies, 2020; Kahmini and Shahgaldi, 2020; Xu et al., 2020; Horst et al., 2021) may soon expand further into patient trials.

\section{Regeneration and Recovery}

Extracellular vesicle therapeutics are also being explored to facilitate/promote recovery and regeneration following injury, surgery, and tissue damage, such as that arising from viral infections [i.e., pulmonary damage in COVID-19 (Borczuk et al., 2020)]. There are currently 13 clinical trials treating COVID-19 with "exosomes" or "extracellular vesicles" (NCT04902183, NCT04798716, NCT04602442, NCT04747574, NCT04491240, NCT04389385, NCT04276987, NCT04657406, NCT04384445, NCT04623671, NCT04493242, NCT04657458, and NCT04969172). Although no large studies have released results, a case report of three critically ill patients administered with amniotic fluid-derived nanoparticles (likely containing EVs and other small extracellular particles) revealed the therapy had no adverse effects and the patients' status improved (Mitrani et al., 2021). There are now clinical trials further evaluating the safety and efficacy of this treatment for COVID19 (NCT04384445, NCT04657406). Another major application of EV therapies is in accelerated and improved healing and regeneration of damaged tissue (Dalirfardouei et al., 2021; 
TABLE 1 | Clinical and preclinical applications of extracellular vesicles.

\begin{tabular}{|c|c|c|c|c|c|c|c|c|}
\hline & EV type/source ${ }^{*}$ & $\begin{array}{l}\text { Method of isolation/ } \\
\text { components }\end{array}$ & Application & Dosage & Method of administration & $\begin{array}{l}\text { Active component/ } \\
\text { mechanism of action }\end{array}$ & Outcome/Stage & $\begin{array}{l}\text { Clinical trial number/ } \\
\text { References }\end{array}$ \\
\hline \multirow[t]{6}{*}{$\begin{array}{l}\text { Delivery } \\
\text { mechanism }\end{array}$} & $\begin{array}{l}\text { Plant vesides containing } \\
\text { curcumin } \\
\text { Paclitaxel liposome }\end{array}$ & & $\begin{array}{l}\text { Method of curcumin delivery } \\
\text { to colon tumors } \\
\text { Drug delivery for advanced } \\
\text { metastatic pancreatic cancer } \\
\end{array}$ & $\begin{array}{l}175 \mathrm{mg} / \mathrm{m}^{2} \text { (body } \\
\text { surface area) }\end{array}$ & \begin{tabular}{|l|} 
Ingestion, tablet taken daily for \\
7 days \\
Intravenous infusion, once every \\
3 weeks \\
\end{tabular} & & $\begin{array}{l}\text { Phase I, active } \\
\text { Phase IV }\end{array}$ & $\begin{array}{l}\text { NCT01294072 } \\
\text { NCT04217096 }\end{array}$ \\
\hline & $\begin{array}{l}\text { Exosomes derived from Lhfpl5 } \\
\text { AAV-plasmid transfected } \\
\text { HEK293T cells }\end{array}$ & $\begin{array}{l}\text { Ultracentrifugation }(20,000 \mathrm{~g} \text {, } \\
100,000 \mathrm{~g})\end{array}$ & $\begin{array}{l}\text { Treatment of hereditary } \\
\text { deafness in mice }\end{array}$ & & \begin{tabular}{|l}
$\begin{array}{l}\text { Direct injection into the ear } \\
\text { (single dose) }\end{array}$ \\
\end{tabular} & $\begin{array}{l}\text { Restore Lhfipl5 protein } \\
\text { expression }\end{array}$ & $\begin{array}{l}\text { Exosomes containing the plasmid } \\
\text { were able to promote expression of } \\
\text { Lhfpl5 and partially restore hearing to } \\
\text { mice }\end{array}$ & Gyorgy et al., 2017 \\
\hline & \begin{tabular}{|l|} 
Exosomes derived from \\
HEK293T cells expressing \\
Lamp2b fused to IL3 fragment, \\
loaded with Imatinib or siRNA \\
\end{tabular} & $\begin{array}{l}\text { Ultracentrifugation }(10,000 \mathrm{~g}, \\
100,000 \mathrm{~g})\end{array}$ & $\begin{array}{l}\text { Treatment of leukemia in } \\
\text { mice }\end{array}$ & $10 \mu \mathrm{g}$ & $\begin{array}{l}\text { Intraperitoneal injection, twice a } \\
\text { week for } 3 \text { weeks }\end{array}$ & Drug/siRNA & $\begin{array}{l}\text { Exosomes targeted IL3 receptor } \\
\text { overexpressed on leukemia cells, and } \\
\text { inhibited cancer cell growth }\end{array}$ & Bellavia et al., 2017 \\
\hline & \begin{tabular}{|l|} 
Exosomes containing \\
5-Fluorouracil and miR-21 \\
inhibitor
\end{tabular} & $\begin{array}{l}\text { Ultracentrifugation }(10,000 \mathrm{~g}, \\
100,000 \mathrm{~g})\end{array}$ & Treatment of tumors in mice & $2 \mathrm{mg}$ & $\begin{array}{l}\text { Intravenous injection } 3 \text { days a } \\
\text { week for at least 6-7 weeks }\end{array}$ & Drug/miRNA inhibitor & $\begin{array}{l}\text { Exosomes down regulated miR-21 } \\
\text { expression and reduced tumor } \\
\text { growth through reversal of drug } \\
\text { resistance }\end{array}$ & Liang et al, 2020 \\
\hline & $\begin{array}{l}\text { Platelet-derived extracellular } \\
\text { vesicles (whole blood, } \\
\text { platelet-rich plasma) loaded } \\
\text { with TPCA-1 drug }\end{array}$ & \begin{tabular}{|l|l} 
Platelet activation, ultracentrifugation \\
\end{tabular} & $\begin{array}{l}\text { Delivery of anti-inflammatory } \\
\text { agents to pneumonia (acute } \\
\text { lung injury) }\end{array}$ & $12.6 \mathrm{mg} / \mathrm{kg}$ & Intravenous injection (one time) & \begin{tabular}{|l} 
TPCA-1 (drug), \\
anti-inflammatory response, \\
lung (ALI-induced) specific
\end{tabular} & \begin{tabular}{|l|} 
EVs containing anti-inflammation \\
agent TPCA-1 reduced inflammation \\
(CD45 immune cells infiltration) and \\
cytokine storm syndrome \\
(pro-inflammatory cytokines) \\
\end{tabular} & Ma et al., 2020 \\
\hline & $\begin{array}{l}\text { HEK293T-derived } \\
\text { aptamer-modified exosomes } \\
\text { carrying sirNA }\end{array}$ & $\begin{array}{l}\text { Ultracentrifugation }(10,000 \mathrm{~g}, \\
100,000 \mathrm{~g})\end{array}$ & $\begin{array}{l}\text { Treatment of orthotopic } \\
\text { prostate cancer mouse } \\
\text { model }\end{array}$ & & $\begin{array}{l}\text { Intravenous injection twice a } \\
\text { week for } 3 \text { weeks }\end{array}$ & \begin{tabular}{|l} 
SIRT6-siRNA, reduced tumor \\
SIRT6 (incl. Notch pathway)
\end{tabular} & $\begin{array}{l}\text { Engineered exosomes impaired the } \\
\text { proliferation and metastasis of } \\
\text { prostate cancer }\end{array}$ & Han et al., 2021 \\
\hline \multirow[t]{5}{*}{$\begin{array}{l}\text { Immuno- } \\
\text { modulation }\end{array}$} & $\begin{array}{l}\text { Human umbilical cord } \\
\text { mesenchymal stem cell derived } \\
\text { exosomes }\end{array}$ & $\begin{array}{l}\text { Concentration (100 kDa cut-off), } \\
\text { centrifugation with density cushion } \\
(100,000 \mathrm{~g})\end{array}$ & $\begin{array}{l}\text { Treatment of inflammatory } \\
\text { bowel disease in mice }\end{array}$ & $400 \mu \mathrm{g}$ & $\begin{array}{l}\text { Intravenous injection, three } \\
\text { times over } 9 \text { days }\end{array}$ & $\begin{array}{l}\text { Decreasing the expression of } \\
\text { IL-7 }\end{array}$ & $\begin{array}{l}\text { Exosomes relieved the severity of } \\
\text { inflammatory bowel disease through } \\
\text { decrease of inflammatory cytokines } \\
\text { and macrophage infittration }\end{array}$ & Mao et al., 2017 \\
\hline & $\begin{array}{l}\text { Bone marrow mesenchymal } \\
\text { stem cell derived EVs }\end{array}$ & Ultracentrifugation $(100,000 \mathrm{~g})$ & Treatment of colitis in mice & $50-200 \mu \mathrm{g}$ & Intravenous injection (one time) & & $\begin{array}{l}\text { EVs attenuated severity of colitis in } \\
\text { mice through downregulation of } \\
\text { inflammatory cytokines, regulation of } \\
\text { antioxidant/oxidant balance, and } \\
\text { moderation of apoptotic occurrence }\end{array}$ & Yang et al., 2015 \\
\hline & \begin{tabular}{|l|} 
IL-1 $1 \beta$ pre-treated human \\
umbilical cord mesenchymal \\
stem cell derived exosomes
\end{tabular} & $\begin{array}{l}\text { Ultracentrifugation }(10,000 \mathrm{~g}, \\
110,000 \mathrm{~g})\end{array}$ & Treatment of sepsis in mice & $30 \mu \mathrm{g}$ & Intravenous injection (one time) & miR-146a & $\begin{array}{l}\text { Exosomes from mesenchymal stem } \\
\text { cells increased survival rates of septic } \\
\text { mice, possibly through } \\
\text { immunomodulation }\end{array}$ & Song et al., 2017 \\
\hline & $\begin{array}{l}\text { Mesenchymal stem cell derived } \\
\text { EVs }\end{array}$ & $\begin{array}{l}\text { Ultracentrifugation }(18,000 \mathrm{~g}, \\
120,000 \mathrm{~g}) \text { and filtration }(0.22 \mu \mathrm{m})\end{array}$ & \begin{tabular}{|l} 
Treatment of autoimmune \\
encephalomyelitis in mice
\end{tabular} & $60 \mu \mathrm{g}$ & Intravenous injection (one time) & & $\begin{array}{l}\text { EVs attenuated the disease } \\
\text { phenotype, T cell proliferative } \\
\text { potency, leukocyte infitration, and } \\
\text { demyelination }\end{array}$ & Jafarinia et al., 2020 \\
\hline & \begin{tabular}{|l|} 
Umbilical cord-blood \\
mesenchymal stem cell derived \\
microvesicles
\end{tabular} & & Type 1 diabetes mellitus & & $\begin{array}{l}\text { Intravenous infusion, two doses } \\
1 \text { week apart }\end{array}$ & & Phase II/III, no results posted & NCT02138331 \\
\hline \multirow[t]{3}{*}{$\begin{array}{l}\text { Regeneration/ } \\
\text { healing }\end{array}$} & $\begin{array}{l}\text { Human mesenchymal stem cell } \\
\text { derived extracellular vesicles }\end{array}$ & $\begin{array}{l}\text { Ultracentrifugation }(10,000 \mathrm{~g}, \\
100,000 \mathrm{~g})\end{array}$ & $\begin{array}{l}\text { Treatment of a murine } \\
\text { multiple sclerosis model }\end{array}$ & $25 \mu \mathrm{g}$ & Intravenous injection (one time) & & $\begin{array}{l}\text { EV reduced inflammation and levels } \\
\text { of circulating cytokines, reduced } \\
\text { brain atrophy, and promoted } \\
\text { remyelination and motor function }\end{array}$ & Laso-Garcia et al., 2018 \\
\hline & $\begin{array}{l}\text { Autologous plasma rich in } \\
\text { platelets and EVs (PVRP) }\end{array}$ & $\begin{array}{l}\text { None, plasma enriched for platelets and } \\
\text { extracellular vesicles }\end{array}$ & $\begin{array}{l}\text { Healing from surgical } \\
\text { treatment of chronic middle } \\
\text { ear infections }\end{array}$ & & $\begin{array}{l}\text { Gelatine sponge soaked in } \\
\text { PVRP applied to the wound } \\
\text { (one time) }\end{array}$ & & Recruiting & NCT04761562 \\
\hline & $\begin{array}{l}\text { Autologous plasma rich in } \\
\text { platelets and EVs (PVRP) }\end{array}$ & $\begin{array}{l}\text { None, plasma enriched for platelets and } \\
\text { extracellular vesicles }\end{array}$ & $\begin{array}{l}\text { Treatment of chronically } \\
\text { inflamed post-surgical bone } \\
\text { cavities (ear) }\end{array}$ & & \begin{tabular}{|l|} 
Ear wicks soaked in PVRP (one \\
time)
\end{tabular} & & $\begin{array}{l}\text { PVRP patients had improved } \\
\text { treatment outcomes (outcomes } \\
\text { measured: health related quality of } \\
\text { life questionnaire and surface area of } \\
\text { inflammation) }\end{array}$ & NCT04281901 \\
\hline
\end{tabular}




\begin{tabular}{|c|c|c|c|c|c|}
\hline EV type/source ${ }^{*}$ & $\begin{array}{l}\text { Method of isolation/ } \\
\text { components }\end{array}$ & Application & Dosage & Method of administration & $\begin{array}{l}\text { Active component/ } \\
\text { mechanism of action }\end{array}$ \\
\hline $\begin{array}{l}\text { Purified exosome product } \\
\text { (platelet derived, PEP, Rion }{ }^{\mathrm{TM}} \text { ) }\end{array}$ & $\begin{array}{l}\text { Combination of filtration and } \\
\text { centrifugation }\end{array}$ & \begin{tabular}{|l|} 
Treatment (safety) of acute \\
myocardial infarction
\end{tabular} & & $\begin{array}{l}\text { Intracoronary infusion (one } \\
\text { time), } 5 \%, 10 \% \text {, or } 20 \% \text { PEP } \\
\text { over } 5 \text { min }\end{array}$ & \\
\hline \begin{tabular}{|l|} 
Purified exosome product \\
(platelet derived, PEP, Rion ${ }^{\top M}$ )
\end{tabular} & $\begin{array}{l}\text { Combination of filtration and } \\
\text { centrifugation }\end{array}$ & $\begin{array}{l}\text { Treatment (safety) of skin } \\
\text { graft donor site wounds }\end{array}$ & & $\begin{array}{l}\text { Topical, } 10 \% \text { or } 20 \% \text { PEP, } \\
10 \% \text { or } 20 \% \text { PEP with } \\
\text { TISSEEL (fibrin sealant) }\end{array}$ & \\
\hline $\begin{array}{l}\text { Allogenic mesenchymal stem } \\
\text { cell derived exosomes } \\
\text { enriched with miR-124 }\end{array}$ & & $\begin{array}{l}\text { Treatment of acute } \\
\text { ischemic stroke }\end{array}$ & & $\begin{array}{l}\text { Stereotaxis/Intraparenchymal, } \\
\text { (one time) }\end{array}$ & \\
\hline $\begin{array}{l}\text { Adipose mesenchymal stem } \\
\text { cell derived secretome }\end{array}$ & $\begin{array}{l}\text { Concentration of conditioned media } \\
\text { ( } 3 \text { kDa cut-off), whole secretome }\end{array}$ & $\begin{array}{l}\text { Treatment of arthritic } \\
\text { osteochondral explants }\end{array}$ & & exvivo & \\
\hline $\begin{array}{l}\text { Mesenchymal stem cell } \\
\text { derived exosomes }\end{array}$ & Sequential ultracentrifugation & Treatment of macular holes & $20-50 \mu \mathrm{g}$ & Intravitreal injection (one time) & \\
\hline $\begin{array}{l}\text { Autologous extracellular } \\
\text { vesicles from serum }\end{array}$ & & Treatment of venous ulcers & & $\begin{array}{l}\text { Peri-wound injection, once a } \\
\text { week for } 3 \text { weeks }\end{array}$ & \\
\hline \begin{tabular}{|l|} 
Allogeneic derived \\
extracellular vesicle from \\
mesenchymal stem cells \\
(AGLE-102, AEGLE \\
Therapeutics)
\end{tabular} & & $\begin{array}{l}\text { Treatment of dystrophic } \\
\text { epidermolysis bullosa } \\
\text { wounds }\end{array}$ & & Up to six administrations & \\
\hline \begin{tabular}{|l} 
Exosomes derived from bone \\
mesenchymal stem cells \\
(BMSC) and BMSCs \\
overexpressing sonic \\
hedgehog (Shh)
\end{tabular} & Exo Quick-TC kit & $\begin{array}{l}\text { Treatment of spinal cord } \\
\text { injuries in rats }\end{array}$ & $40 \mu \mathrm{g}$ & $\begin{array}{l}\text { Intravenous injection, three } \\
\text { injections total (once every } \\
\text { other day) }\end{array}$ & $\begin{array}{l}\text { Increased level of Shh in } \\
\text { injured tissue }\end{array}$ \\
\hline \begin{tabular}{|l|} 
Human placental \\
mesenchymal stem cell \\
derived extracellular vesicles
\end{tabular} & $\begin{array}{l}\text { Ultracentifíugation }(10,000 \mathrm{~g}, \\
100,000 \mathrm{~g})\end{array}$ & Skin rejuvenation & $75 \mu \mathrm{g}$ & $\begin{array}{l}\text { Chitosan hydrogel loaded with } \\
\text { extracellular vesicles or } \\
\text { extracellular vesicles alone, } \\
\text { three injections over } 2 \text { weeks }\end{array}$ & \\
\hline $\begin{array}{l}\text { Mesenchymal stem cell } \\
\text { derived exosomes }\end{array}$ & \begin{tabular}{|l|} 
Filtration $(0.22 \mu \mathrm{m})$ and \\
ultracentrifugation $(100,000 \mathrm{~g})$
\end{tabular} & $\begin{array}{l}\text { Treatment of vasculature } \\
\text { during stent placement }\end{array}$ & & $\begin{array}{l}\text { Coated onto stent, implanted } \\
\text { for } 4 \text { weeks }\end{array}$ & \\
\hline $\begin{array}{l}\text { Adipose mesenchymal stem } \\
\text { cell derived exosomes }\end{array}$ & $\begin{array}{l}\text { ExoQuick kit or ultrafiltration } \\
(0.22 \mu \mathrm{m})\end{array}$ & $\begin{array}{l}\text { Treatment of osteoarthritis } \\
\text { in mice }\end{array}$ & $1 \times 10^{8}$ particles & $\begin{array}{l}\begin{array}{l}\text { Intra-articular injection (one } \\
\text { time) }\end{array} \\
\end{array}$ & $\begin{array}{l}\text { Exosomes regulate mTOR } \\
\text { signaling through miR-100-5p }\end{array}$ \\
\hline $\begin{array}{l}\text { Bone marrow mesenchymal } \\
\text { stem cell derived exosomes } \\
\text { and microparticles/ } \\
\text { microvesicles }\end{array}$ & $\begin{array}{l}\text { Filtration }(0.22 \mu \mathrm{m}) \text { and } \\
\text { ultracentrifugation }(18,000 \mathrm{~g} \text {, } \\
100,000 \mathrm{~g})\end{array}$ & $\begin{array}{l}\text { Treatment of osteoarthritis } \\
\text { in mice }\end{array}$ & $250-500 \mathrm{ng}$ & $\begin{array}{l}\text { Intra-articular injection (one } \\
\text { time) }\end{array}$ & \\
\hline $\begin{array}{l}\text { Mesenchymal stem cell } \\
\text { derived exosomes }\end{array}$ & $\begin{array}{l}\text { Size exclusion and concentration } \\
\text { (100 kDa cut-off) }\end{array}$ & $\begin{array}{l}\text { Treatment of osteoarthritis } \\
\text { in rats }\end{array}$ & $100 \mu \mathrm{g}$ & $\begin{array}{l}\text { Intra-articular injection weekly } \\
\text { for 2-8 weeks }\end{array}$ & $\begin{array}{l}\text { Exosomes enhanced s-GAG } \\
\text { synthesis and suppressed NO } \\
\text { and MMP13 production } \\
\text { through AKT, ERK, and AMPK } \\
\text { signaling pathways. }\end{array}$ \\
\hline $\begin{array}{l}\text { Mesenchymal stem cell } \\
\text { derived exosomes }\end{array}$ & $\begin{array}{l}\text { Ultracentrifugation }(10,000 \mathrm{~g}, \\
110,000 \mathrm{~g})\end{array}$ & $\begin{array}{l}\text { Treatment of osteoarthritis } \\
\text { in mice }\end{array}$ & & $\begin{array}{l}\text { Intra-articular injection every } \\
3 \text { days for } 4 \text { weeks }\end{array}$ & \\
\hline $\begin{array}{l}\text { Bone marrow mesenchymal } \\
\text { stem cell derived exosomes }\end{array}$ & Exo Quick-TC kit & $\begin{array}{l}\text { Treatment of osteoarthritis } \\
\text { in rats }\end{array}$ & $250 \mathrm{ng}$ & $\begin{array}{l}\text { Intra-articular injection (one } \\
\text { time) }\end{array}$ & $\begin{array}{l}\text { Potentially through } \\
\text { miR-26a-5p targeting of } \\
\text { PTGS2 }\end{array}$ \\
\hline $\begin{array}{l}\text { Mesenchymal stem cell } \\
\text { derived exosomes }\end{array}$ & $\begin{array}{l}\text { Concentration, qEV column, } \\
\text { ultracentrifugation }(100,000 \mathrm{~g})\end{array}$ & $\begin{array}{l}\text { Treatment of spinal cord } \\
\text { injuries in rats }\end{array}$ & $100 \mu \mathrm{g}$ & $\begin{array}{l}\text { Adhesive hydrogel onto } \\
\text { damaged tissue or } \\
\text { intravenous injection }\end{array}$ & \\
\hline
\end{tabular}

\begin{tabular}{|c|c|}
\hline Outcome/Stage & $\begin{array}{l}\text { Clinical trial } \\
\text { number/ } \\
\text { References }\end{array}$ \\
\hline Not yet recruiting & NCT04327635 \\
\hline Enrolling by invitation & NCT04664738 \\
\hline Phase I/II, recruiting & NCT03384433 \\
\hline $\begin{array}{l}\text { Secretome reduced the } \\
\text { pathological phenotype of } \\
\text { explanted chondrocytes }\end{array}$ & $\begin{array}{l}\text { NCT04223622 (Niada } \\
\text { et al, 2019) }\end{array}$ \\
\hline \begin{tabular}{|l|} 
Phase I, active \\
\end{tabular} & NCT03437759 \\
\hline Recruiting & NCT04652531 \\
\hline Phase $\mathrm{I} / \mathrm{l}$, not yet recruiting & NCT04173650 \\
\hline $\begin{array}{l}\text { Both BMSC and BMSC-Shh } \\
\text { exosomes promoted repair of } \\
\text { spinal cord injuries, with } \\
\text { BMSC-Shh exosomes more } \\
\text { beneficial }\end{array}$ & Jia et al., 2021 \\
\hline $\begin{array}{l}\text { EV treatment resulted in reversal of } \\
\text { senescent stage of fibroblasts in } \\
\text { aging skin, stimulating skin } \\
\text { regeneration }\end{array}$ & Zhao et al., 2021 \\
\hline $\begin{array}{l}\text { Exosome coated stents } \\
\text { accelerated re-endothelialisation } \\
\text { and decreased in-stent restenosis. } \\
\text { Promoted tissue repair }\end{array}$ & Hu S. et al., 2021 \\
\hline $\begin{array}{l}\text { Exosomes protected against } \\
\text { cartilage damaged and improved } \\
\text { mobility }\end{array}$ & Wu et al., 2019 \\
\hline $\begin{array}{l}\text { Protected cartilage and bone from } \\
\text { degradation }\end{array}$ & Cosenza et al., 2017 \\
\hline $\begin{array}{l}\text { Exosomes reduced pain levels, } \\
\text { reversed degeneration, and } \\
\text { alleviated bone deterioration }\end{array}$ & Zhang S. et al., 2019 \\
\hline $\begin{array}{l}\text { Exosomes impeded cartilage } \\
\text { destruction }\end{array}$ & Wang et al., 2017 \\
\hline $\begin{array}{l}\text { Exosomes loaded with miR-26a-5p } \\
\text { slow osteoarthritic damage in rats }\end{array}$ & Jin et al., 2020 \\
\hline $\begin{array}{l}\text { Mitigated inflammation and } \\
\text { oxidation, promoting nerve } \\
\text { recovery }\end{array}$ & Li L. et al., 2020 \\
\hline
\end{tabular}


TABLE 1 | (Continued)

\begin{tabular}{|c|c|c|c|c|c|c|c|c|}
\hline & EV type/source* & $\begin{array}{l}\text { Method of isolation/ } \\
\text { components }\end{array}$ & Application & Dosage & Method of administration & $\begin{array}{l}\text { Active component// } \\
\text { mechanism of action }\end{array}$ & Outcome/Stage & \begin{tabular}{|l|} 
Clinical trial \\
number/ \\
References \\
\end{tabular} \\
\hline & $\begin{array}{l}\text { Neural stem cell derived } \\
\text { extracellular vesicles }\end{array}$ & $\begin{array}{l}\text { Ultracentrifugation with a density } \\
\text { cushion }(100,000 \mathrm{~g}) \text { followed by } \\
\text { concentration }\end{array}$ & $\begin{array}{l}\text { Treatment of spinal cord } \\
\text { injuries in rats }\end{array}$ & $200 \mu \mathrm{g}$ & Intravenous injection & $\begin{array}{l}\text { Through induction of } \\
\text { autophagy }\end{array}$ & \begin{tabular}{|l|} 
Reduce neuronal apoptosis, \\
neuroinflammation, and promote \\
functional recovery
\end{tabular} & Rong et al., 2019 \\
\hline & \begin{tabular}{|l|} 
Neural stem cell derived \\
extracellular vesicles
\end{tabular} & \begin{tabular}{l|} 
Filtration $(0.22 \mu \mathrm{m})$, concentration \\
(100 kDa cut off)
\end{tabular} & Treatment of stroke in pigs & & $\begin{array}{l}\text { Intravenous injection, three } \\
\text { times over the } 24 \mathrm{~h} \text { following } \\
\text { surgery }\end{array}$ & & $\begin{array}{l}\text { Extracellular vesicles improved } \\
\text { stroked animal outcomes } \\
\text { (decreased lesion volume, brain } \\
\text { swelling, edema, and preserved } \\
\text { white matter integrity, and } \\
\text { improved behavioral and mobility } \\
\text { outcomes) } \\
\end{array}$ & Webb et al., 2018a \\
\hline & $\begin{array}{l}\text { Bone marrow mesenchymal } \\
\text { stem cell derived exosomes }\end{array}$ & $\begin{array}{l}\text { Ultracentrifugation }(10,000 \mathrm{~g}, \\
100,000 \mathrm{~g})\end{array}$ & \begin{tabular}{|l} 
Treatment of cerebral \\
ischemia-reperfusion injury \\
(stroke) in rats
\end{tabular} & $80-120 \mu \mathrm{g}$ & \begin{tabular}{|l|} 
Intravenous injection one time \\
$2 \mathrm{~h}$ following reperfusion
\end{tabular} & Inhibition of neuron pyroptosis & $\begin{array}{l}\text { Exosomes reduced the brain infarct } \\
\text { area and improved neurological } \\
\text { function }\end{array}$ & Liu et al., 2021 \\
\hline & \begin{tabular}{|l|} 
Hypoxia-preconditioned or \\
normoxic mesenchymal stem \\
cell derived extracellular \\
vesicles (one group \\
overexpressing miR-486-5p)
\end{tabular} & $\begin{array}{l}\text { Ultracentrifugation }(10,000 \mathrm{~g}, \\
120,000 \mathrm{~g}) \text { and filtration }(0.22 \mu \mathrm{m})\end{array}$ & \begin{tabular}{|l} 
Treatment of myocardial \\
infarction in mice and \\
non-human primates
\end{tabular} & \begin{tabular}{|l}
$1 \mathrm{mg}$ (non-human \\
primates), $5 \mathrm{\mu g}$ \\
(mice)
\end{tabular} & $\begin{array}{l}\text { Intracardiac injection (one } \\
\text { time) }\end{array}$ & $\begin{array}{l}\text { miR-486-5p promotes } \\
\text { angiogenesis via } \\
\text { downregulation of cardiac } \\
\text { fibroblast MMP19-VEGFA } \\
\text { cleavage }\end{array}$ & $\begin{array}{l}\text { Improved cardiac function, vascular } \\
\text { density, and smaller infarct size }\end{array}$ & Li et al., 2021d \\
\hline & \begin{tabular}{|l|} 
Exosomes derived from \\
mesenchymal stem cells \\
overexpressing miR-133b
\end{tabular} & \begin{tabular}{|l|} 
Ultracentrifugation $(10,000 \mathrm{~g}$, \\
$100,000 \mathrm{~g})$ and filtration $(0.22 \mu \mathrm{m})$
\end{tabular} & Treatment of stroke in rats & $100 \mu \mathrm{g}$ & $\begin{array}{l}\text { Intra-arterial injection (one } \\
\text { time) }\end{array}$ & miR-133b & \begin{tabular}{|l|} 
Exosomes from miR-133b \\
overexpressing MSCs improved \\
recovery following stroke beyond \\
that of exosomes from control \\
MSCs
\end{tabular} & Xin et al., 2017 \\
\hline & \begin{tabular}{|l|} 
Exosomes conjugated to a \\
cardiac homing peptide
\end{tabular} & $\begin{array}{l}\text { Filtration }(0.22 \mu \mathrm{m}) \text { and concentration } \\
(100 \mathrm{kDa} \text { cut-off) }\end{array}$ & $\begin{array}{l}\text { Treatment of myocardial } \\
\text { infarction in mice }\end{array}$ & & $\begin{array}{l}\text { Intravenous injection (one } \\
\text { time) }\end{array}$ & & \begin{tabular}{|l|} 
Exosomes improved cardiac \\
outcomes, with reduced fibrosis \\
and increased angiogenesis
\end{tabular} & Vandergriff et al., 2018 \\
\hline & $\begin{array}{l}\text { Human neural stem } \\
\text { cell-derived extracellular } \\
\text { vesicles }\end{array}$ & $\begin{array}{l}\begin{array}{l}\text { Filtration }(0.22 \mu \mathrm{m}) \text {, ultrafitration } \\
(100 \mathrm{~K})\end{array}\end{array}$ & $\begin{array}{l}\text { Thromboembolic preclinical } \\
\text { stroke model without } \\
\text { immunosuppression, } \\
\text { murine embolic model }\end{array}$ & $\begin{array}{l}2.7 \times 10^{11} \pm 10 \% \\
\text { vesicles } / \mathrm{kg}\end{array}$ & $\begin{array}{l}\text { Intravenous injection, three } \\
\text { times: two, fourteen and } 38 \mathrm{~h} \\
\text { post stroke }\end{array}$ & \begin{tabular}{|l|} 
Decreased tissue loss (TTC \\
metabolic tissue staining), \\
decreased pro-inflammatory \\
effector Th17 response,
\end{tabular} & $\begin{array}{l}\text { EVs were neuroprotective, reduced } \\
\text { lesion volume and improved } \\
\text { functional outcomes }\end{array}$ & Webb et al., 2018b \\
\hline & $\begin{array}{l}\text { Bone marrow mesenchymal } \\
\text { stem cell derived extracellular } \\
\text { vesicles }\end{array}$ & $\begin{array}{l}\text { Ultracentrifugation }(12,000 \mathrm{~g}, \\
100,000 \mathrm{~g})\end{array}$ & $\begin{array}{l}\text { Treatment of a murine } \\
\text { model of rheumatoid } \\
\text { arthritis }\end{array}$ & $50 \mathrm{mg}$ & $\begin{array}{l}\text { Intra-articular injection twice a } \\
\text { week }\end{array}$ & $\begin{array}{l}\text { miR-21, suppressing } \\
\text { TET1/KLF4 }\end{array}$ & $\begin{array}{l}\text { EVs alleviated rheumatoid arthritis } \\
\text { progression }\end{array}$ & Li et al., 2021b \\
\hline & 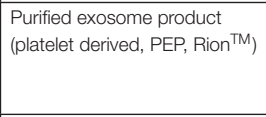 & $\begin{array}{l}\text { Filtration, enucleation, and } \\
\text { centrifugation }\end{array}$ & $\begin{array}{l}\text { Treatment of ischemic } \\
\text { wound healing in rabbits }\end{array}$ & $\begin{array}{l}0.6 \mathrm{~mL} 20 \% \text { PEP } \\
(100 \% \text { is } 5 \times 10 \mathrm{e} 12 \\
\text { particles } / \mathrm{mL})\end{array}$ & $\begin{array}{l}\text { Topical, one group as a } \\
\text { "biogel" combined with a fibrin } \\
\text { sealant (TISSEAL) (one time) }\end{array}$ & $\begin{array}{l}\text { TGF- } \beta \text {. PEP regulated } \\
\text { epithelial transdifferentiation, } \\
\text { collagen reorganization, and } \\
\text { guided tissue development } \\
\end{array}$ & $\begin{array}{l}\text { PEP biogel facilitated dermal } \\
\text { wound healing }\end{array}$ & Shi et al., 2021 \\
\hline & $\begin{array}{l}\text { M2 macrophage-derived } \\
\text { exosomes }\end{array}$ & $\begin{array}{l}\text { Ultracentrifugation }(10,000 \mathrm{~g}, \\
100,000 \mathrm{~g})\end{array}$ & $\begin{array}{l}\text { Treatment of a murine } \\
\text { model of asthma }\end{array}$ & $20 \mu \mathrm{g}$ & Treatment for 3 days in a row & $\begin{array}{l}\text { miR-370, inactivation of } \\
\text { MAPK signaling pathway and } \\
\text { downregulation of FGF1 }\end{array}$ & $\begin{array}{l}\text { Exosomes alleviated asthma } \\
\text { progression }\end{array}$ & Li et al., 2021a \\
\hline & \begin{tabular}{|l|} 
Human amniotic fluid \\
mesenchymal stem cell \\
derived exosomes \\
\end{tabular} & $\begin{array}{l}\text { Ultracentrifugation }(13,000 \mathrm{~g}, \\
100,000 \mathrm{~g})\end{array}$ & $\begin{array}{l}\text { Treatment of isoproterenol } \\
\text { induced cardiac fibrosis in } \\
\text { rats }\end{array}$ & $100 \mu \mathrm{g}$ & $\begin{array}{l}\text { Intravenous injection (one } \\
\text { time) }\end{array}$ & $\begin{array}{l}\text { Increased levels of HIF-1 } 1 \alpha \text { and } \\
\text { VEGF in the heart }\end{array}$ & $\begin{array}{l}\text { Alleviated extracellular matrix } \\
\text { deposition and promoted } \\
\text { angiogenesis, reducing the level of } \\
\text { cardiac remodeling }\end{array}$ & Hu J. et al., 2021 \\
\hline Vaccine & \begin{tabular}{|l} 
Drug treated tumor cells from \\
patients \\
Tumor antigen loaded \\
dendritic cell exosomes
\end{tabular} & None, cell secretome & $\begin{array}{l}\text { Immunotherapy for } \\
\text { malignant glioma } \\
\text { Immunotherapy for lung } \\
\text { cancer }\end{array}$ & & $\begin{array}{l}\text { Cells in small diffusion } \\
\text { chambers with } 0.1 \mu \mathrm{m} \\
\text { exclusion limits, implanted for } \\
48 \mathrm{~h} \\
\text { Intradermal injections once a } \\
\text { week for } 4 \text { weeks } \\
\end{array}$ & \begin{tabular}{|l} 
Immune activation (conclusion \\
reached through cytokine \\
monitoring)
\end{tabular} & $\begin{array}{l}\text { Safety: well tolerated. Increased } \\
\text { progression free survival compared } \\
\text { with historical controls. } \\
\text { Completed, no results posted }\end{array}$ & $\begin{array}{l}\text { NCT01550523 } \\
\text { NCT02507583 } \\
\text { (Andrews et al., 2021) } \\
\\
\text { NCT01159288 }\end{array}$ \\
\hline & $\begin{array}{l}\text { Bacterial outer membrane } \\
\text { vesicles }\end{array}$ & Deoxycholate extraction & $\begin{array}{l}\text { Vaccine against } \\
\text { meningococcal B }\end{array}$ & & $\begin{array}{l}\text { Intramuscular injection, } \\
\text { multi-dose }\end{array}$ & & $\begin{array}{l}\text { Phase III, completed, in use } \\
\text { globally }\end{array}$ & \begin{tabular}{|l|} 
NCT01478347 \\
NCT01717638 \\
NCT00944034 \\
(Claassen et al., 1996; \\
de Kleijn et al., 2001; \\
Gorringe and Pajon, \\
2012)
\end{tabular} \\
\hline
\end{tabular}


TABLE 1 | (Continued)

\begin{tabular}{|c|c|c|c|c|c|c|c|c|}
\hline & EV type/source* & $\begin{array}{l}\text { Method of isolation/ } \\
\text { components }\end{array}$ & Application & Dosage & Method of administration & $\begin{array}{l}\text { Active component/ } \\
\text { mechanism of action }\end{array}$ & Outcome/Stage & $\begin{array}{l}\text { Clinical trial number/ } \\
\text { References }\end{array}$ \\
\hline & Dendritic cell derived exosomes & $\begin{array}{l}\text { Ultracentrifugation }(10,000 \mathrm{~g}, \\
100,000 \mathrm{~g})\end{array}$ & Treatment of tumors in mice & $3-5 \mu \mathrm{g}$ & Intradermal injection (one time) & $\begin{array}{l}\text { Immune activation of T } \\
\text { lymphocytes against tumor } \\
\text { antigens }\end{array}$ & $\begin{array}{l}\text { Suppression or eradication of } \\
\text { established tumors }\end{array}$ & Zitvogel et al., 1998 \\
\hline & $\begin{array}{l}\text { Patient-dendritic cell derived } \\
\text { exosomes loaded with peptides } \\
\text { for MHC }\end{array}$ & $\begin{array}{l}\text { Filtration }(3 / 0.8 \mu \mathrm{m}) \text { and concentration } \\
(500 \mathrm{kDa}) \text {, density cushion }\end{array}$ & \begin{tabular}{|l|}
$\begin{array}{l}\text { Treatment of melanoma } \\
\text { patients }\end{array}$ \\
\end{tabular} & $0.13-0.40 \times 10^{14}$ & $\begin{array}{l}\text { Intradermal and subcutaneous } \\
\text { injections, four vaccinations } \\
\text { over } 4 \text { weeks }\end{array}$ & & $\begin{array}{l}\text { Phase I, exosome administration was } \\
\text { not toxic and had variable immune } \\
\text { response in patients }\end{array}$ & Escudier et al., 2005 \\
\hline & $\begin{array}{l}\text { Patient-dendritic cell derived } \\
\text { exosomes loaded with antigenic } \\
\text { peptides }\end{array}$ & $\begin{array}{l}\text { Filtration }(3 / 0.8 \mu \mathrm{m}) \text { and concentration } \\
(500 \mathrm{kDa}) \text {, density cushion }\end{array}$ & \begin{tabular}{|l} 
Treatment of non-small cell \\
lung cancer patients
\end{tabular} & $1.3 \times 10^{13}$ & $\begin{array}{l}\text { Intradermal and subcutaneous } \\
\text { injections, four vaccinations } \\
\text { over } 4 \text { weeks }\end{array}$ & & $\begin{array}{l}\text { Phase I, exosome therapy well } \\
\text { tolerated and variable immune } \\
\text { response in patients }\end{array}$ & Morse et al., 2005 \\
\hline & $\begin{array}{l}\text { E. coli outer membrane vesicles } \\
\text { (OMVs) through fusion or } \\
\text { attachment of target proteins } \\
\text { with surface protein }\end{array}$ & $\begin{array}{l}\text { Filtration }(0.45 \mu \mathrm{m}, 0.22 \mu \mathrm{m}) \text {, } \\
\text { concentration }(50-\mathrm{K}) \text {, and } \\
\text { ultracentrifugation }(150,000 \mathrm{~g})\end{array}$ & $\begin{array}{l}\text { Promotion of immune } \\
\text { response against tumors in } \\
\text { mice }\end{array}$ & $50 \mu \mathrm{g}$ & $\begin{array}{l}\text { Subcutaneous injection, twice } \\
\text { (4 days apart) }\end{array}$ & $\begin{array}{l}\text { OMVs delivered antigens to } \\
\text { lymph nodes, stimulated } \\
\text { dendritic maturation, promotes } \\
\text { cytokine release. }\end{array}$ & $\begin{array}{l}\text { Elicited a strong T-lymphocyte } \\
\text { mediated anti-tumor immune } \\
\text { response in mice, including immune } \\
\text { memory }\end{array}$ & Hu S. et al., 2021 \\
\hline & $\begin{array}{l}\text { Dendritic cell derived exosomes } \\
\text { loaded with antigenic peptides }\end{array}$ & $\begin{array}{l}\text { Filtration }(3 / 0.8 \mu \mathrm{m}) \text { and concentration } \\
(500 \mathrm{kDa}) \text {, density cushion }\end{array}$ & $\begin{array}{l}\text { Treatment of patients with } \\
\text { non-small cell lung cancer }\end{array}$ & & $\begin{array}{l}\text { Intradermal injections, four } \\
\text { vaccinations over } 4 \text { weeks }\end{array}$ & $\begin{array}{l}\text { Dendritic cell exosomes } \\
\text { increased activity of natural killer } \\
\text { cells }\end{array}$ & $\begin{array}{l}\text { Phase Il, boosted natural killer cell } \\
\text { activity against tumors in some } \\
\text { patients }\end{array}$ & Besse et al., 2016 \\
\hline & $\begin{array}{l}\text { E. coli OMVs engineered to } \\
\text { present influenza antigen-fused } \\
\text { proteins }\end{array}$ & $\begin{array}{l}\text { Filtration }(0.22 \mu \mathrm{m}) \text { and } \\
\text { ultracentrifugation }(121,560 \mathrm{~g})\end{array}$ & $\begin{array}{l}\text { Vaccine against H1N1/H3N2 } \\
\text { influenza A virus }\end{array}$ & $20-40 \mu \mathrm{g}$ & $\begin{array}{l}\text { Subcutaneous injection, two } \\
\text { injections } 4 \text { weeks apart }\end{array}$ & Influenza antigens & $\begin{array}{l}\text { Mice vaccinated with generated } \\
\text { OMVs are protected against H1N1 } \\
\text { influenza A virus }\end{array}$ & $\begin{array}{l}\text { Rappazzo et al., 2016; } \\
\text { Watkins et al., } 2017\end{array}$ \\
\hline & $\begin{array}{l}\text { E. coli OMVs engineered to } \\
\text { present viral antigen-fused } \\
\text { proteins }\end{array}$ & $\begin{array}{l}\text { Filtration }(0.22 \mu \mathrm{m}) \text {, concentration } \\
(100 \mathrm{kDa} \text { cut-off) and ultracentrifugation } \\
(150,000 \mathrm{~g})\end{array}$ & \begin{tabular}{|l|} 
Vaccine against H1N1 \\
influenza and MERS-CoV \\
viruses
\end{tabular} & $5 \mu \mathrm{g}$ & $\begin{array}{l}\text { Intramuscular injection, two } \\
\text { injections } 3 \text { weeks apart }\end{array}$ & Viral antigens & $\begin{array}{l}\text { H1N1 vaccine protected against } \\
\text { H1N1 viral infection. MERS-CoV } \\
\text { vaccine raised antibodies in vivo } \\
\text { which neutralized inactivated } \\
\text { MERS-COV in vitro }\end{array}$ & Shehata et al., 2019 \\
\hline & $\begin{array}{l}\text { CT-26 derived exosomes } \\
\text { containing miR-124-3p mimic }\end{array}$ & Isolated using Exocib kit & Treatment of tumors in mice & $20 \mu \mathrm{g}$ & $\begin{array}{l}\text { Subcutaneous injection three } \\
\text { times with a 3-day interval }\end{array}$ & $\begin{array}{l}\text { miR-124-3p mimic, elicited a } \\
\text { strong anti-tumor immune } \\
\text { response }\end{array}$ & $\begin{array}{l}\text { Exosomes inhibited tumor growth } \\
\text { and increased median survival time }\end{array}$ & Rezaei et al., 2021 \\
\hline \multirow[t]{6}{*}{ COVID-19 } & $\begin{array}{l}\text { Bone marrow mesenchymal } \\
\text { stem cell derived extracellular } \\
\text { vesicles (ExoFlo }{ }^{\mathrm{TM}} \text {, Direct } \\
\text { Biologics }^{\mathrm{TM}} \text { ) }\end{array}$ & & $\begin{array}{l}\text { Treatment of COVID-19 } \\
\text { associated acute respiratory } \\
\text { distress syndrome }\end{array}$ & & Intravenous infusion & & Phase II & \begin{tabular}{|l|} 
NCT04657458 \\
NCT04493242
\end{tabular} \\
\hline & $\begin{array}{l}\text { Allogenic adipose mesenchymal } \\
\text { stem cell derived exosomes }\end{array}$ & & $\begin{array}{l}\text { Treatment of COVID-19 } \\
\text { pneumonia }\end{array}$ & $2 \times 10^{8}$ particles & $\begin{array}{l}\text { Inhalation, once a day for } \\
5 \text { days }\end{array}$ & & $\begin{array}{l}\text { Phase I completed, results not } \\
\text { posted }\end{array}$ & NCT04276987 \\
\hline & $\begin{array}{l}\text { CD24 overexpressing } \\
\text { T-Rex } \\
\text { exosomes }\end{array}$ & & Treatment of COVID-19 & $\begin{array}{l}1 \times 10^{8}, 5 \times 10^{8}, \\
1 \times 10^{9}, 1 \times 10^{10} \\
\text { particles }\end{array}$ & $\begin{array}{l}\text { Inhalation, once a day for } \\
5 \text { days }\end{array}$ & & \begin{tabular}{|l|} 
Phase $/ / I$, , recruiting \\
\end{tabular} & \begin{tabular}{|l|} 
NCT04747574 \\
NCT04902183
\end{tabular} \\
\hline & $\begin{array}{l}\text { Donor derived COVID-19 } \\
\text { specific T-cell derived exosomes }\end{array}$ & & Treatment of COVID-19 & $2 \times 10^{8}$ particles & $\begin{array}{l}\text { Inhalation, once a day for } \\
5 \text { days }\end{array}$ & & Phase $1 / 1 /$, active & NCT04389385 \\
\hline & $\begin{array}{l}\text { Zofin } \\
(\text { Organicell } \\
\text { TM }) \text {-nanoparticles } \\
\text { derived from perinatal sources }\end{array}$ & $\begin{array}{l}\text { Contains soluble factors as well as } \\
\text { extracellular vesicles and nanoparticles }\end{array}$ & \begin{tabular}{|l|} 
Treatment of COVID-19 \\
associated acute respiratory \\
distress syndrome \\
\end{tabular} & $1-5 \times 10^{11}$ particles & $\begin{array}{l}\text { Intravenous infusion, once every } \\
4 \text { days (three doses total) }\end{array}$ & & \begin{tabular}{|l|} 
Phase $/ / I$, , recruiting \\
\end{tabular} & \begin{tabular}{|l|} 
NCT04384445 \\
NCT04657406
\end{tabular} \\
\hline & $\begin{array}{l}\text { Zofin }{ }^{\mathrm{TM}} \\
\left(\text { Organicell } \mathrm{TM}^{\mathrm{M}} \text { )-nanoparticles }\right. \\
\text { derived from perinatal sources }\end{array}$ & $\begin{array}{l}\text { Contains soluble factors as well as } \\
\text { extracellulur vesicles and nanoparticles }\end{array}$ & $\begin{array}{l}\text { Treatment of COVID-19 } \\
\text { associated acute respiratory } \\
\text { distress syndrome in three } \\
\text { patients }\end{array}$ & $\begin{array}{l}2.83 \mathrm{mg} / 3.26 \times 10^{11} \\
\text { particles }\end{array}$ & $\begin{array}{l}\text { Intravenous infusion, three-four } \\
\text { doses over } 9 \text { days }\end{array}$ & & $\begin{array}{l}\text { Therapy was safe for all three } \\
\text { patients, and all were transferred out } \\
\text { of ICU following treatment }\end{array}$ & Mitrani et al., 2021 \\
\hline
\end{tabular}

*Nomenclature presented is that used in study/trial. 
Hu S. et al., 2021; Jia et al., 2021; Lou et al., 2021; Saludas et al., 2021; Zhao et al., 2021). There are promising results in the utilization of EVs to repair arthritic joints (NCT04223622) (Cosenza et al., 2017; Wang et al., 2017; Wu et al., 2019; Zhang S. et al., 2019; Jin et al., 2020) and spinal-cord injuries (Rong et al., 2019; Li L. et al., 2020; Jia et al., 2021), with tissue restoration in EV treatments exceeding that of untreated animals/tissue. As these are recent developments, mechanism of action and clinical translation are still underway. However, there are many clinical trials addressing the regenerative capacity of EVs in surgical and dermal wound healing and tissue regeneration (NCT04652531, NCT04173650, NCT04664738, NCT04761562, and NCT04281901). The regenerative capacity of EVs is also relevant in rescuing and restoring function in damaged organs, including brain (Galieva et al., 2019; Beard et al., 2020) and heart (Kennedy et al., 2020). Animal models of stroke treated with EVs show improved outcomes (Doeppner et al., 2015; Otero-Ortega et al., 2017; Tian et al., 2018; Webb et al., 2018a; Spellicy et al., 2020; Liu et al., 2021), in particular those derived from MSCs overexpressing miR-133b (Xin et al., 2017). Indeed, overexpression of miRNAs in EVs represents a promising avenue, with a clinical trial administering EVs enriched with miR-124 for stroke recovery underway (NCT03384433). Cardiac damage following myocardial infarction is debilitating and previously un-preventable, however, there has been significant preclinical success using EVs in reducing infarct size and restoring cardiac function in various in vivo models (Barile et al., 2014; Bian et al., 2014; Chen C. W. et al., 2018; Vandergriff et al., 2018; Hu S. et al., 2021; Saludas et al., 2021; Zhu et al., 2021b). There is now a clinical trial treating patients with an EV product following acute myocardial infarction (NCT04327635). While we wait for results from these trials to be released, the applications and modulation of EV therapies will continue to be developed for the next phase.

\section{Combination Therapies}

The therapeutic and clinical potential of EVs is further elevated through their biocompatibility and capacity to be surface modified and coupled with other remedial approaches. As discussed, protein or nucleic acid landscape can be modulated in parental cells to generate vaccines (Rappazzo et al., 2016; Watkins et al., 2017; Shehata et al., 2019; Polak et al., 2020; Hu S. et al., 2021) or bio-modified (biosimilar) therapeutics (Xin et al., 2017). These combination therapies can also utilize the protection, stability, and targeting capacity that EVs provide to mediate the delivery of drugs or gene vectors which are otherwise degraded or cleared. Trials in vivo have proven the efficacy and feasibility of EV-mediated adeno-associated virus (AAV) and siRNA delivery when uptake levels of the component alone are sub-optimal (Gyorgy et al., 2017; Munagala et al., 2021). Indeed, in Lhfpl5-/- hereditary deafness, EV-mediated delivery of AAV was more effective in rescuing hearing than AAV treatment alone (Gyorgy et al., 2017). Additionally, EVs delivering siRNA$K R A S$ were able to successfully silence KRAS in murine tumor tissues, reducing tumor size; the same technology also enabled the delivery of plasmids to successfully replace/restore genes (Munagala et al., 2021). Furthermore, the incorporation of drugs and molecular factors into EVs improves their bioavailability and delivery, increasing efficacy of treatment (Aqil et al., 2017; Bellavia et al., 2017; Luan et al., 2017; Liang et al., 2020, 2021). EVs containing curcumin (a natural anti-inflammatory compound) significantly inhibited tumor size when compared with either component alone by increasing curcumin's bioavailability (Aqil et al., 2017). Indeed, the success of this treatment in vivo has led to an active clinical trial investigating the effect of curcumin-containing plant exosomes in the treatment of colon cancer (NCT01294072). While there are few clinical trials using EV-combination therapies (NCT04747574, NCT01294072, and NCT03384433), the pre-clinical success supports the translational potential of this approach.

\section{Commercial Pursuit of Clinical Translation}

Already the revolution of EV therapeutics is underway, with many emerging and established companies now focused on their development and application (Gimona et al., 2017; Zipkin, 2019). Ventures in treatments for dermatological disorders and skin repair (Aegle Therapeutics, XOStem Inc., Exogenus Therapeutics), as well as cancer (Aethlon Medical, Unicyte AG, TAVEC Pharmaceuticals, Puretech Health, EV Therapeutics Inc., Anjarum Biosciences, Codiak Biosciences) and neurological disorders/diseases (Stemcell Medicine Ltd., Puretech Health, Evox Therapeutics, Codiak Biosciences) dominate the commercial EV-based therapeutic landscape. Codiak Biosciences have identified two EV-associated membrane proteins (internal/lumen or external orientated), which they use as scaffolds to link molecules of interest and engineer EVs for therapeutic application; this engineering platform $\left(\mathrm{engEx}^{\mathrm{TM}}\right)$ has been utilized to develop exoSTING (EVs enriched in stimulator of interferon genes in the lumen) (Jang et al., 2021), and exoIL12 (Lewis et al., 2021), currently in Phase 1/2 clinical trial (NCT04592484). Significant efforts in other areas include wound healing (RION Health), metabolic disorders (Evox Therapeutics), fibrotic and immunological conditions (Puretech Health), acute respiratory distress syndrome (Direct Biologics), kidney and liver disease (Unicyte AG), and inflammation (Direct Biologics, Cell-Factory BVBA, Puretech Health). Also in development are treatments for specific debilitating and/or life-threatening disorders (VivaZome Therapeutics), retinal disease (ReNeuron), genetic diseases (Anjarium Biosciences), diabetes (Unicyte AG), stroke (ReNeuron), lymphatic disorders (Puretech Health), and cystic fibrosis (OmniSpirant). With EV therapeutics being developed to combat a wide variety of diseases, understanding these membranous entities, their activities, and their engineering are all critical for achieving full therapeutic potential.

\section{EVS AS NANOCARRIERS OF FUNCTIONAL CARGO}

Native EVs are cell-derived, lipid-bound nanoparticles (30$1000 \mathrm{~nm}$ ) that facilitate intercellular communication through targeted delivery of bioactive cargo to alter recipient cell 
phenotype (Al-Nedawi et al., 2008; Skog et al., 2008; AlvarezErviti et al., 2011; Peinado et al., 2012; Kamerkar et al., 2017; Wu et al., 2019; Cocozza et al., 2020; Li et al., 2021b) [reviewed in Vader et al. (2016), Murphy et al. (2019), and Russell et al. (2019)]. EVs are involved in transferring molecular cargo, between animal cells (Valadi et al., 2007; Mittelbrunn et al., 2011; Ono et al., 2019), from parasite to its mammalian host (Buck et al., 2014; Coakley et al., 2017), and from plant to fungal cells (Cai et al., 2018). In addition to their role in communication between cells and organs, EVs are excellent therapeutic delivery systems due to their: (i) ability to protect bioactive cargo, (ii) inherent biocompatibility, (iii) small size and negative surface charge, (iv) ability to cross biological membranes, including blood-brain barrier (BBB), and (v) capacity to target specific cells. The rigid structured membranes [resulting from an abundance of sphingomyelin (Niemela et al., 2004; Saeedimasine et al., 2019; Smith et al., 2020) and cholesterol (Needham and Nunn, 1990; Leftin et al., 2014)] of EVs protect biological macromolecules from degradation [i.e., nucleases (Skog et al., 2008; Cheng et al., 2014; Fernando et al., 2017) and proteases (Haney et al., 2015; Cvjetkovic et al., 2016; Sterzenbach et al., 2017; Zaborowski et al., 2019)] and micro-environmental changes [i.e., pH (Parolini et al., 2009; Aoi and Marunaka, 2014) and osmolarity (Fathali et al., 2017)]. Therefore, compared to soluble factors, EVs more efficiently deliver a complex variety of active biomolecules (Obregon et al., 2009) resulting in greater potency (Mitchell et al., 2019; Cocozza et al., 2020; Gurung et al., 2020). As a result of their cellular origin, EVs are associated with low immunogenicity (Zhu et al., 2017; Sharma et al., 2020) and are capable of interacting with innate immune cells through surface-expressed components (Admyre et al., 2003; Tietjen et al., 2014; Rao et al., 2015; Antes et al., 2018) [e.g., anti-phagocytic signals (Rodriguez et al., 2013; Gordon et al., 2017; Kamerkar et al., 2017; Hsu et al., 2018; Tang Y. et al., 2019; Cordonnier et al., 2020; Daassi et al., 2020) and opsonins (Miksa et al., 2009)]. EV-mediated crosstalk may occur unidirectionally or reciprocally or even via systemic communication, during which EVs target to various tissues and organs. Importantly, the EV surfaceome also facilitates inherent targeting properties/tropism (Nakamizo et al., 2005; Kidd et al., 2009; Hoshino et al., 2015; Wu et al., 2020) and direct signal transduction (Nazarenko et al., 2010; Rana et al., 2011; Sobo-Vujanovic et al., 2014; Vinas et al., 2018). Further, EV surface composition is important for traversing biological barriers [e.g., BBB (Haney et al., 2015; Hall et al., 2016; Kojima et al., 2018)] through receptormediated transcytosis. The mechanisms by which EVs are internalized by target cells are still poorly understood, often uptake is cell and context dependent. Currently known cellular entry routes of EVs are complex mechanisms ranging through receptor-mediated endocytosis, lipid raft interactions, clathrin interactions, phagocytosis, micropinocytosis and possibly direct fusion (Mathieu et al., 2019). As such, uptake and intracellular mechanisms of trafficking and localization requires more indepth evaluation exploring subcellular analyses using highresolution microscopy, subcellular composition studies, or novel live-cell reporters (Chen M. et al., 2018; Sung et al., 2020). In this section, we discuss EVs as carriers of functional cargo and their therapeutically promising characteristics.

\section{Cell Reprogramming Using EVs}

Preclinical development of EVs have focused on their ability to horizontally transfer bioactive components, eliciting transcriptional and translational modulation (Valadi et al., 2007), antigen presentation (Gurnani et al., 2004; Garcia et al., 2016), and functional regulation in recipient cells (Al-Nedawi et al., 2008; Skog et al., 2008; Alvarez-Erviti et al., 2011; Peinado et al., 2012; Kamerkar et al., 2017; Wu et al., 2019; Zhang Q. et al., 2019; Cocozza et al., 2020; Li et al., 2021b). A landmark study demonstrated that embryonic stem cell derived EVs contribute to epigenetic reprogramming of target cells (Ratajczak et al., 2006); EVs were enriched in key players for early pluripotency, hematopoietic stem cells ( $\mathrm{Scl}, \mathrm{HoxB} 4$ and GATA 2), and induced MAPK/Akt phosphorylation. Here, mRNA could be delivered by EVs to target hematopoietic stem/progenitor SKL cells and translated as Oct- 4 protein expression. Of note, the biological effects of EVs were perturbed following heat inactivation or pretreatment with RNAse, indicating major involvement of the horizontal transfer of mRNA/proteins by EVs in the observed phenomena. Recently, adipocytes have been shown to release lipid-filled EVs that serve as the primary source of lipid for adipose-resident macrophages (Flaherty et al., 2019). Adipocyte-derived EVs have been described previously, primarily as regulators of inflammation and systemic insulin resistance (Thomou et al., 2017). The uptake of adipocyte EVs facilitated the direct transfer of lipids, and a macrophage-type specific transcriptional activation of lipid metabolism in bone marrow cells., revealing a form of intercellular communication and nutrient exchange with important implications for obesityassociated pathologies (Flaherty et al., 2019). Thus, EVs exert functional effects on recipient cells by modifying their composition through protein, lipid or nucleic acid transfer. This mechanism of action has also been demonstrated in other diseases (i.e., sepsis, fibrosis, cardiomyopathy) where various induced disease models were used to highlight the protective and regenerative roles of EVs, as well as identify the key EV-associated bioactive molecules involved in such functions (Table 2), which provides a strategy to improve the efficacy of EV treatment. In an acute myocardial infarction (AMI) murine model (Gu et al., 2018), EV-mediated transfer of miR-21 protected cardiomyocytes from oxidative stress-induced apoptosis (Xiao J. et al., 2016; Shi et al., 2018) through the inhibition of pro-apoptotic PDCD4 (Xiao J. et al., 2016; Gu et al., 2018) and cell cycle-regulator PTEN (Shi et al., 2018). Treatment of miR-21 mimics in vitro and in vivo then significantly reduced apoptosis in cardiomyocytes following AMI, and dramatically attenuated infarct size in mouse hearts. As conduits of bioactive molecule transfer, EVs are also exploited as nanocarriers/delivery systems that provides a sustainable mode of miRNA delivery. Transfer of miRNAs from miR-let7c-overexpressing MSCs to renal cells via secreted EVs, suppressed the expression of fibrotic genes, thus reducing interstitial collagen production, attenuating renal fibrosis, and improving kidney structure (Wang et al., 2016). 
TABLE 2 | Evidence supporting the role of extracellular vesicle cargo in intercellular communication.

\begin{tabular}{|c|c|c|c|c|c|c|c|c|}
\hline Concept & $\begin{array}{l}\text { Repro- } \\
\text { gramming }\end{array}$ & Tropism & Donor cell & Recipient cell & Active cargo & Approach used to confirm cargo functionality & Key findings & References \\
\hline \multirow[t]{7}{*}{ Protein-based } & Y & $\mathrm{N}$ & \begin{tabular}{|l|} 
EGFRvill-positive gliomas \\
(U373 (human \\
astrocytoma) cells)
\end{tabular} & \begin{tabular}{|l|} 
EGFRvill-negative gliomas \\
(U373) and human umbilical \\
vein endothelial cells (HUVECS)
\end{tabular} & EGFRvIII & \begin{tabular}{|l|} 
Western blot validation of MAPK and Akt \\
phosphorylation, changes in expression of \\
EGFRvill-regulated genes (VEGF, Bcl-xL, p27), and \\
functionally, morphological transformation and \\
increase in anchorage-independent growth capacity
\end{tabular} & $\begin{array}{l}\text { (i) Determined that EGFRvill-positive gliomas release EVs that express EGFRvill, } \\
\text { (ii) demonstrated activation of associated signaling pathways (MAPK and Akt), } \\
\text { changes in expression of EGFRvill-regulated genes (VEGF, Bcl--XL, p27), and (iii) } \\
\text { functionally, morphological transformation and increase in } \\
\text { anchorage-independent growth capacity }\end{array}$ & Al-Nedawi et al., 2008 \\
\hline & $\mathrm{Y}$ & $N$ & Human U87 glioma cells & $\begin{array}{l}\text { Brain microvascular endothelial } \\
\text { cells (HMBVECs) }\end{array}$ & $\begin{array}{l}\text { Angiogenin, L-6, } \\
\text { IL-8, TIMP-1, VEGF } \\
\text { and TIMP-2 }\end{array}$ & $\begin{array}{l}\text { Validated enrichment of angiogenic proteins in EVs } \\
\text { compared to cells using western blot, human } \\
\text { angiogenesis antibody array, and functional output } \\
\text { (increased angiogenesis) }\end{array}$ & $\begin{array}{l}\text { (i) Demonstrated EV protection of RNA content through exogenous treatment of } \\
\text { RNAse, (ii) demonstrated that recipient cells can translate EV-associated RNA } \\
\text { (i.e., Gluc mRNA) by observing Gluc activity following EV treatment, (iii) mRNA } \\
\text { analysis of glioma-derived EVs highlighted their biological role in angiogenesis, } \\
\text { (iv) EVs increased HMBVEC angiogenesis upon treatment, (v) identified } \\
\text { angiogenic proteins enriched in EVs through human angiogenesis antibody array } \\
\text { and angiogenesis assay }\end{array}$ & Skog et al., 2008 \\
\hline & $\mathrm{Y}$ & $\mathrm{Y}$ & \begin{tabular}{|l|} 
Organotropic human \\
breast and pancreatic \\
cancer cell lines that \\
metastasise to the lung \\
(MDA-MB-231), liver \\
(BXPC-3 and HPAF-II), or \\
both (MDA-MB-468), and \\
MDA-MB-231 sub-lines \\
that colonize lung, bone or \\
brain (4175-LuT, \\
$1833-$ BoT or $831-B \mathrm{BrT})$ \\
respectively
\end{tabular} & $\begin{array}{l}6-8 \text {-week-old NCr nude } \\
\text { (NCRNU-F sp./sp.) females, } \\
\text { human lung fibroblasts Wl-38, } \\
\text { human bronchial epithelial cells } \\
\text { HBEpC, human Kupffer cells }\end{array}$ & $\begin{array}{l}\text { Integrins } \alpha 6 \beta 4 \text { and } \\
\alpha \vee \beta 5\end{array}$ & $\begin{array}{l}\text { Knockdown of integrin expression using short hairpin } \\
\text { RNAs (shRNAs) demonstrated three-fold reduction of } \\
\text { EVs in the lung compared with control EVs, and } \\
\text { blocking of cognate ligands of specific integrins } \\
\text { markedly reduced uptake by recipient cells }\end{array}$ & \begin{tabular}{|l|} 
(i) Validated natural and efficient homing capacity of EVs derived from three \\
metastatic cancer cell lines to their corresponding primary sites of metastasis \\
(see donor cells), (ii) demonstrated that EV with specific homing can induce \\
metastasis in corresponding target organ, (ii) highlighted association of specific \\
integrins to EV homing capacity, (iv) demonstrated selective uptake of EVs by \\
specific cell types in target organ via expression of cognate ligands on recipient \\
cells, (v) observed EV treatment upregulated gene expression, particularly \\
pro-inflammatory S100 genes involved in metastasis, as demonstrated by an \\
increase in proliferation and migration in recipient cells following EV treatment, \\
(vi) proposed that integrin expression in plasma-derived EVs is good biomarker \\
for organotropism
\end{tabular} & Hoshino et al., 2015 \\
\hline & $\mathrm{Y}$ & Y & $\begin{array}{l}\text { Murine microglia cell line } \\
(\mathrm{BV}-2)\end{array}$ & $\begin{array}{l}\text { Myeloid cells, primary microglia, } \\
\text { and bone marrow and } \\
\text { peritoneal macrophages, and } \\
\text { female C57BL/6 mice and } \\
\text { R26-stop-dtTomato mice }\end{array}$ & LL-4, MFGE8 & $\begin{array}{l}\text { Overexpression of LL-4 upregulated anti-inflammatory } \\
\text { markers (arg1 and ym1) in myeloid cells in vitro, and } \\
\text { in primary microglia and peritoneal macrophages, } \\
\text { upregulated anti-inflammatory markers (CD206 and } \\
\text { arg1), and decreased pro-inflammatory marker iNOS, } \\
\text { both at the protein and mRNA levels. MFGE8 } \\
\text { inhibition via their corresponding integrin avp5 } \\
\text { significantly reduced the biological effect of } \\
\text { lL-4 + EVs as well as downstream mRNA expression }\end{array}$ & 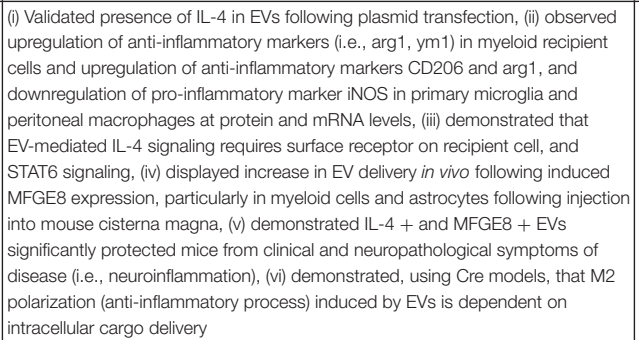 & Casella et al, 2018 \\
\hline & $\mathrm{Y}$ & $\mathrm{Y}$ & $\begin{array}{l}\begin{array}{l}\text { Mouse melanoma } \\
\text { (B16F10) cells }\end{array} \\
\end{array}$ & $\begin{array}{l}\text { Mouse bone marrow-derived } \\
\text { cells (BMDCs) }\end{array}$ & MET & $\begin{array}{l}\text { Silencing MET using shRNA and crizotinib (MET } \\
\text { inhibitor) }\end{array}$ & $\begin{array}{l}\text { (i) Demonstrated EV-mediated contribution to tumor growth and metastasis } \\
\text { through transfer of MET to mobilize BMDCs to form a pre-metastatic niche, and } \\
\text { (ii) reduced tumor growth using EVs expressing low levels of MET }\end{array}$ & Peinado et al, 2012 \\
\hline & $\mathrm{Y}$ & Y & \begin{tabular}{|l|} 
Pancreatic ductal \\
adenocarcinoma cells \\
(PDACs)-Mouse \\
(R6560B, PAN02) and \\
human PDACS (BCPC-3)
\end{tabular} & $\begin{array}{l}\begin{array}{l}\text { Mouse and human liver Kupffer } \\
\text { cells }\end{array} \\
\end{array}$ & MIF & Silencing MIF using shRNA & $\begin{array}{l}\text { (i) Demonstrated EV-associated MIF homing to and activation of Kupffer cells in } \\
\text { liver to release TGFB, and induce fibrotic pre-metastatic niche and recruitment of } \\
\text { BMDC, then (iii) inhibited liver pre-metastatic niche initiation by suppressing MIF } \\
\text { expression in EVs }\end{array}$ & Costa-Silva et al., 2015 \\
\hline & $\bar{Y}$ & $\mathrm{~N}$ & \begin{tabular}{|l|} 
Primary rat \\
cardiomyocytes (1-2 days \\
old rat pups), H9C2 \\
(embryonic rat heart \\
tissue)
\end{tabular} & $\begin{array}{l}\text { HUVECS and primary adult } \\
\text { cardiac rat microvascular ECs } \\
\text { (CMVEC) }\end{array}$ & GLUT1, GLUT4 & $\begin{array}{l}\text { Western blot validation of GLUT1/4 presence in EVs, } \\
\text { demonstrated EV-associated GLUT1/4-mediated } \\
\text { glucose uptake by endothelial cells (function), and } \\
\text { established EV-association with GLUT1/4 through } \\
\text { co-localization of fluorescent EVs and GLUT1/4 }\end{array}$ & $\begin{array}{l}\text { (i) Glucose starvation of parental cells increased production of EVS, which } \\
\text { contained GLUT1/4 (demonstrated via western blot), (ii) established } \\
\text { EV-associated GLUT-mediated glucose uptake by endothelial cells through EV } \\
\text { and GLUT-inhibitor (FAS) treatment, and (iii) demonstrated EV-associated } \\
\text { GLUT1/4 uptake by endothelial cells through fluorescent imaging (co-localization } \\
\text { of EV marker CD63 and GLUT1/4) }\end{array}$ & Garcia et al., 2016 \\
\hline
\end{tabular}


TABLE 2 | (Continued)

\begin{tabular}{|c|c|c|c|c|c|c|c|c|}
\hline Concept & \begin{tabular}{|l|}
$\begin{array}{l}\text { Repro- } \\
\text { gramming }\end{array}$ \\
\end{tabular} & Tropism & Donor cell & Recipient cell & Active cargo & Approach used to confirm cargo functionality & Key findings & References \\
\hline \begin{tabular}{|l|} 
Glycolipid-based \\
\end{tabular} & $Y$ & $\mathrm{~N}$ & \begin{tabular}{|l|} 
Murine neuroblastoma \\
Neuro2a (N2a), murine \\
microglial cell line (BV-2)
\end{tabular} & \begin{tabular}{|l|} 
Wild-type C57BL/6 mice, \\
heterozygotic transgenic mice \\
expressing human APP bearing \\
the Swedish and Indiana \\
(KM670/671NL, V717F) \\
mutations (APPswelnd or J20 \\
strain)
\end{tabular} & $\begin{array}{l}\text { Glycosphingolipid } \\
\text { (GSL)-glycan }\end{array}$ & $\begin{array}{l}\text { Cleavage of EV-associated GSL glycans sufficiently } \\
\text { prevents the association of EVs with AB: } \\
\text { deglycosylation of GSL-glycans on EVs using } \\
\text { EGCase inhibited EV-dependent amyloid fibril } \\
\text { formation, cleavage of sialic acids using sialidase } \\
\text { demonstrated similar reductions in fibril formation, } \\
\text { and steric blocking of GM1 or GM2 ganglioside by } \\
\text { cholera toxin subunit B or anti-GM2 antibody } \\
\text { significantly suppressed amyloid formation }\end{array}$ & 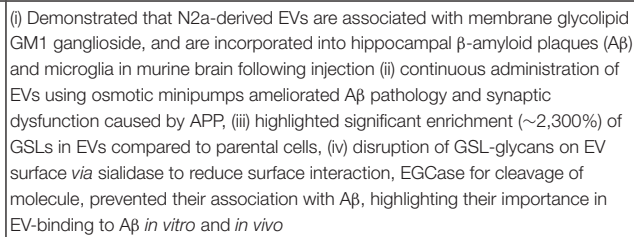 & Yuyama et al., 2014 \\
\hline \multirow[t]{8}{*}{\begin{tabular}{|l} 
RNA-based \\
\end{tabular}} & Y & $\mathrm{N}$ & $\begin{array}{l}\text { Murine embryonic stem } \\
\text { cells (ESC) }\end{array}$ & \begin{tabular}{|l|} 
Murine hematopoietic \\
progenitor cells (HPC), murine \\
Sca-1 + / kit + /lin- (SKL) cells
\end{tabular} & Oct4 & \begin{tabular}{|l|} 
Demonstrated enrichment of Oct- $4 \mathrm{mRNA}$ and \\
protein in EVs compared to parental cells, and that \\
upon treatment with EVs, recipient cells displayed \\
increased expression of Oct-4 protein. Further \\
demonstrated Oct-4 mRNA-mediated \\
reprogramming by pre-treating EVs with RNAse, \\
which diminished Oct-4 expression in recipient cells \\
\end{tabular} & 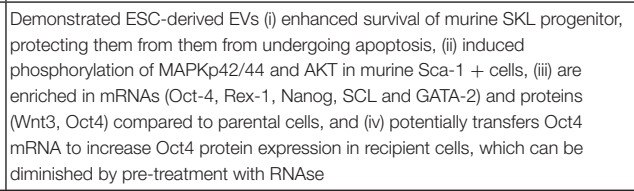 & Ratajczak et al., 2006 \\
\hline & Y & $\mathrm{N}$ & Colorectal cancer (SW480) & ) $5 W 480$ & miR-19b & \begin{tabular}{|l|} 
Inhibition of EV production using sphingomyelinase \\
inhibitor gw4869, and worked with analogous system \\
of inhibition and overexpression of miR-19b
\end{tabular} & $\begin{array}{l}\text { (i) Demonstrated EV-associated miR-19b downregulated oxaliplatin sensitivity in } \\
\text { SW480 cancer cells, then (ii) inhibited EV production using gw4869 which } \\
\text { restored sensitivity }\end{array}$ & Gu Y. Y. et al., 2019 \\
\hline & Y & N & 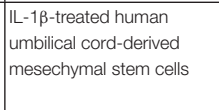 & $\begin{array}{l}\text { Mouse bone marrow-derived } \\
\text { macrophages (BMDMs) }\end{array}$ & miR-146a & $\begin{array}{l}\text { Overexpression of miR-146a showed the same effect } \\
\text { as EV treatment whereas the inhibition of this miR (by } \\
\text { transfection) abrogated the efficiency of M2 } \\
\text { polarization }\end{array}$ & $\begin{array}{l}\text { (i) Inhibition of EV production caused a M1 polarization (ii) EV treatment caused } \\
\text { M2 polarization in macrophages. (iii) Exosomal miR-146a was the key player for } \\
\text { macrophage M2 polarization leading to an increased survival in septic mice. }\end{array}$ & Song et al., 2017 \\
\hline & Y & $\mathrm{N}$ & $\begin{array}{l}\text { Amniotic fluid stem cells } \\
\text { (AFSCs) }\end{array}$ & CTx-damaged granulosa cells & $\begin{array}{l}\operatorname{miR}-10 a \text { and } \\
\text { miR-146a }\end{array}$ & \begin{tabular}{|l|} 
Inhibition of RNA activity through RNAse treatment of \\
AFSC-EVs reduced protective function, attributed \\
function to miR10a and miR-146a by using \\
liposomes as nanocarrier, and demonstrated similar \\
effects to $\mathrm{EV}$ treatment, and inhibition of miR-146a \\
and miR-10a by transfection of parental cells \\
suppressed rescue effects in recipient cells \\
\end{tabular} & $\begin{array}{l}\text { (i) AFSC-CM or EV treatment decreased cytotoxicity and apoptosis of granulosa } \\
\text { cells (GCS), and AFSC-EVS preserved healthy follicles in mice, (ii) identified } \\
\text { mir-146a and miR-10a enrichment in AFSC-EVs and through KO of these } \\
\text { factors, attributed mechanism of function to apoptosis-related downstream } \\
\text { targets including IRAK1 and TRAF6, and BIM respectively, (iii) highlighted } \\
\text { miRe-144a and miR-10a functions using liposome-mediated encapsulation and } \\
\text { delivery to damaged GCS }\end{array}$ & Xiao G. Y. et al,, 2016 \\
\hline & $Y$ & $\mathrm{~N}$ & $\begin{array}{l}\text { Adipose derived } \\
\text { mesenchymal stem cells } \\
\text { (ADMSCs) }\end{array}$ & Human dermal fibroblasts (HDF) & miR-21 and miR-29c & $\begin{array}{l}\text { Transfection of MSC-EV with the corresponding miR } \\
\text { mimics dramatically enhanced (more than } 10 \text {-fold) } \\
\text { the transfer of miRs to the fibroblasts, while } \\
\text { transfection of MSC-EV with antagomir significicantly } \\
\text { decreased expression in fibroblasts }\end{array}$ & $\begin{array}{l}\text { (i) Compared to conditioned media and soluble fraction, ADMSC-EVs caused } \\
\text { the most significicant decrease in } \alpha \text {-SMA mRNA expression in receipient cells, } \\
\text { preventing HDF differentiation into fibrotic myofibroblasts, (ii) identififed } \\
\text { pro-fibrotic mir-21 and anti-fibrotic miR-29c as most enriched in ADMSC-EVs, } \\
\text { and (iv) demonstrated dramatically enhanced transfer and function of miRNAs in } \\
\text { fibroblasts following transffection with mimics and significantly decreased transfer } \\
\text { and function of miRNAs following transfection with antagomirs }\end{array}$ & Basalova et al, 2020 \\
\hline & $\mathrm{Y}$ & $\mathrm{N}$ & $\begin{array}{l}\text { Blood/serum (mice, } \\
\text { human) }\end{array}$ & \begin{tabular}{|l|} 
In vitro-primary neonatal rate \\
cardiac myocytes (NRCMs) and \\
in vivo-intramyocardial \\
injection
\end{tabular} & miR-21 & $\begin{array}{l}\text { Addition of miR-21 mimics to cells induced } \\
\text { cardioprotection, and inhibition of PDCD4 } \\
\text { (downstream target of miR-21) resulted in the same } \\
\text { cardioprotective effect }\end{array}$ & $\begin{array}{l}\text { (i) Demonstrated selective enrichment of miR-21 in EVs compared to } \\
\text { supernatant, and its inhibitory effects on PDCD4 expression as well as } \\
\text { anti-apoptotic effects in recipient cells, then (ii) demonstrated EV-mediated } \\
\text { reduction of infarct size in mice hearts }\end{array}$ & Gu et al., 2018 \\
\hline & Y & $\mathrm{N}$ & \begin{tabular}{|l|} 
Bone marrow \\
mesenchymal stem cells
\end{tabular} & C-kit + cardiac stem cells & min-21 & \begin{tabular}{|l|} 
Function of miR-21 highlighted through transfection \\
with mimic and inhibitor and observing respective \\
functions, where miR-21 mimic markedly decreased \\
apoptosis and miR-21 inhibition increased apoptosis, \\
also observed expression of downstream regulators \\
pAKT and PTEN which pathway is responsible for \\
regulating apoptosis in recipient cells
\end{tabular} & 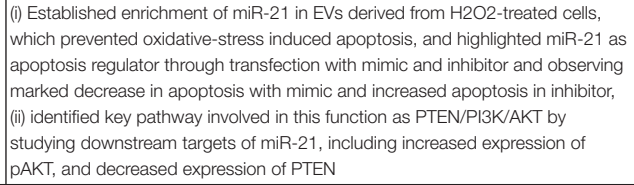 & Shi et al., 2018 \\
\hline & Y & $\mathrm{N}$ & Plant (Arabidopsis) & Fungal (Botrytis cinerea) & \begin{tabular}{|l|} 
Several dozen \\
different small RNAs \\
(e.g., TAS1c-siR483, \\
TAS2-siR453, \\
IGN-siR1, and \\
miRNA166)
\end{tabular} & \begin{tabular}{|l|} 
Transferred host sRNAs induce silencing of fungal \\
genes critical for pathogenicity. Host sRNAs were \\
protected from nuclease digestion, tetraspanins \\
associated with their transferring to fungal cells, with \\
transferred host sRNAs silence fungal virulence \\
genes and suppress fungal pathogenicity (directly \\
regulates virulence not growth). Host mutant strains \\
(lacking target sRNAs) showed reduced virulence.
\end{tabular} & $\begin{array}{l}\text { Findings support that transferred host sRNAs (Arabidopsis) contribute to host } \\
\text { immunity by silencing fungal pathogen (B. cinerea) genes. Demonstrates } \\
\text { cross-kingdom sRNA trafficking }\end{array}$ & Cai et al., 2018 \\
\hline
\end{tabular}


TABLE 2 | (Continued)

\begin{tabular}{|c|c|c|c|c|c|c|c|c|}
\hline Concept & \begin{tabular}{|l|}
$\begin{array}{l}\text { Repro- } \\
\text { gramming }\end{array}$ \\
\end{tabular} & Tropism & Donor cell & Recipient cell & Active cargo & Approach used to confirm cargo functionality & Key findings & References \\
\hline & Y & $\mathrm{N}$ & \begin{tabular}{|l|}
$\begin{array}{l}\text { Nematode } \\
\text { (Heligmosomoides } \\
\text { polygyrus) }\end{array}$ \\
\end{tabular} & $\begin{array}{l}\text { Murine intestinal epithelial } \\
\text { (MODE-K) cells }\end{array}$ & \begin{tabular}{|l|} 
Various microRNAs \\
(miR-193, miR-10 \\
and miR-200), Y \\
RNAs, and \\
nematode Argonaute \\
protein
\end{tabular} & $\begin{array}{l}\text { Microarray analysis identified (128 genes differentially } \\
\text { expressed upon treatment) with II33r and Dusp1 as } \\
\text { key suppressed genes, and Dusp1 repressed by } \\
\text { nematode miRNAs. validated by RT-qPCR, and } \\
\text { control EV (mouse intestinal cell) treatment. Identify } \\
\text { miRNAs from filarial nematode in serum of infected } \\
\text { mice }\end{array}$ & $\begin{array}{l}\text { (i) miRNA secretion into host tissues is conserved among parasitic nematodes, } \\
\text { (ii) secreted nematode miRNAs that have identical seed sites to mouse miRNAs } \\
\text { can downregulate DUSP1 through conserved sites in its } 3^{\prime} \text { UTR, (iii) suppress an } \\
\text { innate Type } 2 \text { response in vivo, (iv) mechanism by which helminths manipulate } \\
\text { their hosts (combination of RNA - and protein-based regulatory function) and } \\
\text { provide a mechanistic framework for RNA transfer between animal species }\end{array}$ & Buck et al., 2014 \\
\hline & $\mathrm{Y}$ & $\mathrm{N}$ & \begin{tabular}{|l|} 
Nematode \\
(Heligmosomoides \\
polygyrus)
\end{tabular} & \begin{tabular}{|l|} 
Bone marrow stem cells, bone \\
marrow macrophages, \\
MODE-K cells
\end{tabular} & N/A & \begin{tabular}{|l|} 
Macrophage internalization of EVs causes \\
downregulation of type 1 and type 2 \\
immune-response-associated molecules (LL-6 and \\
TNF, and Ym1 and RELM $\alpha$ ) and inhibits expression of \\
the IL-33 receptor subunit ST2. EV target antibodies \\
abrogated suppression of alternative activation and \\
associated with increased co-localization of \\
intracellular EVs with lysosomes.
\end{tabular} & $\begin{array}{l}\text { (i) Internalized EVs can induce alternative activation and IL-33-mediated } \\
\text { signaling in macrophage to counter parasite expulsion, (ii) EV target antibodies } \\
\text { increase their co-localization with lysosome in macrophages (iii) targeting EVs by } \\
\text { vaccination provide protective immunity against the parasite, highlighting their } \\
\text { key role in establishing infection }\end{array}$ & Coakley et al., 2017 \\
\hline & $\mathrm{Y}$ & $\mathrm{N}$ & \begin{tabular}{|l|}
$\begin{array}{l}\text { Raij B-cell line, } \\
\text { Jurkat-derived J77 T cell } \\
\text { line, and primary dendritic } \\
\text { cells (DCs) derived from } \\
\text { human monocytes }\end{array}$ \\
\end{tabular} & Antigen-presenting cells (APCs) & $\begin{array}{l}\text { miR-335 and } \\
\text { miR-92a }\end{array}$ & $\begin{array}{l}\text { (i) Demonstrated miRNA transfer via immunological } \\
\text { synapse (IS) through co-culture of J77 celll } \\
\text { overexpressing miR-355 with Raji B cells following } \\
\text { treatment of SEE which activates formation of IS, (ii) } \\
\text { blocking EV production significantly impaired miRNA } \\
\text { transfer via EVs, (iii) demonstrated miR-355 synaptic } \\
\text { transfer downregulates its target SOX4 in recipient } \\
\text { APCS }\end{array}$ & $\begin{array}{l}\text { (i) Profiled and identified enrichment of small RNA species in EVs compared to } \\
\text { parental cells, (ii) demonstrated that miRNAs are transferred via immunological } \\
\text { synapse between immune cells and APCs through overexpression of miR-355, } \\
\text { (iii) inhibition of EV production through nSMase2 significantly impaired transfer of } \\
\text { EV-associated miRNAs, (iv) using lucifierase assays, demonstrated synaptic } \\
\text { transffer of miR-335 downregulates miR-335 downstream target SOX4 in the } \\
\text { APC }\end{array}$ & Mittelbrunn et al., 2011 \\
\hline & Y & $\mathrm{N}$ & \begin{tabular}{|l|} 
Mast-cell line (MC/9), \\
primary bone \\
marrow-derived mast cells \\
(BMMC) and human \\
mast-cell line (HMC-1) \\
\end{tabular} & $\begin{array}{l}\text { MC/9, BMMC, HMC-1, mouse } \\
\text { CD4 + T cells }\end{array}$ & $\begin{array}{l}\text { mRNA coding for } \\
\text { proteins (Cox5b, } \\
\text { Hspa8, Shmt1, } \\
\text { Ldh1, Zfp125, Gpi1 } \\
\text { and Rad23b) }\end{array}$ & \begin{tabular}{|l|} 
(i) In vitro translation assay was conducted, \\
comprising of mRNA isolation and translation, then \\
separation of resultant proteins by two-dimensional \\
PAGE to identify seven new proteins which were \\
excised and analyzed by LC-MS/MS, (ii) \\
demonstrated and quantified EV-mediated mRNA \\
transfer using radioactive labels and scintillation \\
counting, (iii) demonstrated interspecies mRNA \\
translation, where human mast cells translated two \\
mouse proteins corresponding to the EV-associated \\
mouse mRNA
\end{tabular} & 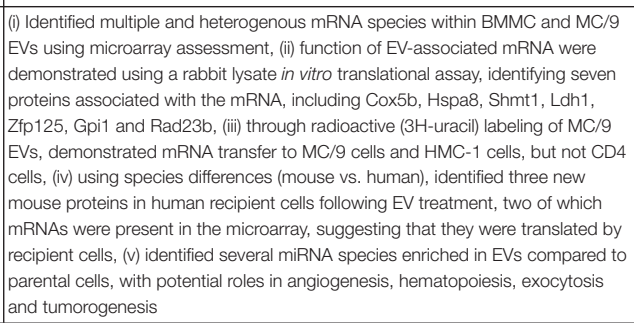 & Valadi et al., 2007 \\
\hline & $\mathrm{Y}$ & $\mathrm{N}$ & $\begin{array}{l}\text { Adipose derived } \\
\text { mesenchymal stem cells } \\
\text { (ADMSCs) }\end{array}$ & HUVECS & miR-125a & $\begin{array}{l}\text { Overexpression of miR-125a (i) inhibited expression } \\
\text { of downstream target DLL4 (angiogenic repressor), (ii) } \\
\text { increased angiogenesis, (iii) upregulated } \\
\text { pro-angiogenic genes and downregulated } \\
\text { anti-angiogenic genes, whereas inhibition of } \\
\text { miR-125a (by transfection) exerted the opposite } \\
\text { effect on endothelial cells }\end{array}$ & $\begin{array}{l}\text { (i) Demonstrated that EV treatment increased angiogenesis in vitro and in vivo, (ii) } \\
\text { determined miR-125a enrichment in EVs compared to parentat cells, (iii) } \\
\text { established miR-125a functional influence on HUVECS to increase angiogenesis, } \\
\text { and upregulation of pro-angiogenic and downregulation of anti-angiogenic gene } \\
\text { expression (iv) inhibitifd downstream target of miR-125a (DLL4-angiogenic } \\
\text { repressor) and its influence on angiogenesis through endothelial tip formation }\end{array}$ & Liang et al., 2016 \\
\hline
\end{tabular}


Extracellular vesicles have also been shown to contain and transfer tyrosine kinase receptors (i.e., EGFRvIII) to increase downstream signaling events (MAPK, AKT) and expression of EGFRvIII-regulated genes (VEGF, $B c l-x L, p 27$ ) involved in tumor vascularization, survival and proliferation (Al-Nedawi et al., 2008). EV-mediated delivery of functional receptors can also be physiological, as demonstrated by the transfer of glucose transporters (GLUT) 1 and 4 between cardiomyocytes and endothelial cells during metabolic stress to increase glucose uptake by endothelial cells and mediate plasma glucose concentration (Garcia et al., 2016). In addition to their functional value, the presence of intact receptors in EVs can facilitate loading of bioactive ligands through their ligandreceptor interaction, increasing the efficacy of $\mathrm{EV}$ function on recipient cells. As a cerebral hypoxia/ischemia treatment, EVbound transferrin receptor was exploited to load apotransferrin into EVs, which, when administered to animal demyelination models, conferred neuroprotection and reduced white matter damage, neuronal loss, and astrogliosis through apotransferrinactivated differentiation of oligodendroglial cells in the brain (Mattera et al., 2020).

This protective effect of EVs have also been shown to rescue adverse side-effects following chemotherapy-induced damage. EVs derived from amniotic fluid stem cells enriched in prosurvival miR-146a and miR-10a were directly injected into murine ovaries, where they promoted the survival and elevated the apoptotic resistance of granulosa cells in mice undergoing chemotherapy; side effects can otherwise cause premature ovarian failure and aberrant fertility (Xiao G. Y. et al., 2016). This is attributed to the apoptosis- and inflammation-related downstream targets of EV-associated and transferred miR-146a and miR-10a, including IRAK1 and TRAF6, and BIM respectively (Xiao G. Y. et al., 2016). However, if these anti-apoptotic EVs are trafficked to off-target sites (i.e., tumors), they can significantly reduce the sensitivity of tumor cells to chemotherapy treatment, as demonstrated by EV-mediated transfer of miR-19b ( Gu Y. Y. et al., 2019). Therefore, stringent regulation of EVassociated bioactive cargo and components of interest is critical in developing EVs for therapeutic application.

For further streamlining of functional/therapeutic effect, $\mathrm{EV}$ donor cell source is a critical factor for consideration, particularly in the field of regenerative medicine, where MSCs, with unique multipotent differentiation potential (Sasaki et al., 2008; Sarugaser et al., 2009; Dos Santos et al., 2019), are expansively explored in various pathologies and regenerative applications. Importantly, MSC-derived EVs have been shown to alleviate CNS-associated disorders/injuries, including subcortical stroke [i.e., through axonal sprouting, tract connectivity, remyelination and oligodendrogenesis (Otero-Ortega et al., 2017)], and, cerebral ischemic-reperfusion injury [i.e., by conferring neuroprotection through modulation of M1-M2 microglia toward an anti-inflammatory phenotype (Liu et al., 2021)]. They are also an avenue for treatment of physical ailments, such as osteoarthritis [i.e., by attenuating inflammation and regulating extracellular matrix synthesis/degradation (Cosenza et al., 2017; Wang et al., 2017; Zhang S. et al., 2019)], skeletal muscle injury [i.e., through promotion of skeletal muscle cell proliferation, differentiation and migration (Mitchell et al., 2019)], and ageing [i.e., by ameliorating dermal fibroblast senescence and promoting skin rejuvenation (Zhao et al., 2021)]. In models for cardiac injury, MSC-derived EVs have been shown to promote proliferation and differentiation of epicardial-derived cells and improve cardiac morphology (Arslan et al., 2013; Zhu et al., 2021b). In fact, improvements for sustained administration of MSC-EVs have been made to enhance their effects at sites of cardiac (Chen C. W. et al., 2018), spinal cord (Li L. et al., 2020), or hepatic injury (Mardpour et al., 2019), by loading them into biocompatible hydrogels which are then administered to target sites.

For therapeutic development, it must be noted that EV composition and release is influenced by environmental and signaling changes occurring in donor cells \{i.e., hypoxia, stress [metabolic (Fan et al., 2020), heat, oxidative], infection (Pegtel et al., 2010) and cell activation (Gao et al., 2019, 2020) $\}$ as a mechanism of homeostatic maintenance (Takahashi et al., 2017) [reviewed in Desdin-Mico and Mittelbrunn (2017)], thus, EV donor cell culture conditions may be modified accordingly to suit various clinical applications. For instance, MSCs under high oxygen level-induced oxidative stress release depolarized mitochondria to remove accumulated reactive oxygen species (ROS) generated as a result of oxidative phosphorylation (Phinney et al., 2015). The EV-associated mitochondria are transferred to and metabolically reprogram recipient cells with potent regenerative effects, as observed in cardiomyopathy (Plotnikov et al., 2008; Ikeda et al., 2021), and renal (Plotnikov et al., 2010) and pulmonary (Islam et al., 2012) injury. Another key, yet not fully explored consideration in this study, is the synergistic function of EV cargo. For example, in a pulmonary silicosis-induced murine model, MSC-derived EVs transfer both mitochondria and anti-inflammatory and immunomodulatory miR-451 to macrophages; increasing their metabolic state while inhibiting their activation and protecting them from excessive inflammation caused by accumulated mitochondrial ROS (Phinney et al., 2015). The synergistic function performed in this study by EV-associated mitochondria and anti-inflammatory miRNA is therefore a well-balanced one, highlighting a need for in-depth EV composition characterization during their development as therapeutics. Modifying protein cargo loading into EVs can be manipulated in donor cells directly and exploiting endogenous protein sorting mechanisms. Ubiquitinlike 3 (UBL3) was identified as the protein sorting target which can interact with and post-translationally modify cargo proteins (i.e., Ras and tubulin) to enhance their loading into EVs (Ageta et al., 2018). Through donor cell transfection of mutated, oncogenic RasG12V, a binding partner of UBL3, this study demonstrated effective loading into released EVs and subsequent downstream signaling activation in target cells (Ageta et al., 2018). Development of loading proteins into EVs from the cytosol in a free form has been shown via optically reversible protein-protein interactions; EXPLORs (Yim et al., 2016). This approach is based on the selective interaction of cargo protein and tetraspanin CD9, allowing cargo proteins to be freely localized in the recipient cells. On the other hand, loading of specific miRNA can be achieved by exploiting the 
short sequence motifs over-represented in miRNAs commonly enriched in EVs, and the sumoylation of their binding partner hnRNPA2B1, which is required to facilitate miRNA sorting into EVs (Villarroya-Beltri et al., 2013). Other loading RNAbased methods using RNA binding proteins include EXOsomal transfer into cells (EXOtic) using the interaction between C/D box RNA structure and L7Ae ribosomal protein fused with tetraspanin CD63 (Kojima et al., 2018), and conjugated mRNA sequence with interaction between trans-activating response (TAR) sequence and trans-activator of transcription (Tat) protein (with membrane protein ARMMs) (Wang Q. et al., 2018), to load specific mRNAs into EVs. Further, this latter study demonstrated a highly versatile platform for packaging and intracellular delivery of therapeutic macromolecules, including protein, RNAs, and the genome-editing CRISPR-Cas9/guide RNA complex (Wang Q. et al., 2018). While the molecular mechanisms of cargo sorting into EVs are still being understood, it may be useful to consider the above characteristics of target molecules and their compatibility with endogenous donor cell cargo sorting machinery to improve their loading efficiency and consistency for EV-based therapeutic development.

\section{Targeted Delivery of EVs}

Specific components present in the EV surfaceome (selections of proteins presented on the external side of the lipid bilayer), allow for preferential uptake by specific cells, tissues, and organs (Peinado et al., 2012; Oksvold et al., 2014; Costa-Silva et al., 2015; Hoshino et al., 2015; Belov et al., 2016; Rodrigues et al., 2019; Wu et al., 2020). Although this capacity for tropism is supported by various reports, our understanding of the complexities behind this intrinsic targeting in native EVs remains incomplete, though they are widely attributed to their biological origin. Like their progenitor cells, plateletderived EVs have an intrinsic affinity with inflammatory sites and atherosclerotic plaques, binding to activated/inflamed vascular walls and plaques through various receptors including CD40L (Mach et al., 1997; Lievens et al., 2010), glycoproteins Iba and aIIb (Guo et al., 2015; Pawlowski et al., 2017), and P-selectin (Dinkla et al., 2016; Pawlowski et al., 2017). Thus, plateletderived EVs hold great potential to be exploited as nanocarriers of anti-inflammatory reagents to ameliorate inflammatory diseases including pneumonia (Ma et al., 2020) and atherosclerosis (Song et al., 2019). EV homing to specific organs also play roles in disease progression, such as those derived from pancreatic ductal adenocarcinoma cells (PDAC) (a cancer commonly associated with liver metastasis), which demonstrated natural homing to the liver upon in vivo administration, where they were selectively taken up by Kupffer cells (Costa-Silva et al., 2015). Though the molecular mechanism behind this liver tropism is unknown, the current hypothesis is that EVs express surface components to facilitate a specific interaction with target cells. Indeed, EVs derived from tumors with metastatic organ tropism (lung, liver, or brain) express different integrin complexes; lung-tropic: $\alpha 6 \beta 4$ and $\alpha 6 \beta 1$, liver-tropic: $\alpha v \beta 5$, braintropic: ITG $\beta 3$ (Hoshino et al., 2015). EVs containing these integrin complexes bind to S100-A4-positive fibroblasts and surfactant protein C-positive epithelial cells in the lungs, Kupffer cells in the liver, or CD31-positive endothelial cells in the brain (Hoshino et al., 2015), respectively. Lung-tropism is also influenced by non-integrin proteins, with genetic knockdown of SLCO2A1, CD13, and CLIC1 in cervical adenocarcinoma cells (HCA1) resulting in the decreased accumulation of EVs in lung tissue (Wu et al., 2020). EVs' tropism to particular organs and cells may also be mediated by surface ligands that interact with cognate receptors on recipient cells to induce binding and subsequent uptake. This ligand-receptor interaction (i.e., EV chemokine receptor CXCR4 to recipient cellexpressed chemokine SDF-1 $\alpha$ ) mediated targeting of endothelial colony forming cell-derived EVs to the kidney, thus preventing kidney injury and neutrophil infiltration following ischemic injury through the transfer of PTEN-inhibitor miR-486-5p (Vinas et al., 2018).

Other surface-expressed molecules that mediate EV-cell interaction include glycosphingolipid glycan groups, which are present on neuroblastoma-derived EVs, facilitating their binding to and clearance of $\beta$-amyloid aggregates in the brain (Yuyama et al., 2014). Their ability to target the brain highlights the potential of EV-based treatments for brain cancer and Alzheimer's disease. Other mechanisms for brain-tropism also exist, such as the natural homing capacity of EVs derived from specialized immune cells in the central nervous system (CNS) (i.e., microglia) to the brain, where they reduced multiple sclerosis-associated inflammation in myeloid cells and astrocytes through the transfer of anti-inflammatory cytokine IL-4 (Casella et al., 2018). These studies highlight the natural ability of EVs to transverse the $\mathrm{BBB}$, an ability mediated in-part by surface components (i.e., heparan sulfate proteoglycans, mannose 6-phosphate receptor, $\mathrm{CD} 46$, integrin complexes $\alpha \mathrm{V} \beta 6$ and $\alpha \mathrm{V} \beta 3$, and endothelial- and leukocyte-associated transmembrane protein ICAM-1) which allow receptor-mediated transcytosis (Banks et al., 2020; Joshi and Zuhorn, 2021); a transcellular route allowing EVs to traverse brain endothelial capillary cells toward brain parenchyma. Further characterization of surface components which possess tropic-capacity will allow for refinement and selection of EV therapeutics.

\section{Biodistribution and Clearance of Native EVs}

As mediators of inter-organ communication, EVs must evade immune clearance for as long as possible to remain in circulation prior to cellular uptake (Smyth et al., 2015; Charoenviriyakul et al., 2017). The mononuclear phagocyte system (MPS) [previously termed reticuloendothelial system (RES)] encompasses monocytes, macrophages, and other cells present in liver, spleen, and lungs, and contributes to EV sequestration and clearance (Rao et al., 2015; Smyth et al., 2015). Indeed, following in vivo administration, EVs accumulate in the liver, spleen and/or lung; an occurrence widely observed in EVs derived from dendritic (Wei et al., 2017), MSCs (Grange et al., 2014), myoblasts (Wiklander et al., 2015; Charoenviriyakul et al., 2017), kidney (Lai et al., 2014), glial (Lai et al., 2014), melanoma (Peinado et al., 2012; Takahashi et al., 2013; Imai et al., 2015; Charoenviriyakul et al., 2017), macrophages (Charoenviriyakul et al., 2017), and placental (Tong et al., 2017; Nguyen et al., 2021) cells. With phagocytosis central to 
clearance, EVs avoid engulfment through surface presentation of anti-phagocytic signals including immunomodulatory receptors, most commonly CD47 (Chao et al., 2012; Rodriguez et al., 2013; Kaur et al., 2014; Kamerkar et al., 2017; Tang Y. et al., 2019), PDL1 (Gordon et al., 2017; Hsu et al., 2018; Cordonnier et al., 2020; Daassi et al., 2020), CD24 (Barkal et al., 2019), CD31 (Brown et al., 2002), and CD44 (Vachon et al., 2007; Amash et al., 2016), that act as "don't eat me" signals to phagocytic cells, potentially prolonging their EV half-life in circulation.

Conversely, internalization of EVs ensures the delivery of EV content into target cells, allowing them to exert their effector functions. Phosphatidylserine (PS) is a lipid located on the outer leaflet of EV membranes, forming lipidreceptor interactions [e.g., with immune regulatory receptor TIM4 (Tietjen et al., 2014)] to facilitate EV engulfment and internalization by recipient cells (Lindemann, 1989; Fadok et al., 2000; Gurnani et al., 2004). EVs also express opsonins [e.g., MFGE8 (Dasgupta et al., 2009; Miksa et al., 2009; Casella et al., 2018), $\beta 2$-glycoprotein-1 (Abdel-Monem et al., 2010), developmental endothelial locus-1 (Dasgupta et al., 2012)] that facilitate their internalization through PS-dependent phagocytosis. Indeed, increasing the expression of MFGE8 on microglia-derived EVs elevated their uptake by macrophages and microglial cells in the CNS, facilitating the transfer of EV-loaded anti-inflammatory cytokine (i.e., IL-4) to significantly reduce clinical symptoms of neuro-inflammatory multiple sclerosis, and experimental autoimmune encephalomyelitis (EAE) in a murine model (Casella et al., 2018). Other factors that influence EV biodistribution and uptake in vivo is the microenvironment from which they are released. Tumor-derived EVs can bind to soluble secreted cytokines and chemokines (i.e., CCL2 and IL-6) in the tumor microenvironment through their surface-expressed glycosaminoglycan (GAG) side chains of proteoglycans, significantly increase their uptake in the liver, spleen, and lung (Lima et al., 2021). Through a similar mechanism, EVs expressing GAGs released by glioblastoma bind to, and are decorated with, chemokine ligand CCL18, facilitating their interaction with cognate receptor CCR8 on recipient glioblastoma cells (Berenguer et al., 2018) to increase uptake and induce a proliferative phenotype (Berenguer et al., 2018). Indeed, pharmacological inhibition of this interaction (via CCR8 inhibitor, R243) completely blocked EV-induced tumor growth, thus neutralizing EV-induced phenotypic remodeling (Berenguer et al., 2018).

Despite these insights into EV biodistribution and clearance, attempts to comprehensively define the pharmacokinetics of EVs in vivo have remained inconsistent, with results ranging from their rapid clearance within 2-4 min (Takahashi et al., 2013) (as monitored by fluorescence imaging) up to 7 days, with DiR-labeled EVs localized to the liver and spleen a week following administration (Liu H. et al., 2016). This variation may be resultant of EV labeling with lipophilic dyes, which have been found to remain in the system long after EVs have been degraded or recycled (Takov et al., 2017). Regardless of these uncertainties, EVs possess important qualities-highlighting them as promising modalities for therapeutic applications. Further development toward EV-based clinical application involves their engineering/modification to reduce their immune clearance and prolong their half-life in circulation, improve their biodistribution and tropism to sites of interest, and, enhance their functionality on recipient cells, tissues, and organs.

\section{ENGINEERED EVs}

Native EVs offer unique advantages for cellular regulation and the efficient delivery of therapeutic payloads. However, several studies have highlighted the intrinsic limitations of native EVs including long-term maintenance of parental cell culture with minimal metabolic/phenotypic variation (Lambshead et al., 2018; Cherian et al., 2020; Escude Martinez de Castilla et al., 2021), biodistribution (i.e., organ targeting) (Escude Martinez de Castilla et al., 2021; Lazaro-Ibanez et al., 2021; Ullah et al., 2021; Witwer and Wolfram, 2021), clearance rates [complement and immune systems (RES-MPS system)] (Wiklander et al., 2015; Ha et al., 2016; Kwon, 2020; Lara et al., 2020; Buschmann et al., 2021; Escude Martinez de Castilla et al., 2021; LazaroIbanez et al., 2021), and crucially, difficulties associated with large scale generation (i.e., processing times, variable potency between batches, good manufacturing practice; GMP) (Whitford and Guterstam, 2019; Cherian et al., 2020; Buschmann et al., 2021; Escude Martinez de Castilla et al., 2021; Ullah et al., 2021; Witwer and Wolfram, 2021). Moreover, the regulatory machinery of EVs and their distinct subtypes associated with production and cellular uptake remains largely unknown. Engineering therapeutics based on native EVs offers an alternative approach, employing their advantages while bypassing limitations. As such, the engineering of EVs for therapeutic application is a field undergoing rapid development with applications for regeneration/repair, immune disorders, wound healing and cancer (Commisso et al., 2013; Kordelas et al., 2014; Xitong and Xiaorong, 2016; Gyorgy et al., 2017; Wu et al., 2019; Li L. et al., 2020; Hu S. et al., 2021; Shi et al., 2021). Here, we discuss several strategies recently developed to address such limitations through modification or engineering of EVs including: (i) generation of mimetic EVs/nanovesicles (M-NVs), EV synthetics (synEVs), and EV hybrids (hEVs), (ii) improvement of targeting of native EVs and (iii) customized cargo loading (into native and engineered EVs) to enhance their functional properties (Table 3).

\section{Engineering Alternatives to EVs}

M-NVs simulate the biophysical properties of native EVs, including size (50-200 $\mathrm{nm}$ ), which has been reported to influence half-life in circulation (i.e., nanoparticles smaller than $200 \mathrm{~nm}$ are able to evade RES uptake, and nanoparticles larger than $30 \mathrm{~nm}$ to avoid rapid renal elimination) (Ha et al., 2016; Murphy et al., 2019; Lara et al., 2020; Buschmann et al., 2021; Dooley et al., 2021; Escude Martinez de Castilla et al., 2021; Lazaro-Ibanez et al., 2021; Witwer and Wolfram, 2021). M-NVs can be generated by either top-down (extruding parental cells into nano-sized fragments) to obtain biological M-NVs, or bottom-up methods (selecting cargo and capsule materials i.e., liposomes or polymer nanoparticles) to obtain chemicallydefined synEVs (Nasiri Kenari et al., 2020). Top-down M-NVs 
TABLE 3 | Approaches in engineering extracellular vesicles.

\begin{tabular}{|c|c|c|c|c|c|c|}
\hline & $\begin{array}{c}\text { Modification/ } \\
\text { Generation technique }\end{array}$ & Description & Advantages & Disadvantages & Pre-clinical applications & References \\
\hline \multirow[t]{5}{*}{ Engineered EVs } & Surface functionalization & $\begin{array}{l}\text { Use of chemical reactions to couple } \\
\text { molecules of interest (i.e., peptides, } \\
\text { proteins) to the EV surface (i.e., Click } \\
\text { Chemistry) to enhance targeted delivery or } \\
\text { half-life in circulation. }\end{array}$ & $\begin{array}{l}\text { Targeting to specific organs and areas of } \\
\text { interest (i.e., brain, tumor), increase half-life } \\
\text { and stability in circulation, binding of } \\
\text { negatively charged molecules (i.e., siRNA, } \\
\text { miRNA, mRNA, DNA). }\end{array}$ & $\begin{array}{l}\text { (i) May increase overall size of EVs, (ii) } \\
\text { reduces natural targeting and delivery } \\
\text { capability of EVs, (iii) peptide used must be } \\
\text { very specific to the target site. }\end{array}$ & Targeted therapy. & $\begin{array}{l}\text { Alvarez-Erviti et al., 2011; } \\
\text { Niu et al., } 2021\end{array}$ \\
\hline & $\begin{array}{l}\text { Modification of parental } \\
\text { cells }\end{array}$ & $\begin{array}{l}\text { Genome engineering of parental cells to } \\
\text { modify produced EVs (i.e., surface protein } \\
\text { that influences targeting). }\end{array}$ & $\begin{array}{l}\text { Highly modifiable depending on } \\
\text { application, can target wide range of } \\
\text { luminal molecules for functional } \\
\text { modification of EVs, or surface molecules } \\
\text { for targeting modification of EVs. }\end{array}$ & $\begin{array}{l}\text { Requires extensive validation of the } \\
\text { efficiency and off-target errors of genome } \\
\text { engineering strategies, may alter the } \\
\text { properties and structure of the EV. }\end{array}$ & $\begin{array}{l}\text { Lentivirus transfected MSCs to } \\
\text { overexpress miRNA-let7c, known to } \\
\text { possess anti-fibrotic properties, generated } \\
\text { exosomes capable of transferring this } \\
\text { cargo to renal cells in vitro. }\end{array}$ & $\begin{array}{l}\text { Skog et al., 2008; } \\
\text { Alvarez-Eviti et al., 2011; } \\
\text { Wang et al., } 2016\end{array}$ \\
\hline & Microfluidics & $\begin{array}{l}\text { Fragmentation of cells/lipid micelles using } \\
\text { microfluidic systems (pressure) to generate } \\
\text { EV mimetics or liposomes of consistent } \\
\text { size. }\end{array}$ & $\begin{array}{l}\text { Fast, efficient, scalable, consistent, less } \\
\text { manual handling. }\end{array}$ & Expensive, complex equipment. & $\begin{array}{l}\text { Mimetics were generated from embryonic } \\
\text { stem cells and used to deliver drugs/RNA } \\
\text { in vitro. }\end{array}$ & Jo et al., 2014a \\
\hline & Serial extrusion & $\begin{array}{l}\text { Generation of EV-mimetics by fragmenting } \\
\text { whole cells through micro-sized pore fitters } \\
\text { of descending size to obtain vesicles of } \\
\text { similar size to EVs. }\end{array}$ & $\begin{array}{l}\text { Consistent, scalable generation of EVs } \\
\text { from cells of interest, easily modifiable } \\
\text { protocol to suit application. }\end{array}$ & $\begin{array}{l}\text { Requires extensive manual handling, } \\
\text { additional purification steps, quality } \\
\text { assurance of progenitor cells. }\end{array}$ & $\begin{array}{l}\text { Human MSCs treated with ion oxide } \\
\text { nanoparticles (IONP) were extruded serially } \\
\text { (five times through } 10,5 \text {, and } 1 \mu \mathrm{m} \text { and } \\
400 \mathrm{~nm} \text { ), and demonstrated their feasibility } \\
\text { for spinal cord-injury treatment. }\end{array}$ & Kim H. Y. et al., 2018 \\
\hline & Centrifugation & $\begin{array}{l}\text { Use of centrifugal force to fragment cells } \\
\text { through a membrane generating } \mathrm{EV} \\
\text { mimetics. }\end{array}$ & $\begin{array}{l}\text { Fast, efficient, scalable, less manual } \\
\text { handling compared to extrusion. }\end{array}$ & $\begin{array}{l}\text { Relative scalability depending on } \\
\text { equipment capacity. }\end{array}$ & $\begin{array}{l}\text { Murine embryonic stem cells were } \\
\text { generated by this method and were able } \\
\text { to transfer RNAs. }\end{array}$ & Jo et al., 2014b \\
\hline \multirow[t]{6}{*}{$\begin{array}{l}\text { Post-EV production } \\
\text { engineering }\end{array}$} & $\begin{array}{l}\text { Passive loading } \\
\end{array}$ & $\begin{array}{l}\text { Incubation with molecule of interest for } \\
\text { diffusion loading into Evs. }\end{array}$ & $\begin{array}{l}\text { Efficient protocol, easily modified } \\
\text { depending on application, scalable. }\end{array}$ & $\begin{array}{l}\text { Low loading efficiency in comparison to all } \\
\text { other methods. Depends on Fick's laws } \\
\text { and hydrophobicity of the cargo. }\end{array}$ & $\begin{array}{l}\text { Loading of anti-cancer drugs (Doxorubicin, } \\
\text { Paclitaxel, Gemcitabine) into various EV } \\
\text { systems showed tumor } \\
\text { reduction//limination in murine models. }\end{array}$ & $\begin{array}{l}\text { Jang et al., 2013; Rani } \\
\text { et al., 2015; Gao et al., } \\
\text { 2017; Li Y. J. et al., } 2020\end{array}$ \\
\hline & Serial extrusion & $\begin{array}{l}\text { Generation of EV-mimetics encapsulating } \\
\text { target molecules by performing serial } \\
\text { extrusion of cells in target } \\
\text { molecule-containing buffer. }\end{array}$ & $\begin{array}{l}\text { (i) Surface characteristics similar to EVs } \\
\text { and parentalal cells which improvesen natural } \\
\text { targeting ability, (ii) longer half-life in } \\
\text { circulation, (iil) ititle to no immunogenicity, } \\
\text { (iv) allows loading of therapeutic } \\
\text { molecules, increases targeting capacity } \\
\text { toward site of interest, and reduces side } \\
\text { effects of certain molecules and drugs. }\end{array}$ & $\begin{array}{l}\text { Requires additional purification process, } \\
\text { requires extensive handling. }\end{array}$ & $\begin{array}{l}\text { Comparison of biological EVs and } \\
\text { mimetics VS free chemotherapeutic drug } \\
\text { (Doxorubicin) for delivery and efficacy. The } \\
\text { results showed a better effect and delivery } \\
\text { to cancer cells using EVs and mimetics in } \\
\text { a murine system. }\end{array}$ & Jang et al., 2013 \\
\hline & Sonication & $\begin{array}{l}\text { Treatment with ultrasound produces } \\
\text { transient pores in EV membranes that } \\
\text { allow drug diffusion. }\end{array}$ & Efficient loading of drug molecules. & $\begin{array}{l}\text { Requires rigorous optimization on to } \\
\text { prevent compromising membrane integrity } \\
\text { or the cargo structure, increases EV } \\
\text { instability; small RNA or EV aggregation; } \\
\text { additional equipment or wash step may be } \\
\text { required. }\end{array}$ & $\begin{array}{l}\text { The lysosomal enzyme, tripeptidyl } \\
\text { peptidase- } 1 \text { (TTP1) was loaded into } 10^{11} \\
\text { EVs }(\sim 70 \mu \mathrm{g}) \text {, increasing stability and } \\
\text { targeting to the brain in a murine model of } \\
\text { brain disease. }\end{array}$ & Haney et al., 2019 \\
\hline & Microfluidics & $\begin{array}{l}\text { Addition of cargo molecules to the system } \\
\text { for loading after membrane disruption by } \\
\text { forcing the EVs through microchannels. }\end{array}$ & $\begin{array}{l}\text { Fast, efficient, scalable, consistent, less } \\
\text { manual handling. }\end{array}$ & Expensive, complex equipment. & Drug and RNA delivery system. & Meng et al., 2021 \\
\hline & Electroporation & $\begin{array}{l}\text { Temporary disruption of the EV membrane } \\
\text { using electricity to allow incorporation of } \\
\text { cargo. }\end{array}$ & $\begin{array}{l}\text { Fast, well-established protocol, widely } \\
\text { used to load small molecule drugs and } \\
\text { nucleic acids. }\end{array}$ & $\begin{array}{l}\text { Low loading efficiency ( 15-20\%), low } \\
\text { scalabilitity, requires standardization for } \\
\text { cargo and target EVs, requires rigorous } \\
\text { optimization to prevent compromising } \\
\text { membrane integrity or cargo structure, } \\
\text { increases EV instability; small RNA or EV } \\
\text { aggregation; additional equipment or wash } \\
\text { step may be required. }\end{array}$ & $\begin{array}{l}\text { Utilized to load tumor suppressor miRNAs } \\
\text { into fibroblast-derived EVs to treat ovarian } \\
\text { cancer. Repeated intraperitoneal injections } \\
\text { of miRNA-loaded EVs drastically inhibited } \\
\text { peritoneal dissemination and reduced the } \\
\text { tumor burden in a xenograft ovarian } \\
\text { cancer mouse model. }\end{array}$ & Kobayashi et al., 2020 \\
\hline & Transient permeabilization & $\begin{array}{l}\text { Use of detergents to allow the selective } \\
\text { removal of membrane-bound cholesterol, } \\
\text { creating transient holes/pores in the EV } \\
\text { bilayers, and thus, promoting drug loading. }\end{array}$ & $\begin{array}{l}\text { Simple, efficient, and modifiable protocol, } \\
\text { scalable. }\end{array}$ & $\begin{array}{l}\text { Low efficiency, requires standardization, } \\
\text { use of detergents may degrade critical } \\
\text { biomolecules that influence biological } \\
\text { function, requires rigorous optimization on } \\
\text { to prevent compromising membrane } \\
\text { integrity or cargo structure, increases EV } \\
\text { instability; small RNA or EV aggregation; } \\
\text { additional equipment or wash step may be } \\
\text { required. }\end{array}$ & $\begin{array}{l}\text { Catalase was loaded by saponin } \\
\text { permeabilization of macrophage- and } \\
\text { monocyte- derived EVs to prevent } \\
\text { neurodegeneration and neuroinflammation } \\
\text { in mouse models of Parkinson's disease. }\end{array}$ & Haney et all, 2015 \\
\hline
\end{tabular}


TABLE 3 | (Continued)

\begin{tabular}{|c|c|c|c|c|c|c|}
\hline & $\begin{array}{c}\text { Modification/ } \\
\text { Generation technique }\end{array}$ & Description & Advantages & Disadvantages & Pre-clinical applications & References \\
\hline & Freeze-thaw & $\begin{array}{l}\text { Incorporation of target molecules/drugs } \\
\text { into EVs by increasing membrane } \\
\text { permeability through multiple freeze-thaw } \\
\text { cycles. }\end{array}$ & $\begin{array}{l}\text { Simple and efficient protocol, minimal } \\
\text { handling, able to modify according to } \\
\text { concentration of target molecule/drug. }\end{array}$ & $\begin{array}{l}\text { Biological EV function, and membrane } \\
\text { integrity may decrease or become } \\
\text { compromised with increasing number of } \\
\text { freeze-thaw cycles. }\end{array}$ & $\begin{array}{l}\text { Curcumin was loaded into mouse } \\
\text { embryonic stem cell-derived exosomes by } \\
\text { freezing and thawing three successive } \\
\text { times promoted neurovascular restoration } \\
\text { following ischemia-repertusion injury in } \\
\text { mice. }\end{array}$ & Kalani et al., 2016 \\
\hline \multirow[t]{2}{*}{ Artificially stimulated } & $\begin{array}{l}\text { Overexpression of } \\
\text { biogenesis-associated } \\
\text { genes }\end{array}$ & $\begin{array}{l}\text { Genetic engineering to introduce } \\
\text { enhancers, promoters or sequences } \\
\text { targeting specific genes for } \\
\text { over-expression. }\end{array}$ & Increases yield of EVs. & $\begin{array}{l}\text { Low efficiency and off-target errors of } \\
\text { genome engineering strategies, influences } \\
\text { proteome and potentially function of EVs, } \\
\text { expensive, time consuming. }\end{array}$ & $\begin{array}{l}\text { MSCs with a combination of } \\
N \text {-methyldopamine and norepinephrine } \\
\text { robustly increased exosome production by } \\
\text { three-fold without altering the ability of the } \\
\text { MSC exosomes to induce angiogenesis, } \\
\text { polarize macrophages to an } \\
\text { anti-inflammatory phenotype, or } \\
\text { downregulate collagen expression. }\end{array}$ & Wang Y. et al., 2020 \\
\hline & Artificial blebbing & $\begin{array}{l}\text { Chemical induction of the blebbing } \\
\text { process (paraformaldehyde, dithiothreitol, } \\
\text { N-ethyl maleimide). }\end{array}$ & Efficient and scalable. & $\begin{array}{l}\text { Requires standardization, requires further } \\
\text { processing for chemicals removal. }\end{array}$ & No applications thus far. & Thone and Kwon, 2020 \\
\hline \multirow[t]{2}{*}{ Hybrids } & EVs and liposomes & Fusing EV membranes with lipids. & $\begin{array}{l}\text { Increase half-life and stability in circulation, } \\
\text { modifiable based on lipid used, enhanced } \\
\text { structural integrity, allows loading of target } \\
\text { molecules. }\end{array}$ & $\begin{array}{l}\text { May decrease biocompatibility and } \\
\text { influence EV surface proteins important for } \\
\text { specific organ targeting. }\end{array}$ & $\begin{array}{l}\text { HEK293FT derived EVs were incubated } \\
\text { with Lipofectamine } 2000 \text { and selected } \\
\text { plasmids. }\end{array}$ & Lin et al., 2018 \\
\hline & EV-modified scaffolds & $\begin{array}{l}\text { Incorporating EVs onto scaffolds } \\
\text { comprised of various polymers (i.e., } \\
\text { extracellular matrix proteins, chitosan, silk } \\
\text { fibroin, hydrogels). }\end{array}$ & $\begin{array}{l}\text { Sustained release of EVs over longer } \\
\text { periods of time, higher efficacy than } \\
\text { free-EVs, easy to handle, high } \\
\text { mechanical/tensile strength and } \\
\text { controllable degradability which can be } \\
\text { modified based on polymer/s used, higher } \\
\text { biocompatibility if ECM-based. }\end{array}$ & $\begin{array}{l}\text { Generally required to be in direct contact } \\
\text { with target tissue/organ, which is invasive } \\
\text { if targets are internal, toxicity of residual } \\
\text { crosslinking agents from scaffold } \\
\text { manufacturing, can be pH- or } \\
\text { temperature- sessitive and cause plugging } \\
\text { of needle during injection, unknown } \\
\text { release rate in vivo. }\end{array}$ & $\begin{array}{l}\text { Targeted regeneration of bone, heart, liver, } \\
\text { skin, and vasculature. }\end{array}$ & $\begin{array}{l}\text { Mardpour et al., 2019; Hu } \\
\text { S. et al., 2021; Kim et al., } \\
\text { 2021; Shi et al., 2021; } \\
\text { Zhao et al., } 2021\end{array}$ \\
\hline \multirow[t]{5}{*}{ Synthetics } & Silicon & $\begin{array}{l}\text { Modification of silicone nanoparticles to } \\
\text { display or encapsulate target molecules } \\
\text { and drugs for delivery. }\end{array}$ & $\begin{array}{l}\text { Robust production, able to load target } \\
\text { molecules, high structural integrity, able to } \\
\text { modify porosity and surface chemistry to } \\
\text { control degradation/drug release. }\end{array}$ & $\begin{array}{l}\text { Can be toxic, lower biocompatibility, lacks } \\
\text { surface proteins for targeting and uptake } \\
\text { by recipient cells. }\end{array}$ & $\begin{array}{l}\text { Pre-clinical studies pSivida has shown that } \\
\text { BioSilicon is both biodegradable and } \\
\text { biocompatible, used for controlled release } \\
\text { of substances without penetrating the } \\
\text { cells. }\end{array}$ & O'Farrell et al., 2006 \\
\hline & Iron & $\begin{array}{l}\text { Coating of iron nanoparticles with } \\
\text { proteins/other to target specific tissues. }\end{array}$ & $\begin{array}{l}\text { Many methods of production to suit } \\
\text { application, can cross BBB, increased } \\
\text { structural integrity, FDA approved, suitable } \\
\text { for anemic patients, allows magnetic } \\
\text { guidance for specific site targeting, used } \\
\text { as a label for scaffold-based therapies to } \\
\text { allow for imaging, surface-modifiable by } \\
\text { biocompatible coating. }\end{array}$ & $\begin{array}{l}\text { Can be toxic, lower biocompatibility, } \\
\text { depending on application, metal teeth } \\
\text { fillings may interfere with imaging, } \\
\text { disadvantages associated with production } \\
\text { method (i.e., adverse side effects from } \\
\text { residual surfactants, large-scale synthesis, } \\
\text { cost, temperature regulation). }\end{array}$ & $\begin{array}{l}\text { Medical imaging, cell labeling, iron } \\
\text { replacement therapy for patients with } \\
\text { kidney failure or anemia, macrophage } \\
\text { polarization, magnetic drug targeting, } \\
\text { theranostic applications. }\end{array}$ & Huber, 2005 \\
\hline & Lipids & Bottom-up generation of nanovesicles. & $\begin{array}{l}\text { Scalable, time efficient, customizable lipid } \\
\text { composition and size depending on } \\
\text { application, low cost, consistent } \\
\text { generation. }\end{array}$ & $\begin{array}{l}\text { Low targeting capabilities, lack of surface } \\
\text { proteins, low uptake, low biocompatibility, } \\
\text { faster systemic clearance. }\end{array}$ & $\begin{array}{l}\text { PEG -DOPE nanovesicle generation for } \\
\text { chemotherapeutic drug delivery } \\
\text { (Doxorubicin and emtansine) in a murine } \\
\text { model. }\end{array}$ & $\begin{array}{l}\text { Han et al., 2006; Cao } \\
\text { et al., 2016 }\end{array}$ \\
\hline & Gold & $\begin{array}{l}\text { Gold nanoparticles associated to PEG or } \\
\text { other lipids by cross-linking reactions. }\end{array}$ & $\begin{array}{l}\text { Robust production, chemically inert, } \\
\text { stable, modifiable (size - which influences } \\
\text { toxicity and biocompatibility properties), } \\
\text { radiosensitizing, and anti-microbial } \\
\text { properties. }\end{array}$ & $\begin{array}{l}\text { Can be toxic, largely influenced by size } \\
\text { (i.e., biocompatibility, renal clearance, } \\
\text { tumor tissue permeability, cell uptake, } \\
\text { entry into nuclei), more suitable for } \\
\text { theranostic and imaging applications. }\end{array}$ & $\begin{array}{l}\text { Photothermal therapy. Use of PEG-gold } \\
\text { nanoparticles and drug adsorption for } \\
\text { chemotherapeutics delivery. }\end{array}$ & $\begin{array}{l}\text { Dykman and Khlebtsov, } \\
2011\end{array}$ \\
\hline & Carbon nanotubes & $\begin{array}{l}\text { Controlled carbon concatenation reactions } \\
\text { depending on the desired shape and size. }\end{array}$ & $\begin{array}{l}\text { Robust production, stable, modifiable } \\
\text { (size, tubes, nets, scaffolds - which } \\
\text { influences toxicity and biocompatibility } \\
\text { properties). }\end{array}$ & $\begin{array}{l}\text { Can be toxic, lower biocompatibility, lacks } \\
\text { surface proteins for targeting and uptake } \\
\text { by recipient cells. }\end{array}$ & $\begin{array}{l}\text { Drug, protein, and DNA/RNA delivery } \\
\text { systems by adsorption methods into } \\
\text { biodegradable scaffolds that can penetrate } \\
\text { the cells for cancer therapy, } \\
\text { neurodegenerative diseases, tissue } \\
\text { regeneration in murine and in vitro models. }\end{array}$ & He et al., 2013 \\
\hline
\end{tabular}


are generated by serial extrusion, ultracentrifugation, or pressurebased microfluidic approaches [reviewed in Mentkowski et al. (2018)]. Mechanical extrusion is achieved by forcing the cell suspension to pass through membranes of different pore size to cause cell disruption (Jang et al., 2013). After extrusion of parental cells, the membrane fragments form membrane-derived vesicles due to their physicochemical properties, engulfing the cellular components in suspension and generating mimetic EVs (Jo et al., 2014b). Following this method, M-NVs generated from macrophages through serial extrusion with concurrent loading of catalase (added to the cell suspension before extrusion) demonstrated elevated neuroprotective activity while increasing the yield $\sim 100$-fold, compared to native EVs (Haney et al., 2015).

MN-Vs can also be generated from MIN6 pancreatic $\beta$-cells by serial extrusion i.e., five passages through 10,5 and $1 \mu \mathrm{m}$ polycarbonate membrane filters using a mini extruder (Oh et al., 2015). In parallel, bone marrow MSCs isolated from femurs and tibias of BALB/c mice were embedded in Matrigel and implanted subcutaneously into NSG mice (NOD.CgPrkdcscidIl2rgtm1Wjl/SzJ). Into these subcutaneous patches, $10 \mu \mathrm{g} /$ injection of MIN6 mimetics were administered for a total of four injections in 10 days. The authors demonstrated that the MSCs imbedded in Matrigel formed islet-like clusters with extensive capillary networks as a cause of M-NV administration, and that these were able to maintain the glucose levels of the mice for over 60 days (Oh et al., 2015). This work provided a key insight of the effectiveness of mimetics in vivo as delivery and signaling systems. To understand composition of M-NVs, Hill and collaborators (Nasiri Kenari et al., 2019) performed proteomic profiling of M-NVs and demonstrated their distinct composition from exosomes and parental cells. Although M-NVs shared many similarities with native EVs (physical attributes, key protein EV markers, proteins that overrepresented the original cell), differences were observed in protein post-translational modifications, specifically phosphorylation, ubiquitination, and thiophosphorylation. This raises an important consideration of using $\mathrm{M}-\mathrm{NVs}$ as an alternative nanocarrier when spontaneous endosomal sorting of therapeutics is limited or when modulation of donor cells influences native EV generation. An important consideration of M-NV generation is that despite the 100 to 150 fold increase in yield, this method still relies in parental cells as raw materials which requires the surveillance of their longterm maintenance (genome stability, passage number, cell culture technologies) and culture conditions/media type and potential influence of non-model EV source [i.e., bovine-derived (Eitan et al., 2015; Lehrich et al., 2021; Pham et al., 2021)].

A different stream of research to solve upscaling as a key limitation for native EVs' and M-NVs' pharmaceutical use, focuses on the generation of bottom-up particles denominated synEVs. synEVs have demonstrated a high efficacy and high scalability as drug and vaccine-based delivery systems (Park et al., 2021). Generation of liposomes include extrusion over membrane filters [analogous to mimetic generation (Cao et al., 2016; Nele et al., 2019; Shah et al., 2019)], and hydrophilic microchannels [microfluidic systems (Shah et al., 2019; Kotoucek et al., 2020)]. The development of synEVs has gained immense interest due to COVID-19 vaccine research, including mRNA encapsulated in liposomes by Moderna/NIAID, BioNTech/Pfizer, Arcturus/Duke-NUS, PLA/Walvax Biotech, Imperial College London, and CureVac AG (Park et al., 2021). These synEVs (in particular Moderna/NIAID and Pfizer nonviral vaccines) have shown to be a highly efficient system for delivery and immunoregulatory response (Park et al., 2021). Furthermore, the methods for generation and encapsulation of cargo (i.e., mRNA) into synEVs has demonstrated high efficiency and yield; $>72 \%$ encapsulation rates (Hassett et al., 2019). Although different approaches for generating synEVs with vaccine applications have been employed, in all cases their lipid composition provides key therapeutic advantages, including ability to encapsulate and condensate mRNA, promote delivery to cytosol by increasing cellular uptake (due to their composition compatible with biological membranes i.e., PEGylated lipids, cholesterol and cationic or ionizable lipids), protect mRNA (or any other cargo) from degradation in extracellular spaces, and their components are easily manufactured with GMP in a large scale. The latter demonstrates synEVs represent a unique advantage in combining with production of native EVs, despite issues with their targeted delivery. Unlike cell-derived EVs, synEVs lack targeting and recognition molecules, therefore, their synthesis has been coupled with different functionalization techniques such as bioconjugation (Smyth et al., 2015; Lim et al., 2021) [reviewed in Murphy et al. (2019), Rayamajhi and Aryal (2020), Salmond and Williams (2021), Sharma et al. (2020), and Takayama et al. (2019)] and cargo loading (Haney et al., 2015, 2019) [reviewed in Luan et al. (2017), Nasiri Kenari et al. (2020), Roberts et al. (2020), and Sterzenbach et al. (2017)] to obtain use-specific synEVs (Garcia-Manrique et al., 2018), as well as their fusion with EVs (native or mimetics) to generate EV hybrids (hEVs).

hEVs are a recently developed method to generate vesiclesthey comprise native EV components and synthetic liposomes (Gangadaran and Ahn, 2020). Hybrids could be a more effective alternate to both EVs and liposomes as drug delivery systems by combining the advantages of loading versatility (diverse molecular cargo), targeting capabilities (native EV tropism), and stability (structure stabilization, cargo protection, handling stability) [reviewed in Ou et al. (2021)]. Moreover, hEVs can be generated by different methods such as extrusion, sonication, coincubation or freeze/thaw cycles, which makes them convenient for clinical development and diverse applications (Gangadaran and Ahn, 2020). Freeze/thaw cycle method was used in combination to surface modification techniques to fuse EVs expressing a specific surface protein produced by macrophages and different cancer cell lines (mouse fibroblast sarcoma-derived CMS7-wt, CMS7-HE, and Raw 264.7 macrophages) with liposomes (Sato et al., 2016). Hybrids have also been generated by sonication of an aqueous suspension of macrophage-derived EVs and L- $\alpha$-phosphatidylcholine/Cholesterol liposomes (Rayamajhi et al., 2019). The resulting hybrids are a promising platform for tumor-targeted drug delivery, releasing Doxorubicin predominantly to macrophages, osteosarcoma cells and breast cancer cells (compared to normal fibroblasts) in vitro, demonstrating these hEVs have preferential targeting to parental cells and tumor cells (Rayamajhi et al., 2019). Furthermore, 
a variant of hEVs using native EV sources [bone marrow MSC-derived EVs (purified from conditioned media) and platelet mimetics (generated by a combination of freeze/thaw and consecutive sonication)], were generated by co-extrusion and administered to mice ( $100 \mu \mathrm{g} /$ mice, once a week for 4 weeks), demonstrated increased targeting and pro-angiogenic activity in a mouse model of myocardial infarction in mice (Li et al., 2021c). Here, tropism of platelets toward activated endothelium (which occurs during injury or stress) was inherited by the resulting hybrids enhancing their targeting and accumulation capabilities to the myocardium (compared to native MSC-derived EVs) allowing the targeted delivery of reparative cargo despite systemic administration.

\section{Improved Targeting: Genome Engineering and Surface Functionalization}

Modifying EVs to improve their specific delivery is a key requirement in therapeutic applications. Several engineering approaches have been developed and applied to EVs. Click chemistry, genetic modification, and glycoengineering have proven to be highly efficient methods to increase sitespecific retention, thus reducing off target effects (Smyth et al., 2014; Williams et al., 2018; Rayamajhi and Aryal, 2020). EV composition and function are influenced by the cell source, a characteristic which can be exploited during EV-based therapeutic development (Kim et al., 2020). Many technologies can modify progenitor cells to alter the functional capacity of their derived EVs; one of which is genome engineering, which involves either the knockout [i.e., siRNA, CRISPR (Horodecka and Duchler, 2021)] or overexpression [i.e., Lentiviral/Adenoviral, plasmid, or nucleic acids (siRNA, miRNA, anti-miR) transfections (Li et al., 2013; Zhang et al., 2014; Chen S. et al., 2019; Escude Martinez de Castilla et al., 2021)] of genes (Shi et al., 2020). The composition of EVs released from these modified cells are therefore customized, heavily influencing recipient cell function [i.e., immunomodulatory (Trivedi et al., 2016; Gomez-Ferrer et al., 2021), pro-angiogenic (Zuo et al., 2019; Zhang L. et al., 2021), anti-apoptotic (Wen et al., 2020) or anti-cancer (Kim R. et al., 2018)]. Thus, these strategies are applicable to a range of pathologies, including cardiovascular disease, tissue repair/regeneration, cancer, and immunological disorders. However, continuous improvements are required for these techniques due to their low mutation efficiency and potential off-target sequence error (CRISPR-Cas9) (Siddique, 2016) or low efficiency and variable expression levels by transfected cells (transfection) (Di Blasi et al., 2021) (which may influence the biogenesis/yield/content/function of the produced EVs (Carli et al., 2021) or parental cell viability or proliferation (Lambshead et al., 2018; Cherian et al., 2020; Escude Martinez de Castilla et al., 2021).

In this context, genetic manipulation strategies [e.g., plasmid transfection (Cho et al., 2018; Hong et al., 2019; Shi et al., 2020; Feng et al., 2021), pDisplay vector transfection (Ohno et al., 2013), retroviral transfection (Fan et al., 2013)] pre-EV isolation have been shown to modify the surface of EVs to enable site-specific delivery (Wan et al., 2018) (Table 3). For instance, overexpression of folate receptor $\alpha(\mathrm{FR} \alpha)$ on $\mathrm{EV}$ surface facilitated their specific binding to the brain parenchyma, crossing the $\mathrm{BBB}$, demonstrating a mechanism of brain-specific drug delivery in vivo after an intraventricular injection (Grapp et al., 2013). Furthermore, genome engineering of cardiospherederived cells (CDC) using lentiviral particles to express LAMP2B fused to a cardiomyocyte specific peptide (CMP; WLSEAGPVVTVRALRGTGSW) generated EVs displaying LAMP2B-CMP on their surface, increasing retention time and improving targeted delivery to the heart (Mentkowski and Lang, 2019). Moreover, modification of mouse dendritic cells to express LAMP2B fused to the neuron specific RVG peptide was shown to target EVs with siRNA-BACE1 to neuronal cells (Alvarez-Erviti et al., 2011). The therapeutic potential of this system was demonstrated by mRNA (60\%) and protein $(62 \%)$ knockdown of BACE1, a therapeutic target in Alzheimer's disease. This strategy was also employed to modify BMSCs for the generation of EVs expressing LAMP2B coupled with ischemic myocardium-targeting peptide (IMTP; CSTSMLKAC), which caused a significant increase of EV accumulation in cardiac tissue when compared to peptide sequence (non-targeted) controls (Antes et al., 2018; Wang X. et al., 2018). Altogether, these studies highlight the capacity of genome engineering to generate surface modifications that enhance EV targeting capabilities. On the other hand, off-target errors during genome editing complicate validation and are time consuming/expensive, thus would impede upscaling. It was also observed that despite their targeting capabilities, engineered EVs accumulate in non-targeted tissue/organs, including liver and kidney (Wang X. et al., 2018); determination of the EVs' effects at these sites and an improved understanding of EV-site interaction are required for clinical applications. Engineering methods can also be combined to refine EV-based therapeutics. Decoy mimetic EVs have been generated through mechanical extrusion of genetically engineered parental-cells overexpressing surface receptor ACE2 (Rao et al., 2020). These mimetic EVs were fused with human myeloid mononuclear THP-1 mimetics, to generate hEVs. Upon administration to a murine model of acute pneumonia, these hEVs suppressed immune disorder and decreased lung injury (Rao et al., 2020).

A different approach for surface engineering is modification post-EV isolation. These modifications can be performed through glycoengineering [attachment of glycans to proteins by generation of covalent bonds (Williams et al., 2018; Williams C. et al., 2019; Sharma et al., 2020; Della Rosa et al., 2021; Lim et al., 2021; Martins et al., 2021)] and click chemistry [reactions which involve conjugation of molecules in a modular fashion, for example, the bio-orthogonal copper-free azide alkyne cyclo-addition (Smyth et al., 2014; Ouyang et al., 2018; Murphy et al., 2019; Takayama et al., 2019)], and are used for targeting (Kooijmans et al., 2016) and cloaking strategies (Kooijmans et al., 2016; Suk et al., 2016), also known as "surface functionalization"(Rayamajhi and Aryal, 2020). For example, glycoengineering of anti-EGFR nanobody to the phosphatidylserine (PS) of EVs derived from blood, or Neuro2A cells, promotes their uptake by $\mathrm{EGFR}^{+}$cells in a dose-dependent manner and decreases their non-specific binding to other cells 
(Suk et al., 2016). Further, this modification resulted in an increased circulation time of $>60 \mathrm{~min}$ for engineered EVs in comparison to $10 \mathrm{~min}$ for native EVs (Suk et al., 2016). Together, these results provide an effective strategy for cloaking and targeting using glycoengineering.

A combination of glycoengineering and click chemistry has been employed as a highly- efficient and specific approach to modify the EV surface through irreversible bioconjugation (Smyth et al., 2014; Takayama et al., 2019). This allows EV surface functionalization for delivery of small molecules, large biomacromolecules, and polymers without altering particle size or function. Murine MSC-derived EVs were modified by copperfree click chemistry to generate an Ale-EVs system (EVs coupled with Alendronate, a medication used for osteoporosis) administered to an in vivo model of ovariectomy (OVX)-induced osteoporosis (Wang Y. et al., 2020). These Ale-EVs had an affinity to bone tissue and promoted regeneration under osteoporotic conditions with low toxicity. Similar methods, including genetic modification of parental cells and/or post-EV isolation methods can also be used to enrich surface-ligands on EVs, which can then induce/inhibit signaling or target specific recipient cells for delivery (Jafari et al., 2020). As a direct approach to modify the surface of MSC-derived EVs by click chemistry conjugation, $c($ RGDyK) peptide which exhibits affinity to integrin $\alpha v \beta 3$ and expressed in reactive cerebral vascular endothelial cells after ischemia, was used for improved delivery (11-fold tropism to the lesion region of ischemic brain) and treatment of stroke (Tian et al., 2018). Additionally, surface modifications using click chemistry can be used to chemoenzymatically label EVs to visualize cellular uptake in real time. EVs isolated from conditioned media of human breast cancer MCF-7 cells were purified and an alkyne group (click chemistry target) substituted for the choline group from native EV phosphatidylcholine by an enzymatic reaction using phospholipase D (Jiang et al., 2020). Using the alkyne-azide click chemistry, fluorescent Cy5 dye was covalently fused and used to track cellular internalization in real time using fluorescent confocal microscopy in vitro (Jiang et al., 2020). Furthermore, the surface modification did not alter EV size (compared with native EVs by nanoparticle tracking analysis) (Jiang et al., 2020). This study provides an efficient method for tracking EVs that could be applied to monitor biodistribution, targeting and uptake of engineered EVs.

\section{Cargo Loading Strategies}

In addition to cargo loading via surface conjugation (Wang Y. et al., 2020), other strategies used to load cargo into EVs include parental cell modification, passive diffusion, and active loading. Overexpression of components in parental cells is an effective way to increase abundance in resulting EVs for greater function. Transfection of MSCs with miR-133b resulted in accumulation ( $\sim 2.5$-fold higher levels) of miR-133b in EVs (when compared to EVs from non-transfected MSCs), which subsequently improved functional recovery, reduced lesion volume, and increased neuron survival in an in vivo model of spinal cord injury ( $\mathrm{Li}$ et al., 2018). Several other studies have modified either parental cells (pre-EV isolation) or EVs directly (post-EV isolation) for improved therapeutic response [reviewed in Lara et al.
(2020), Nagelkerke et al. (2021), Ullah et al. (2021), and Witwer and Wolfram (2021)] such as in cancer (Zhang et al., 2014), neurodegeneration and Parkinson's disease (Haney et al., 2015), and kidney fibrosis (Wang et al., 2016; Tang T. T. et al., 2019).

An alternative to modifying parental cells is the direct incorporation of specific molecules (i.e., miRNA, siRNA, protein, lipids, drugs) into EVs through passive or active methods (Luan et al., 2017; Sterzenbach et al., 2017; Nasiri Kenari et al., 2020; Nazimek and Bryniarski, 2020). Incubation of EVs with active components is a passive method of loading that involves the diffusion of drugs or molecules with varied encapsulation efficiency through the EV membrane. This approach has facilitated loading of siRNAs, miRNAs, proteins (i.e., catalase; an antioxidative enzyme, Parkinson's disease treatment) (Haney et al., 2015), and anti-cancer drugs [i.e., Paclitaxel (Saari et al., 2015; Kim et al., 2016), Doxorubicin (Smyth et al., 2015), Imatinib (Bellavia et al., 2017)] into EVs for delivery. The loading efficiency is dependent on incubation time, cargo concentration and physicochemical properties of the cargo (i.e., solubility, surface area polarity, lipophilicity, hydrophobicity) (Liu C. et al., 2016; Luan et al., 2017; Kim et al., 2020). To address this variability, active loading methods have been implemented (co-incubation with membrane permeabilizers, i.e., saponin) to improve loading efficiency of specific molecules by up to 11-fold (Fuhrmann et al., 2015). This involves temporary and controlled disruption of EV membrane, usually accomplished by sonication, electroporation, membrane permeabilizers, freeze-thaw cycles, or cell extrusion (Table 3) to allow entry of cargo into EVs.

Sonication of EVs (using sonic waves) for therapeutic cargo loading is a widely used method for various clinical applications. Using this technique, macrophage-derived EVs were successfully loaded with Doxorubicin and Paclitaxel, allowing resulting vesicles to target cancer cells and inhibit tumor growth. These modified EVs are an attractive therapy for pulmonary metastases and triple negative breast cancer in murine models (Kim M. S. et al., 2018; Haney et al., 2020). Importantly, these studies observed that $\mathrm{pH}$, temperature, and sonication configuration (time, power, probe, or water bath) affected loading efficiency, and required optimization (dependent on the cargo properties). Using an electrical pulse to temporarily disrupt the $\mathrm{EV}$ membrane, electroporation is a widely used method for loading small molecule drugs and nucleic acids into EVs to treat Alzheimer's disease (Alvarez-Erviti et al., 2011), and breast (Ohno et al., 2013), lung (Takenaka et al., 2019), and ovarian (Kobayashi et al., 2020) cancers. The loading efficiency of nucleic acids (i.e., siRNA) through electroporation ranges between 15 and $20 \%$, demonstrating a robust method for cargo loading (Jhan et al., 2020).

As an alternative to physical membrane disruption, incubation of EVs with chemical membrane permeabilizers also allows efficient loading of therapeutic cargo into EVs. Incubation of EVs with the detergent-like molecule saponin has been used to incorporate antioxidant catalase and the enzyme tripeptidyl peptidase-1 (TPP1) into bone marrow macrophage-derived EVs (up to $6.3 \mu \mathrm{g} / 10^{11}$ particles for catalase, or $50 \mu \mathrm{g} / 10^{11}$ particles for TPP1 were incorporated) (Haney et al., 2015, 2019). The loaded EVs significantly inhibit neurodegeneration 
and neuroinflammation in mouse models of Parkinson's disease (Haney et al., 2015) and Batten disease (Haney et al., 2019). Other techniques used for EV cargo loading include multiple freeze-thaw cycles (Kalani et al., 2016), and serial extrusion of cell suspension through decreasing pore sizes in a buffer containing cargo of interest (Kim H. Y. et al., 2018). Studies comparing these processes highlight serial extrusion as the most efficient method for cargo loading, resulting in stable EVs with elevated functional effects (Fuhrmann et al., 2015; Haney et al., 2015; Kim et al., 2016; Le Saux et al., 2020). In the context of EV-based therapeutics, all cargo loading methods have intrinsic advantages and disadvantages that must be considered (Table 3 ). The methods applied should be modified according to the clinical/disease/model context (i.e., model and tissues of interest, biological/clinical question). Altogether, these advances in EV engineering provide highly customizable and combinatorial techniques to overcome current limitations of native EV as therapeutics, thus improving delivery, efficacy, and function. These advancements have allowed rapid development of EV-based therapeutics for transition to preclinical and clinical development.

\section{CHALLENGES TO FURTHER DEVELOPMENT OF EV THERAPIES}

With increasing attention on EV-based therapeutics, the need for further refinement and standardization of design, production, and clinical administration approaches is critical. Specifically, there remain several fundamental challenges the field must come to terms with; low yield of production, scalable and standardized EV generation, standardized dose and potency monitoring, determination and quantification of molecular bioactivity for regulatory purposes, and unsatisfactory targeting capacity. Fortunately, international efforts to address aspects of these are ongoing (Lener et al., 2015; Reiner et al., 2017; Witwer et al., 2019; Gandham et al., 2020; Nguyen et al., 2020; Nieuwland et al., 2020; Rankin-Turner et al., 2021). In this section, we outline the challenges faced in EV therapeutic development, with an emphasis on the updated research and technologies offering avenues for preclinical and clinical advancement (Figure 1).

\section{Scalability and Standardization of EV Production}

Clinical translation of EVs demands the development of standard, scalable, and cost-effective approaches for their production. For EV-based therapeutics, manufacturing requires high capacity and scalability without influencing the composition or potency of EVs (Whitford and Guterstam, 2019). A lack of clinical grade purification protocols suitable for large-scale production, and an incomplete understanding and standardization of variables influencing EV production represent main challenges in this area. Selection of an appropriate donor cell for native EVs (Charoenviriyakul et al., 2017) and monitoring variables such as growth state (epithelial, mesenchymal, or adherent/anchorage-dependent) (Tauro et al., 2013; Willms et al., 2016) can assist with this. Owing to significant functional advantages in regenerative medicine including wound healing and tissue repair, and therapeutic advantages in antiinflammatory and low immunogenicity properties, amniotic and adipose cell-derived EVs are considered as a suitable candidates for therapeutic EV research and translation (Tan et al., 2018; Shukla et al., 2020). Aspects of culture influencing cell state include type of cell culture system [conventional and bioreactor systems (Mitchell et al., 2008; Mendt et al., 2018; Palviainen et al., 2019)] and media/supplements used (product and batch variance) (Quah and O'Neill, 2007; de Jong et al., 2012; Li et al., 2015; Patel D. B. et al., 2017; Thery et al., 2018; Zhu et al., 2021a). Moreover, modifications in culture parameters resultant of scaled-up systems, $\mathrm{pH}$, mass transfer, and hydrodynamic (or shear) force, can result in modified cell state and growth, viability, expression, and activity of cell receptor/signaling, potentially impacting the composition and therapeutic efficacy of derived EVs. Further strategies exist to stimulate EV production and enhance yield have been reported, including $N$-methyldopamine and norepinephrine (Wang J. et al., 2020). However, the extent to which these factors impact EV composition, efficacy or other factors associated with their therapeutic use remains predominantly unknown (Colao et al., 2018; Adlerz et al., 2020) [reviewed in Whitford and Guterstam (2019)]. Therefore, as the therapeutic effects of EVs can be modulated by these variables, there is an emphasis on parental cell characteristics that should be carefully considered to exploit their clinical application (for example, therapeutic potency, immunogenicity, targeting selectivity), including their capacity to be manipulated (i.e., genetic engineering, transfection efficiency, genetic stability) or parental cell immortalization. For primary and immortalized cells, a thorough, risk-based analysis must be conducted, for the cells and their derived EVs, in addition to modified cells [reviewed in Rohde et al. (2019)]. In the context of EVs for therapeutic use, parental cell immortalization has been shown to enable sustainable production of EVs without influencing their therapeutic efficacy or immunosuppressive activity (Chen et al., 2011), however, safety concerns have been raised for the procedures and requirements to monitor oncogenicity and genetic drift [reviewed in Herrmann et al. (2021) and Xunian and Kalluri (2020)]. Recently, the production of therapeutic EVs has been amplified (Cha et al., 2018) by enhancing the biological functions of MSC-aggregates (spheroids) and their large-scale EV production (Cha et al., 2018). This study further highlighted key requirements in quality control (QC) monitoring cell source throughout changes in production and maintenance, monitoring morphological, size, and structural characteristics of derived EVs, their cytokine and miRNA expression and in vitro function, demonstrating they retained their stemness and marker gene expression during dynamic culture (Tan et al., 2018; Shukla et al., 2020). A safety concern with stem cells is the use of animal-derived serum for cell growth; the presence of such cross-species factors may cause issues from a regulatory standpoint in the production of therapeutics. Alternatively, using xeno-free culture media components or EV-depleted serum should be considered and influence on the compositions or physiological properties of derived EVs should be monitored. Accumulating evidence indicates that other naturally-derived EV 


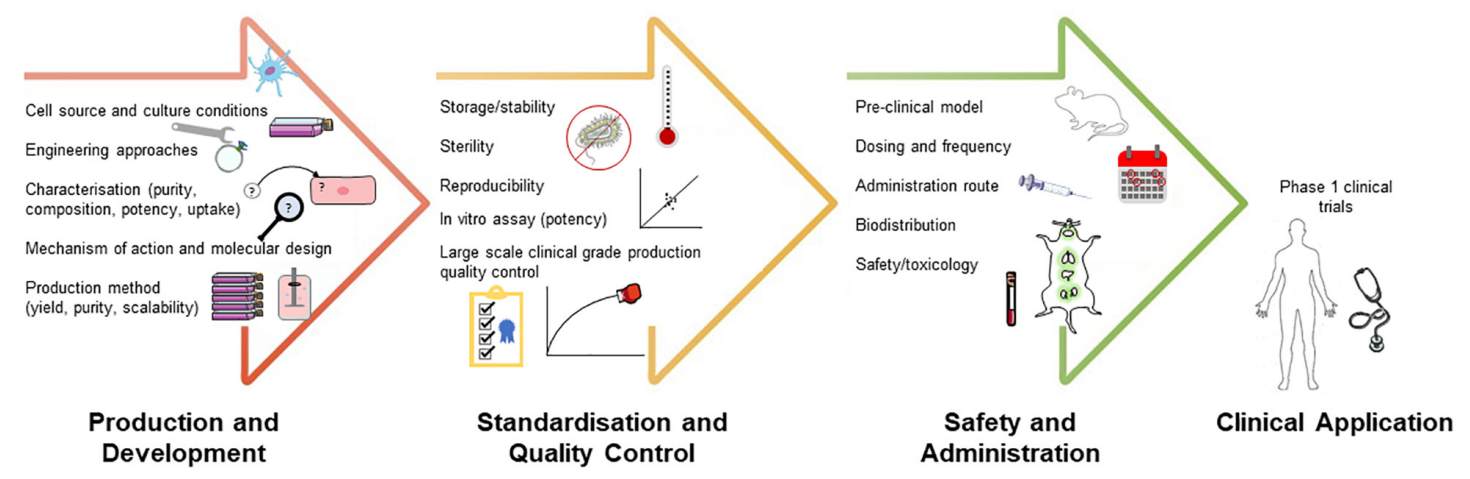

FIGURE 1 | Challenges and translational considerations of development of EV-based therapeutics. Developing rational targeting or therapeutic strategies for these different stages will advance the application of EV-based therapeutics.

source, including plant-based (NCT01668849, NCT01294072) (Dad et al., 2021) and bovine-milk-derived EVs (Grossen et al., 2021) may be sustainable alternatives for large-scale utility of engineered EVs. Bacterial EVs from non-pathogenic or probiotic bacterial source may also be harnessed as potential EV-based delivery carriers for anti-inflammatory function (Kuhn et al., 2020), with further advantages in their versatility in being readily functionalized (Shehata et al., 2019; Cheng et al., 2021) and their scalable production (Gujrati et al., 2014; Cheng et al., 2021).

For EV-based therapeutics to be considered a viable option for clinical applications, large-scale commercial production is required. For small-scale manufacturing, cells can be expanded in multilayered flasks, spinners, wave bags or fixed-bed or hollowfiber bioreactors depending on their growth characteristics, while for large-scale culture, cells can be grown in largecapacity enclosed (stirred-tank) bioreactors or platform-rocker wave bags (Whitford and Guterstam, 2019). Presently, largescale production of functional homogeneous stem cell-derived EVs for therapeutic utility has been developed using filtration $(0.2 \mu \mathrm{m})$ and conventional ultracentrifugation (Mendt et al., 2018), and size-based chromatography fractionation (Reiner et al., 2017). While large-scale production of GMP-grade EVs for clinical trialing employs a combined approach of ultrafiltration coupled with sucrose/deuterium oxide (with ultracentrifugation cushion) (Lamparski et al., 2002; Nikfarjam et al., 2020). Further, GMP-grade EVs from human cardiac progenitor cells for therapeutic application have been isolated from $8 \mathrm{~L}$ of bioreactor-derived culture medium using tangential flow filtration (TFF) (without ultracentrifugation) in an integrated closed circuit which encompasses the full downstream process (clarification, concentration, diafiltration, and final sterilizing filtration) (Andriolo et al., 2018). This approach provides a high product yield ( $\geq 58 \%, 3 \times 10^{13}$ particles), formulated in a clinical grade solution (Plasma-Lyte A) with concomitant consistent reduction of contaminants (total protein removal 97-98\%). Importantly, this study employed a characterization QC strategy, including monitoring with suitable sensitivity, precision, and accuracy, according to regulatory guidelines. Commercially, companies including Codiak Biosciences employ TFF perfusion or alternating TFF perfusion to increase cell viability and isolate MSC-derived EVs using sequential filtration $(0.8 / 0.45 \mu \mathrm{m})$, while others such as Evox Therapeutics Inc., use a combination of ultrafiltration and size-exclusion liquid chromatography. Larger-scale versions of other methods to isolate and enrich EVs (and subtypes within) may be possible with continuous-flow ultracentrifuges, size exclusion/ligand-activated core-bead technologies using distinct multimodal chemistry, microfluidics, field-flow fractionation, precipitation, continuous chromatography, and other industrial equipment, but feasibility of their use for EVs is limited (Li X. et al., 2019; Whitford and Guterstam, 2019; Yang et al., 2020; Martinez-Greene et al., 2021).

Profiling EV composition is a key strategy in understanding the influence had by modification and production variables. Technologies central to these efforts include mass spectrometry and nucleic acid sequencing. Indeed, proteomics can provide validation of modified (fusion) protein transfection in donor cells and act as a QC metric to evaluate the expression of donor cell and EV proteome and different EV/non-EV markers (Greening et al., 2017; Thery et al., 2018). Furthermore, proteomics can be employed with other biophysical/biochemical approaches to define and monitor the impact of culture media formulation from a single cell source on EV composition and surface protein epitope expression (Zhu et al., 2021a). Additionally, nontargeted metabolite profiling can assess how the metabolomic composition of EVs is influenced by conventional cell culture and bioreactor cell growth conditions (Palviainen et al., 2019). Proteomics and RNA sequencing has also been employed to indicate that cellular architecture (i.e., 2D vs. 3D) modifies transcriptomic and proteomic cargo of EVs (potentially altering overall function), the latter of which may affect efficiency of association and consequently uptake by recipient cells (Rocha et al., 2019). With significant therapeutic implications, the influence of engineered microtissues and immunoisolation devices on EV composition has recently been reported (Kompa et al., 2021; Millan et al., 2021), where microtissue stem cells cultured in a TheraCyte device 3D environment increased EV yield while additional markers (not detectable in EVs secreted by cells cultured in standard $2 \mathrm{D}$ conditions) were identified using proteomic profiling. Such findings reveal that cell growth conditions and media formulations influence the 
yield, surface epitopes (including tetraspanins), and broad (proteome/transcriptome/metabolome) composition of derived EVs. Thus, these are critical considerations in the scalable manufacture of clinical-grade EV therapeutics, as such variables may have profound impact on their utility. For instance, modifying the abundance of transmembrane proteins such as MHC complexes on their surface may affect their low immunogenicity (Petersen et al., 2011; Robbins and Morelli, 2014; Wahlund et al., 2017), a characteristic important for the utility of EVs as therapeutics.

As complex entities, EV therapeutics will require a suite of QC measures for successful clinical translation. A combination of discovery and pre-selected/targeted "omic" analyses will enhance our understanding of bioactive EV composition, cargo selection/loading; such knowledge could be translated to monitor generation, modification, and manufacture of EVbased therapeutic products with high throughput, sensitivity, and specificity. Indeed, in-depth monitoring is essential as EV preparations for preclinical application; often most studies use a combination of EVs (subtypes) in addition to various cellderived and extracellular elements (i.e., secretomes) [reviewed in Rohde et al. (2019) and Witwer et al. (2019)]. For the successful translation of EVs to the clinic, the identification of critical quality attributes (e.g., size, purity, molecular composition) that impact the potency and stability of the product is essential (Figure 1). Considering the difficulties in standardized isolation and characterization of EVs, another strategy would be to prioritize therapeutic efficacy over purity (Wiklander et al., 2019; Herrmann et al., 2021). Recently, engineered recombinant EVs and reference particles have been suggested as reference materials to monitor technical variability of $\mathrm{EV}$ generation and their applications and promote intra- and inter-laboratory studies (Kim M. S. et al., 2018; Varga et al., 2018; Geeurickx et al., 2019, 2021). This could be applied to manufacturing and scalability in generating and monitoring EVs.

Increased and sustainable EV production is essential for the successful application and development of EV-based therapeutics. Recently, cellular nanoporation has been shown to increase production of exosomes as a universal nucleic-acid carrier for applications requiring transcriptional manipulation [up to 50-fold greater exosome yield and $>103$-fold increase in exosomal mRNA transcripts (Yang et al., 2020)]. Further, M-NVs generated by microfluidic and extrusion techniques have a high and consistent production yield, in comparison to native EVs, overcoming their incumbent production and isolation challenges and represent a promising alternative to native EVs for scalable and clinical application. Considerations of such approaches in terms of physical parameters may present new difficulties in establishing a standardized protocol for their generation, efficiency of molecular incorporation, modification, and storage (Shah et al., 2019; Meng et al., 2021). Further, M-NVs are comprised of diverse, undefined molecules derived from donor cells, which may cause potential safety concerns, similar to native EVs. As such, a careful screening of producer cells is essentialfocused on the consistency of long-term cell growth, and specific therapeutic potency and bioactive effect. In addition, the ability of M-NVs post-generation to encapsulate drugs (i.e., hydrophilic, negatively charged macromolecular drugs) remains inefficient (generally $<30 \%$ incorporation), highlighting the need to further refine composition to enhance encapsulation efficiency (Yoon et al., 2015; Molinaro et al., 2016).

Key criteria in the development of EV-based therapeutics is the stability, preservation and storage of EV therapies (Jeyaram and Jay, 2017; Kusuma et al., 2018). Recently, the effects of storage conditions on EVs for functional analysis and therapeutic use was investigated (Wu et al., 2021), evaluating temporal EV stability/quantity across various storage temperatures and freezethawing cycles. Importantly, storage alters EV size distribution and impacts cellular uptake and biodistribution, with $-20^{\circ} \mathrm{C}$ (short-term) and $-80^{\circ} \mathrm{C}$ (long-term) storage recommended. Further, for GMP-compliant EVs, several studies have reported native $\mathrm{EV}$ storage at $-80^{\circ} \mathrm{C}$ in single-dose aliquots (preliminary stability studies indicate no loss of functional activity in up to 7 months) (Andriolo et al., 2018) and modified EVs storage at $-80^{\circ} \mathrm{C}$ for up to 5 months with no change in potency or activity (Mendt et al., 2018).

Overall, challenges of industrial scale-up and specific variables that will impact transition to clinical development must be addressed and monitored in early development. The clinical and commercial demands of EV-based therapeutic production such as high, consistent yield, reproducible composition/purity, and efficiency can eventually be met with modifications to existing technologies for improved scalability (Colao et al., 2018; Adlerz et al., 2020).

\section{Analytical Assessment of EVs: Potency and Molecular Insights for Regulatory Purpose}

In delivering EV-based therapeutics dosing remains a significant challenge, with dose selection, assessment, and administration (route, frequency, time window) all factors in achieving therapeutic benefit without adverse effects. Development of appropriate potency assay that employ relevant functional end points (Nguyen et al., 2020), and demarcate in vitro potency (dependent on EV property and cell type) and in vivo efficacy is required (Willis et al., 2017; Witwer et al., 2019). Such potency assays need to be standardized and context-/disease-/modeldependent, which are unfortunately currently limited in their acceptance and utilitization (Adlerz et al., 2020).

Analytical assessment and monitoring, and rigorous in vitro and in vivo testing for safety and efficacy must precede approval of EV-based therapeutics [as comprehensively discussed (Reiner et al., 2017; Nguyen et al., 2020)]. Several seminal clinicalgrade EV studies have reported specific potency assessments including in vitro anti-/pro-activity, sterility, in vivo pro- activity, and toxicity or immunogenicity assays (Andriolo et al., 2018; Mendt et al., 2018). Analytical assessments include: (i) molecular fingerprinting (identify bioactive/target molecule/s), monitoring of multiple components and influence of preparation/isolation method on donor and cell-derived product), (ii) potency assays (Nguyen et al., 2020) (monitoring therapeutic effect in vitro/in vivo), and (iii) mechanistic assays (identify mode of action) (Willis et al., 2017; Colao et al., 2018; Surman et al., 
2019; Witwer et al., 2019). Such analytical assessments may provide quality control in the transition from research-grade to clinical (GMP)-grade EVs [reviewed in Adlerz et al. (2020) and Willis et al. (2017)].

At present there are no standardized methods in quantifying EV concentration and dosage. Moreover, comparative studies of EV monitoring techniques has shown that protein concentration is not relative to particle number (Lobb et al., 2015); consequently such criteria is insufficient to determine dosing. Quantitative EV analytical methods include reporting cell equivalents, protein concentration, and quantitative analytical measurement [dynamic light scattering (DLS), single-particle interferometric reflectance imaging sensing, tuneable resistive pulse sensing (RPS), nanoflow cytometry and nanoparticle tracking analysis (NTA)] (Arab et al., 2021). Significant concerns have recently been presented around existing singleparticle analysis capabilities (e.g., sizing, counting, tetraspanin phenotyping) (Arab et al., 2021). Moreover, single-particle technologies will be required to separate heterogeneous EV populations into well-defined and easily recognized subgroups. Therefore, consideration of limitations in some analytical platforms is a key requirement [e.g., resolution and accuracy of the quantitative analysis of EVs using single-particle analysis capabilities (Welsh et al., 2020; Arab et al., 2021)]. In order to fully characterize a therapeutic nanoparticle preparation, it is imperative to consider particle size, particle size distribution, charge, number of particles or concentration, and the molecular composition (Nelson et al., 2020). Absolute values measured for particle or protein concentration thus need to be critically evaluated and compared to control condition, using calibration/standardized measurements at specific dose as required. Current methods have shown to be efficient in quantifying the biophysical parameters [light-scattering methods (multiangle light scattering, DLS, NTA, particle interferometric reflectance imaging sensing), RPS, transmission- and cryogenicelectron microscopy, and small angle neutron scattering], hence providing the tools to validate and standardize nanoparticle therapeutics (Buzas et al., 2017). It should be noted, these technologies are not able to determine the particle type or chemical/molecular makeup of a sample, making it difficult to determine whether the sample contains EVs, protein aggregates, or other non-membranous particles (Arab et al., 2021). This limitation requires optimization of sample purity prior to size measurement.

Expectantly, EV heterogeneity confounds aspects of therapeutic application, with subtypes varying in composition and function. One of the challenges of EV biology is identification of specific EV-subtype markers (Thery et al., 2018). If aiming to purify EVs for stringent biochemical analysis (e.g., define cargo for regulatory purposes, quality control, therapeutic design) and specific functionality (e.g., identification of bioactive cargo, therapeutic screening), then rigorous purification and fractionation strategies are critical [reviewed in Gandham et al. (2020); Xu et al. (2016)]. Current research indicates that further subdivisions of EVs are needed to accurately differentiate subtypes (e.g., biogenesis, size, charge, molecular cargo), which may in turn offer unique therapeutic avenues. A key advantage here is the considerations of quality assessment and quantification of EV preparations based on recommendations of MISEV2018 and EVTRACK (Consortium et al., 2017; Thery et al., 2018). These considerations will be essential for generation of clinical-grade EVs or standardized engineered EVs (Lener et al., 2015; Merino-Gonzalez et al., 2016; Paganini et al., 2019; Meng et al., 2020; Salmond and Williams, 2021) (Figure 1).

To establish consistency in the therapeutic assessment of clinically translated EVs, effective dosing harmonization is a key requirement. It is recommended to consider the type of payload, whether it is a drug (Doxorubicin, Aspirin, Gemcitabine), an enzyme/protein (caspase, TTP1) or other biological component (nucleic acids, lipids). It is known these groups possess different pharmacokinetics and thus different units have been assigned to describe their activity or effect i.e., drug dosing is expressed in terms of mass of active substance ( $\mu \mathrm{g}, \mathrm{mg}, \mathrm{g}$ ) per pharmaceutical presentation unit (capsule, ampule, particles, grams) (Powell et al., 2021); enzymes and protein dosing is expressed in terms of enzymatic catalytic activity or IU ( $1 \mathrm{IU}=1 \mu \mathrm{mol} / \mathrm{min}=1 / 60 \mu \mathrm{mol} / \mathrm{s} \approx 16.67 \mathrm{nmol} / \mathrm{s}$ ) (Units of Enzyme Activity, 1979; Iupac, 2018); lastly, biological payload such as nucleic acids and lipids could potentially be expressed in units of mass or activity depending on their function. Another consideration is the function and effect of the native/engineered EVs itself, aside from specified cargo. As vesicles interact with the host, proper controls should be established to determine their protective [i.e., RNAse-mediated degradation effect (Mendt et al., 2018)] and measured effect without the cargo of interest (Kennedy et al., 2020). Studies have shown that dosing variations of purified EV (from 30 to $300 \mu \mathrm{g}$ of protein) did not present any adverse consequences and still exerted their desired effect in a myocardial infarction model in vivo (Barile et al., 2014). This suggests the key for dosing is not the particle itself but the cargo, especially if incorporated post-isolation.

As EVs are biological entities, their complex and variable nature challenges the highly regulated requirements for pharmaceutical production. A solution to this is functional assessment of each batch [cell source consistency (Viaud et al., 2011; Andriolo et al., 2018; Mendt et al., 2018) and EV production for specific patient-derived cell source based on EV yield (Mendt et al., 2018), positive/negative EV markers (Andriolo et al., 2018; Mendt et al., 2018), reviewed in Nguyen et al. (2020)]; identification and quantification of key markers indicating functional competency could aid this process (van Balkom et al., 2019) [i.e., tissue-based immunoregulation (Ma et al., 2020)]. Mapping specifically regulated proteins using microfluidic approaches (Zhao et al., 2016; Fang et al., 2017; Xu et al., 2018) or quantitative proteomics onto known protein networks has highlighted mechanism of action (Martin-Jaular et al., 2021) and is being applied to EV research (manufacture, composition, and function). Proteomic approaches allow researchers to understand protein signatures of native and engineered EVs (Nasiri Kenari et al., 2019; van Balkom et al., 2019), which may have implications in quality control platforms to confirm the identity and test for purity of therapeutic EVs. Proteomics has been used to assess plasma EVs after separation from 
lipoproteins (i.e., lipoprotein particle depletion) (Karimi et al., 2018), tissue-derived stress/damage markers following cardiac$\mathrm{EV}$ isolation (Claridge et al., 2021), and oncogenic mutations on EV proteome landscape (Al-Nedawi et al., 2008; Lobb et al., 2017; Emmanouilidi et al., 2019; Chennakrishnaiah et al., 2020; Shafiq et al., 2021; Tawil et al., 2021). Several key omic-based studies have provided direct insight into the composition and (re)classification of EVs, their biogenesis and content (Greening et al., 2015; Kowal et al., 2016; Jeppesen et al., 2019; Kugeratski et al., 2021; Martinez-Greene et al., 2021; Rai et al., 2021). Moreover, an aptamer-based proteomic analysis (SOMAscan) has enabled multiplexed, highly-sensitive, and specific protein detection in human blood and other biomatrices, and applied to profile EVs (Welton et al., 2017). Other high-throughput MS approaches, such as multiple/parallel reaction monitoring MS (MRM/PRM-MS) enable rapid and accurate identification and quantification of protein biomarkers in broad dynamic range (Anwar et al., 2019; Makridakis et al., 2020). Indeed, MRM-MS has been used for identification of Mycobacterium tuberculosis peptides in patient derived exosomes (Kruh-Garcia et al., 2014), highlighting the sensitivity and specificity of this approach in EVs. Additionally, RNA profiling has been used to confirm the absence of inhibitory miRNAs (Rohde et al., 2019).

The application of multi-omic technologies, such as transcriptomics and proteomics are emerging as crucial for understanding how EVs perform therapeutic functions (Li et al., 2021d). In the wider drug development field, omics technologies are already in use to better understand mechanisms of action and identify off-target effects (Jia et al., 2019; Friman et al., 2021). Additionally, comprehensive profiling of patient and population proteomes/transcriptomes contribute to in silico predictions of drug efficacy [reviewed in El-Khateeb et al. (2019)]. Integration of cellular technologies [microphysiological systems or "tissue chips" (Ronaldson-Bouchard and Vunjak-Novakovic, 2018; Low et al., 2021; Zhang S. et al., 2021)] aimed to closely mimic in vivo conditions to assess the potency of experimental biological products and understanding of tissue-specific effect will be important future developments in clinical translation. The development of new technologies, such as machine learning and control algorithms, to interface with microphysiological systems may further advance their use in systems biology and precision medicine (Zhang Y. S. et al., 2017). For clinical translation, the FDA does not require any understanding of the mechanism by which a drug acts, moving directly to clinical trials without this knowledge may be a clear path. However, often limitations in understanding how the drug or biological regulator works may contribute to unfortunate outcomes, off-target/side effects, or poor/ineffective dosing; understanding mechanism of action may help to stratify/focus clinical trials to those patients most likely to respond (No Author, 2010). Significant changes in the FDA (Critical Path Initiative) now support development of patient screens to improve the chances for drug approval, and integration of pharmacogenomic data (proteomics, metabolomics, genome-wide association study data) in developing and evaluating medicines. In the context of EV-based therapeutics, identification of active components as a constituent of the total EV will enable optimization and improvements in dosing and effect (Xin et al., 2017; Jia et al., 2021).

\section{Tissue Targeting and Delivery of Therapeutic EVs}

Specific, targeted delivery presents a major challenge for EVbased therapeutics. Sophisticated solutions are required to minimize off-target accumulation and maximize efficacy through the targeted transport and delivery of cargo (Vargason et al., 2021). Indeed, a major obstacle preventing widespread usage of other types of regulatory therapeutics (i.e., nucleic acid polymers/oligonucleotides) is efficient delivery to target organs and tissues, minimizing off-target accumulation [reviewed in Roberts et al. (2020)]. In nanoparticle-based therapeutics, the pharmacokinetics, biodistribution and targeting are all influenced by design and biological factors of the nanoparticle constructs (Haun and Hammer, 2008; Calderon et al., 2009; Haun et al., 2011; Gu W. et al., 2019) [reviewed in Mitchell et al. (2021) and Wei et al. (2018)]. Additionally, different cell types and phenotypes internalize and traffic nano-carriers differently (MacParland et al., 2017; Patel S. et al., 2017; Brownlee and Seib, 2018) [reviewed in Biswas and Torchilin (2014) and Howard et al. (2014)]. This is especially relevant for EV therapeutics, as the heterogeneity of EVs can contribute to differential recognition and binding specificity and target cell uptake (Chivet et al., 2014; Choi et al., 2019) [reviewed in Mathieu et al. (2019)]. Characterization of such mechanisms will be essential in the field's pursuit of accurate, potent, on-target delivery and uptake of EV therapeutics.

Drug targeted delivery can be passive, where circulating nanoparticles [e.g., coated with platelet or red blood cell membranes (Usman et al., 2018)], extravasate through leaky vasculature and accumulate in surrounding tissue via the enhanced permeability and retention (EPR) effect (Chan et al., 2010; Hu et al., 2011; Howard et al., 2014; Luk et al., 2016). Alternatively, targeting can be active, relying on membrane moieties to bind protein/peptide receptors/sequences on target cells or tissues (Peer et al., 2007; Bertram et al., 2009; Cheng et al., 2020; Yang et al., 2020). The relatively large surface area to volume ratio of EVs enables highly efficient surface interactions, highlighting the latter form of targeting as a promising avenue for development. Recently, the inflammationtargeting ability of platelet-derived EVs (PEVs) was verified, with drug-incorporated PEVs able to target inflamed lungs in vivo to precisely deliver and modify the immune response at the site of inflammation (Ma et al., 2020), revolutionizing the way inflammatory diseases can be treated. While effective, the molecular interactions (perhaps surface-based) behind this functional delivery are not yet understood. However, there are known protein signatures on EV surfaces which direct uptake in specific organs (Hoshino et al., 2015); unfortunately, very few targeting moieties have been identified and characterized on EVs. Defining additional signatures is essential for the refinement of targeted EV therapeutics, and will require analysis of their surfaceome and biodistribution, as well as the molecular signatures of proteins/peptides exposed in the targeted 
tissue/cell pathology [reviewed in Howard et al. (2014) and Shao et al. (2018)].

The surface proteome of EV subtypes (exosomes) has been defined using various proteolytic and biotinylation approaches (Cvjetkovic et al., 2016; Williams C. et al., 2019; Xu R. et al., 2019) with their topology determined using similar methods (Jeppesen et al., 2019). This has provided insights into components exposed and available for cell-interaction. Recently, proteins with exposed regions on the EV surface, CD63 and LAMP2B, have been the base for topologically distinct scaffolds for fusion proteins containing targeting sequences, enabling the flexible engineering of EV surface for applications in disease-targeted drug delivery and therapy (Curley et al., 2020). Use of these fusion protein scaffolds of attachment of components with known binding partners enriched at target sites has successfully assisted in increased targeted uptake, but has not abolished non-specific uptake (Munagala et al., 2021). Development of new scaffolds is dependent on the display of a N- or C-terminal on the outer surface of EVs, with topology of the surface proteins essential (Jeppesen et al., 2019). However, the surface signature of EVs is highly heterogeneous, which presents a challenge in designing targeting scaffolds present on all EVs, rather than a subtype, and could reflect different baseline functionalities (Kowal et al., 2016; Xu R. et al., 2019). Furthermore, despite the high lipid content and diversity on EVs, the role of lipids (i.e., glycosphingolipids) in drug delivery, specific tissuederived EVs (Flaherty et al., 2019), and how other surface moieties facilitate delivery (Zhu et al., 2018; Mentkowski and Lang, 2019) is still poorly understood. Comprehensive multi-omic surfaceome studies of homogeneous EVs will assist in understanding which effectors (e.g., tetraspanins, integrin receptors/ligands, glycoproteins, membrane lipids) facilitate direct functional content transfer and targeting, findings which will be critically important in exploiting EVs as drug delivery systems (Kooijmans et al., 2021; Richter et al., 2021). Combining surfaceome characterization with techniques to study tropism (Hoshino et al., 2015; Wu et al., 2020) and biodistribution (Wu et al., 2020) will assist in identification of components that determine targeting and interaction.

Understanding the biodistribution of EVs is critical for the identification of targeting-moieties and ensuring dosage at the intended site/tissue. While simple, fast, and relatively inexpensive to use, lipophilic dyes can present issues for biodistribution studies. Dyes can form micelles (Puzar Dominkus et al., 2018) and interfere with EV size, charge, uptake, biodistribution and clearance (Lai et al., 2014; Dehghani et al., 2020), raising questions about their suitability for this application (Takov et al., 2017). Indeed, EVs are likely degraded and/or recycled in vivo resulting in inaccurate spatiotemporal information (Takov et al., 2017)-a consideration when using such dyes is their capacity to interact with other membranes and remain visible in such tissues. Fortunately, alternatives to dye-based tracking are emerging; recent developments in live cell reporters allow visualization of EV biogenesis, uptake and intracellular trafficking (Sung et al., 2020). Fusing surface proteins to NanoLuc or ThermoLuc allow highly sensitive in vivo quantification or real time imaging, respectively, at low cost and in semi-high throughput (Kojima et al., 2018; Gupta et al., 2020). Additionally, other reporter systems have been used to label EVs for in vivo imaging, spatiotemporal dynamics, and pharmacokinetic analysis of administered EVs (Takahashi et al., 2013; Lai et al., 2014; Sung et al., 2020; Wu et al., 2020). Imaging technologies have shown EV biodistribution is influenced by route of administration (intravenous, intraperitoneal, and subcutaneous injection) and dosage (Ohno et al., 2013; Takahashi et al., 2013; Wiklander et al., 2015). Mode of delivery also effects the plasma pharmacokinetic patterns of EVs, while different subpopulations of EVs differ in their in vivo biodistributions (Gupta et al., 2020). This variation presents a challenge for the clinical application of systemically administered EV therapies, with altered biodistribution complicating potential dosage and off-target effects. However, non-systemic administration of EVs may bypass this challenge.

Delivery of EV-based therapeutics directly to the site of interest overcomes the limitations of current therapeutic delivery strategies and can ensure sequestration of the therapeutic. Lungbased pathologies are employing inhalation as the method of administration to ensure site-specific delivery (NCT04389385, NCT04747574, and NCT04276987). Injections of EVs to sites of damage are another method of focusing delivery, with therapeutic application of EVs directly to arthritic joints (Wang et al., 2017; Wu et al., 2019; Li et al., 2021b), venous ulcers (NCT04652531), inner ears (Gyorgy et al., 2017), eyes (NCT03437759), and heart [damaged myocardium (Yao J. et al., 2021)]. While suitable for individual treatments at injectionaccessible sites, ongoing release of EV-based therapeutics at inaccessible sites raises a challenge. The injection or topical application of hydrogels and biogels offer a form of slowrelease EV administration directly to the site of injury ( $\mathrm{Li}$ L. et al., 2020; Shi et al., 2021; Zhao et al., 2021; Zhu et al., 2021b). Furthermore, the recent development of EVcoated scaffolds, such as cardiac stents and cardiac fibrin patches, allow for the therapeutics extended release at the site of damage (Hu S. et al., 2021; Yao J. et al., 2021). As a minimally-invasive direct therapeutic delivery strategy, EVs have been shown to be released in high capacity in vivo from human stem cells within a semi-permeable chamber inserted subcutaneously for cardiac therapy (Kompa et al., 2021). Coating implants for expedited healing and recovery is an area with great therapeutic potential, however, refinements and standardization will be required prior to clinical translation. Developments utilizing shape memory materials [e.g., smart or intelligent materials (Huang et al., 2019; Zhao et al., 2019)] and dynamic response composites which can adapt to external stimuli, could offer significant advantages in EV-coated implant/scaffold systems for wound treatment (Melocchi et al., 2021). Further improvements to EV-based therapeutic delivery will be made with additional molecular characterization of EVtissue tropism, biodistribution, and delivery mechanism designs to ensure the specificity of therapeutic delivery for specific cell types. 


\section{CONCLUSION}

Extracellular vesicle-based therapeutics hold the greatest clinical promise when a combination of native and engineered aspects are utilized. Native EVs hold innate therapeutic potentialthey are biocompatible, stable, and due to their specific targeting, facilitate therapeutic use. However, there are significant challenges associated with their commercialization and clinical development, with engineered EVs allowing modified content, increased production, and targeting for improved therapeutic outcome. Regardless of native or engineered state, there are several aspects which must be considered prior to pharmaceutical translation and clinical application (Figure 1), primarily the source, standardized EV generation/isolation and characterization, defining composition/potency/dose/safety, understanding targeting and biodistribution, and elucidating mechanism of action in target cell(s). This review details diverse scalable processes/strategies for EV generation and isolation, and development/integration of methods for research/clinical grade quality control. In developing EV-based therapeutics, a quantitative analysis of pharmacokinetics, biodistribution, and influence of storage conditions on shelf life, are essential. Indeed, several seminal studies have reported a clinically feasible approach for EV production, scalability, and storage for therapeutic application (Gimona et al., 2017; Andriolo et al., 2018; Mendt et al., 2018; Witwer et al., 2019). Interestingly, for EV-based therapeutic development, as discussed (Grangier et al., 2021), the most advanced scale-up strategies preferentially use abundant quantities of available biomaterials (biofluids, blood products including plasma, red blood cells, platelets) and produce engineered EVs or secretome-based products for translation. Such strategies may be the result of the clinical translation of prior regulatory requirements in the established, licensed use of these products as medicines, abundant supply, human origin, and biotechnology and cell therapy industry links to accelerate clinical translation. The use of these products has significantly inherent translational advantages for hemostasis, for regenerative medicine, and as drug-delivery vehicles (Johnson et al., 2021). Once quality control concerns have been addressed and applied by the field, clinical trials will be able to advance further (Gandham et al., 2020). Successful translation of EV therapeutics in immunomodulation, regeneration and repair, and combination therapies will provide desperately needed treatments globally, transforming the current bio-pharmaceutical landscape.

Considering that EVs carry and transfer various functional molecular cargo, quantitative global analyses to understand EV-associated components [e.g., EV-mediated transfer of proteins/lipids/RNAs between specific cell types and organs (Costa-Silva et al., 2015; Hoshino et al., 2015; Flaherty et al., 2019; Rodrigues et al., 2019; Kugeratski et al., 2021; Nguyen et al., 2021)] warrants further investigation. Increasingly, the field is shifting toward systems biology to understand EVs (Xu et al., 2016; Gezsi et al., 2019), integrating different analysis platforms to achieve multi-omic characterization of EVs for therapeutic application-their source (different donor origins, organ/tissue-derived), composition (including core and surfaceome/interactome landscape), and capacity to reprogram target cells and phenotype (Hoshino et al., 2015, 2020; Melo et al., 2015; Kowal et al., 2016; Xu et al., 2016; Figueroa et al., 2017; Greening et al., 2017; Flaherty et al., 2019; Rontogianni et al., 2019; Xu H. et al., 2019; Jung et al., 2020; Bijnsdorp et al., 2021; Kugeratski et al., 2021; Rai et al., 2021). Further development of these technologies will facilitate the advancement and refinement of EV-based therapeutics. Indeed, developments in EV-based function in cross-kingdom delivery [i.e., RNAs in trafficking from plant to regulate fungal pathogens (Cai et al., 2018)] may further develop effective delivery methods of pathogen-targeting regulatory RNAs for therapeutic and agriculture use.

Designing EV-based therapeutics is reliant on identification of components with a beneficial effect at a target site. Given their complex composition, mechanisms by which EVs induce their therapeutic effects remain incompletely understood. As a priority, a major challenge toward therapeutic utility of EVs is their heterogeneity in content and composition inherent in their biogenesis and generation. This heterogeneity currently complicates the design, dose, standardization, regulation, and delivery of EV-based therapeutics. Enrichment strategies that can distinguish between different EVs may help identify the functional sub-population and enrich for active components. Such an approach will not only result in more potent therapeutic applications but allow decoding and translation of molecular insights and mechanisms of action underlying function. The design of simple, effective, and cost-efficient processes to assess the required purity of EVs will facilitate muchneeded standardization in the field. Careful consideration and standardized/regulatory requirements for challenges raised in this and other key reviews (Willis et al., 2018; Whitford and Guterstam, 2019; Wiklander et al., 2019; Gandham et al., 2020; Nguyen et al., 2020; Rankin-Turner et al., 2021) will assist in development of EV-based therapeutics, bringing them closer to the clinic (Davis et al., 2008; Chan et al., 2010; Buss and Bhatia, 2020; Li et al., 2021c; Swingle et al., 2021; Yang et al., 2021).

\section{AUTHOR CONTRIBUTIONS}

BC, JL, and QP contributed equally to all aspects of the design, writing, figure generation, and editing of this manuscript. DG contributed to the design, writing, and editing of the manuscript. All authors approved the submitted version.

\section{FUNDING}

This work was supported by National Health and Medical Research Council project grant (DG: \#1139489 and 1057741), and Helen Amelia Hains Fellowship (DG). This work is supported by the Victorian Government's Operational Infrastructure Support Program. BC is supported by an Australian Government Training Program (RTP) scholarship and Baker Institute Bright Sparks Scholarship Top Up. JL and QP are supported by joint Baker Institute-La Trobe University Research Training Program scholarships. 


\section{REFERENCES}

Abdel-Monem, H., Dasgupta, S. K., Le, A., Prakasam, A., and Thiagarajan, P. (2010). Phagocytosis of platelet microvesicles and beta2- glycoprotein I. Thromb. Haemost. 104, 335-341. doi: 10.1160/TH09-12-0849

Abels, E. R., Maas, S. L. N., Nieland, L., Wei, Z., Cheah, P. S., Tai, E., et al. (2019). Glioblastoma-Associated Microglia Reprogramming Is Mediated by Functional Transfer of Extracellular miR-21. Cell Rep. 28, 3105-3119e3107. doi: 10.1016/j.celrep.2019.08.036

Aday, S., Hazan-Halevy, I., Chamorro-Jorganes, A., Anwar, M., Goldsmith, M., Beazley-Long, N., et al. (2021). Bioinspired artificial exosomes based on lipid nanoparticles carrying let-7b-5p promote angiogenesis in vitro and in vivo. Mol. Ther. [Preprint]. doi: 10.1016/j.ymthe.2021.03.015

Adlerz, K., Patel, D., Rowley, J., Ng, K., and Ahsan, T. (2020). Strategies for scalable manufacturing and translation of MSC-derived extracellular vesicles. Stem Cell Res. 48:101978. doi: 10.1016/j.scr.2020.101978

Admyre, C., Grunewald, J., Thyberg, J., Gripenback, S., Tornling, G., Eklund, A., et al. (2003). Exosomes with major histocompatibility complex class II and co-stimulatory molecules are present in human BAL fluid. Eur. Respir. J. 22, 578-583. doi: 10.1183/09031936.03.00041703

Ageta, H., Ageta-Ishihara, N., Hitachi, K., Karayel, O., Onouchi, T., Yamaguchi, H., et al. (2018). UBL3 modification influences protein sorting to small extracellular vesicles. Nat. Commun. 9:3936. doi: 10.1038/s41467-018-06197-y

Al-Nedawi, K., Meehan, B., Micallef, J., Lhotak, V., May, L., Guha, A., et al. (2008). Intercellular transfer of the oncogenic receptor EGFRvIII by microvesicles derived from tumour cells. Nat. Cell Biol. 10, 619-624.

Altan-Bonnet, N. (2016). Extracellular vesicles are the Trojan horses of viral infection. Curr. Opin. Microbiol. 32, 77-81.

Alvarez-Erviti, L., Seow, Y., Yin, H., Betts, C., Lakhal, S., and Wood, M. J. (2011). Delivery of siRNA to the mouse brain by systemic injection of targeted exosomes. Nat. Biotechnol. 29, 341-345. doi: 10.1038/nbt.1807

Amash, A., Wang, L., Wang, Y., Bhakta, V., Fairn, G. D., Hou, M., et al. (2016). CD44 Antibody Inhibition of Macrophage Phagocytosis Targets Fcgamma Receptor- and Complement Receptor 3-Dependent Mechanisms. J. Immunol. 196, 3331-3340. doi: 10.4049/jimmunol.1502198

Andrews, D. W., Judy, K. D., Scott, C. B., Garcia, S., Harshyne, L. A., Kenyon, L., et al. (2021). Phase Ib Clinical Trial of IGV-001 for Patients with Newly Diagnosed Glioblastoma. Clin. Cancer Res. 27, 1912-1922. doi: 10.1158/10780432.CCR-20-3805

Andriolo, G., Provasi, E., Lo Cicero, V., Brambilla, A., Soncin, S., Torre, T., et al. (2018). Exosomes From Human Cardiac Progenitor Cells for Therapeutic Applications: Development of a GMP-Grade Manufacturing Method. Front. Physiol. 9:1169. doi: 10.3389/fphys.2018.01169

Antes, T. J., Middleton, R. C., Luther, K. M., Ijichi, T., Peck, K. A., Liu, W. J., et al. (2018). Targeting extracellular vesicles to injured tissue using membrane cloaking and surface display. J. Nanobiotechnol. 16:61. doi: 10.1186/s12951018-0388-4

Anwar, M. A., Dai, D. L., Wilson-McManus, J., Smith, D., Francis, G. A., Borchers, C. H., et al. (2019). Multiplexed LC-ESI-MRM-MS-based Assay for Identification of Coronary Artery Disease Biomarkers in Human Plasma. Proteom. Clin. Appl. 13:e1700111. doi: 10.1002/prca.201700111

Aoi, W., and Marunaka, Y. (2014). Importance of pH homeostasis in metabolic health and diseases: crucial role of membrane proton transport. Biomed. Res. Int. 2014:598986. doi: 10.1155/2014/598986

Aqil, F., Munagala, R., Jeyabalan, J., Agrawal, A. K., and Gupta, R. (2017). Exosomes for the Enhanced Tissue Bioavailability and Efficacy of Curcumin. AAPS J. 19, 1691-1702. doi: 10.1208/s12248-0170154-9

Arab, T., Mallick, E. R., Huang, Y., Dong, L., Liao, Z., Zhao, Z., et al. (2021). Characterization of extracellular vesicles and synthetic nanoparticles with four orthogonal single-particle analysis platforms. J. Extracell Vesicl. 10:e12079. doi: 10.1002/jev2.12079

Arslan, F., Lai, R. C., Smeets, M. B., Akeroyd, L., Choo, A., Aguor, E. N., et al. (2013). Mesenchymal stem cell-derived exosomes increase ATP levels, decrease oxidative stress and activate PI3K/Akt pathway to enhance myocardial viability and prevent adverse remodeling after myocardial ischemia/reperfusion injury. Stem Cell Res. 10, 301-312. doi: 10.1016/j.scr.2013.01.002
Banks, W. A., Sharma, P., Bullock, K. M., Hansen, K. M., Ludwig, N., and Whiteside, T. L. (2020). Transport of Extracellular Vesicles across the BloodBrain Barrier: Brain Pharmacokinetics and Effects of Inflammation. Int. J. Mol. Sci. 21:4407. doi: 10.3390/ijms21124407

Barile, L., Lionetti, V., Cervio, E., Matteucci, M., Gherghiceanu, M., Popescu, L. M., et al. (2014). Extracellular vesicles from human cardiac progenitor cells inhibit cardiomyocyte apoptosis and improve cardiac function after myocardial infarction. Cardiovasc. Res. 103, 530-541.

Barkal, A. A., Brewer, R. E., Markovic, M., Kowarsky, M., Barkal, S. A., Zaro, B. W., et al. (2019). CD24 signalling through macrophage Siglec-10 is a target for cancer immunotherapy. Nature 572, 392-396. doi: 10.1038/s41586-019-1456-0

Basalova, N., Sagaradze, G., Arbatskiy, M., Evtushenko, E., Kulebyakin, K., Grigorieva, O., et al. (2020). Secretome of Mesenchymal Stromal Cells Prevents Myofibroblasts Differentiation by Transferring Fibrosis-Associated microRNAs within Extracellular Vesicles. Cells 9:1272. doi: 10.3390/cells9051272

Beard, K., Meaney, D. F., and Issadore, D. (2020). Clinical Applications of Extracellular Vesicles in the Diagnosis and Treatment of Traumatic Brain Injury. J. Neurotrauma 37, 2045-2056.

Bellavia, D., Raimondo, S., Calabrese, G., Forte, S., Cristaldi, M., Patinella, A., et al. (2017). Interleukin 3- receptor targeted exosomes inhibit in vitro and in vivo Chronic Myelogenous Leukemia cell growth. Theranostics 7, 1333-1345. doi: 10.7150/thno.17092

Belov, L., Matic, K. J., Hallal, S., Best, O. G., Mulligan, S. P., and Christopherson, R. I. (2016). Extensive surface protein profiles of extracellular vesicles from cancer cells may provide diagnostic signatures from blood samples. J. Extracell Vesicles 5:25355. doi: 10.3402/jev.v5.25355

Berenguer, J., Lagerweij, T., Zhao, X. W., Dusoswa, S., van der Stoop, P., Westerman, B., et al. (2018). Glycosylated extracellular vesicles released by glioblastoma cells are decorated by CCL18 allowing for cellular uptake via chemokine receptor CCR8. J. Extracell Vesicles 7:1446660. doi: 10.1080/ 20013078.2018.1446660

Bertram, J. P., Williams, C. A., Robinson, R., Segal, S. S., Flynn, N. T., and Lavik, E. B. (2009). Intravenous hemostat: nanotechnology to halt bleeding. Sci. Transl. Med. 1:11ra22. doi: 10.1126/scitranslmed.3000397

Besse, B., Charrier, M., Lapierre, V., Dansin, E., Lantz, O., Planchard, D., et al. (2016). Dendritic cell-derived exosomes as maintenance immunotherapy after first line chemotherapy in NSCLC. Oncoimmunology 5:e1071008. doi: 10.1080/ 2162402X.2015.1071008

Bian, S., Zhang, L., Duan, L., Wang, X., Min, Y., and Yu, H. (2014). Extracellular vesicles derived from human bone marrow mesenchymal stem cells promote angiogenesis in a rat myocardial infarction model. J. Mol. Med. 92, 387-397. doi: 10.1007/s00109-013-1110-5

Bijnsdorp, I. V., Schelfhorst, T., Luinenburg, M., Rolfs, F., Piersma, S. R., de Haas, R. R., et al. (2021). Feasibility of phosphoproteomics to uncover oncogenic signalling in secreted extracellular vesicles using glioblastoma-EGFRVIII cells as a model. J. Proteomics 232:104076. doi: 10.1016/j.jprot.2020.104076

Biswas, S., and Torchilin, V. P. (2014). Nanopreparations for organelle-specific delivery in cancer. Adv. Drug Deliv. Rev. 66, 26-41. doi: 10.1016/j.addr.2013. 11.004

Borczuk, A. C., Salvatore, S. P., Seshan, S. V., Patel, S. S., Bussel, J. B., Mostyka, M., et al. (2020). COVID-19 pulmonary pathology: a multi-institutional autopsy cohort from Italy and New York City. Mod. Pathol. 33, 2156-2168. doi: 10.1038/ s41379-020-00661-1

Brown, S., Heinisch, I., Ross, E., Shaw, K., Buckley, C. D., and Savill, J. (2002). Apoptosis disables CD31-mediated cell detachment from phagocytes promoting binding and engulfment. Nature 418, 200-203. doi: 10.1038/ nature00811

Brownlee, W. J., and Seib, F. P. (2018). Impact of the hypoxic phenotype on the uptake and efflux of nanoparticles by human breast cancer cells. Sci. Rep. 8:12318. doi: 10.1038/s41598-018-30517-3

Buck, A. H., Coakley, G., Simbari, F., McSorley, H. J., Quintana, J. F., Le Bihan, T., et al. (2014). Exosomes secreted by nematode parasites transfer small RNAs to mammalian cells and modulate innate immunity. Nat. Commun. 5: 5488 .

Buschmann, D., Mussack, V., and Byrd, J. B. (2021). Separation, characterization, and standardization of extracellular vesicles for drug delivery applications. $A d v$. Drug Deliv. Rev. 174, 348-368. 
Buss, C. G., and Bhatia, S. N. (2020). Nanoparticle delivery of immunostimulatory oligonucleotides enhances response to checkpoint inhibitor therapeutics. Proc. Natl. Acad. Sci. U.S.A. 117, 13428-13436. doi: 10.1073/pnas.2001569117

Buzas, E. I., Gardiner, C., Lee, C., and Smith, Z. J. (2017). Single particle analysis: Methods for detection of platelet extracellular vesicles in suspension (excluding flow cytometry). Platelets 28, 249-255. doi: 10.1080/09537104.2016.1260704

Cai, Q., Qiao, L., Wang, M., He, B., Lin, F. M., Palmquist, J., et al. (2018). Plants send small RNAs in extracellular vesicles to fungal pathogen to silence virulence genes. Science 360, 1126-1129. doi: 10.1126/science.aar4142

Calderon, A. J., Muzykantov, V., Muro, S., and Eckmann, D. M. (2009). Flow dynamics, binding and detachment of spherical carriers targeted to ICAM-1 on endothelial cells. Biorheology 46, 323-341. doi: 10.3233/BIR-2009-0544

Cao, H., Dan, Z., He, X., Zhang, Z., Yu, H., Yin, Q., et al. (2016). Liposomes Coated with Isolated Macrophage Membrane Can Target Lung Metastasis of Breast Cancer. ACS Nano 10, 7738-7748.

Carli, A. L. E., Afshar-Sterle, S., Rai, A., Fang, H., O'Keefe, R., Tse, J., et al. (2021). Cancer stem cell marker DCLK1 reprograms small extracellular vesicles toward migratory phenotype in gastric cancer cells. Proteomics 2021:e2000098. doi: $10.1002 /$ pmic. 202000098

Casella, G., Colombo, F., Finardi, A., Descamps, H., Ill-Raga, G., Spinelli, A., et al. (2018). Extracellular Vesicles Containing IL-4 Modulate Neuroinflammation in a Mouse Model of Multiple Sclerosis. Mol. Ther. 26, 2107-2118. doi: 10.1016/j. ymthe.2018.06.024

Cha, J. M., Shin, E. K., Sung, J. H., Moon, G. J., Kim, E. H., Cho, Y. H., et al. (2018). Efficient scalable production of therapeutic microvesicles derived from human mesenchymal stem cells. Sci. Rep. 8:1171. doi: 10.1038/s41598-018-19211-6

Chan, J. M., Zhang, L., Tong, R., Ghosh, D., Gao, W., Liao, G., et al. (2010). Spatiotemporal controlled delivery of nanoparticles to injured vasculature. Proc. Natl. Acad. Sci. U.S.A. 107, 2213-2218. doi: 10.1073/pnas.0914585107

Chao, M. P., Weissman, I. L., and Majeti, R. (2012). The CD47-SIRPalpha pathway in cancer immune evasion and potential therapeutic implications. Curr. Opin. Immunol. 24, 225-232. doi: 10.1016/j.coi.2012.01.010

Charoenviriyakul, C., Takahashi, Y., Morishita, M., Matsumoto, A., Nishikawa, M., and Takakura, Y. (2017). Cell type-specific and common characteristics of exosomes derived from mouse cell lines: Yield, physicochemical properties, and pharmacokinetics. Eur. J. Pharm. Sci. 96, 316-322. doi: 10.1016/j.ejps.2016.10. 009

Chen, C. W., Wang, L. L., Zaman, S., Gordon, J., Arisi, M. F., Venkataraman, C. M., et al. (2018). Sustained release of endothelial progenitor cell-derived extracellular vesicles from shear-thinning hydrogels improves angiogenesis and promotes function after myocardial infarction. Cardiovasc. Res. 114, 1029-1040. doi: $10.1093 / \mathrm{cvr} / \mathrm{cvy} 067$

Chen, G., Huang, A. C., Zhang, W., Zhang, G., Wu, M., Xu, W., et al. (2018). Exosomal PD-L1 contributes to immunosuppression and is associated with anti-PD-1 response. Nature 560, 382-386.

Chen, M., Qiu, T., Wu, J., Yang, Y., Wright, G. D., Wu, M., et al. (2018). Extracellular anti-angiogenic proteins augment an endosomal protein trafficking pathway to reach mitochondria and execute apoptosis in HUVECs. Cell Death Differ. 25, 1905-1920. doi: 10.1038/s41418-018-0092-9

Chen, M., Xu, R., Ji, H., Greening, D. W., Rai, A., Izumikawa, K., et al. (2016). Transcriptome and long noncoding RNA sequencing of three extracellular vesicle subtypes released from the human colon cancer LIM1863 cell line. Sci. Rep. 6:38397. doi: 10.1038/srep38397

Chen, R., Huang, H., Liu, H., Xi, J., Ning, J., Zeng, W., et al. (2019). Friend or Foe? Evidence Indicates Endogenous Exosomes Can Deliver Functional gRNA and Cas9 Protein. Small 15:e1902686.

Chen, S., Tang, Y., Liu, Y., Zhang, P., Lv, L., Zhang, X., et al. (2019). Exosomes derived from miR-375-overexpressing human adipose mesenchymal stem cells promote bone regeneration. Cell Prolif. 52:e12669. doi: 10.1111/cpr.12669

Chen, T. S., Arslan, F., Yin, Y., Tan, S. S., Lai, R. C., Choo, A. B., et al. (2011). Enabling a robust scalable manufacturing process for therapeutic exosomes through oncogenic immortalization of human ESC-derived MSCs. J. Transl. Med. 9:47. doi: 10.1186/1479-5876-9-47

Cheng, K., Zhao, R., Li, Y., Qi, Y., Wang, Y., Zhang, Y., et al. (2021). Bioengineered bacteria-derived outer membrane vesicles as a versatile antigen display platform for tumor vaccination via Plug-and-Display technology. Nat. Commun. 12:2041. doi: 10.1038/s41467-021-22 308-8
Cheng, L., Sharples, R. A., Scicluna, B. J., and Hill, A. F. (2014). Exosomes provide a protective and enriched source of miRNA for biomarker profiling compared to intracellular and cell-free blood. J. Extracell Vesicl. 3:23743. doi: 10.3402/jev. v3.23743

Cheng, Q., Wei, T., Farbiak, L., Johnson, L. T., Dilliard, S. A., and Siegwart, D. J. (2020). Selective organ targeting (SORT) nanoparticles for tissue-specific mRNA delivery and CRISPR-Cas gene editing. Nat. Nanotechnol. 15, 313-320. doi: 10.1038/s41565-020-0669-6

Chennakrishnaiah, S., Tsering, T., Gregory, C., Tawil, N., Spinelli, C., Montermini, L., et al. (2020). Extracellular vesicles from genetically unstable, oncogenedriven cancer cells trigger micronuclei formation in endothelial cells. Sci. Rep. 10:8532. doi: 10.1038/s41598-020-65640-7

Cherian, D. S., Bhuvan, T., Meagher, L., and Heng, T. S. P. (2020). Biological Considerations in Scaling Up Therapeutic Cell Manufacturing. Front. Pharmacol. 11:654. doi: 10.3389/fphar.2020.00654

Chivet, M., Javalet, C., Laulagnier, K., Blot, B., Hemming, F. J., and Sadoul, R. (2014). Exosomes secreted by cortical neurons upon glutamatergic synapse activation specifically interact with neurons. J. Extracell Vesicles 3:24722. doi: 10.3402/jev.v3.24722

Cho, E., Nam, G. H., Hong, Y., Kim, Y. K., Kim, D. H., Yang, Y., et al. (2018). Comparison of exosomes and ferritin protein nanocages for the delivery of membrane protein therapeutics. J. Control Release 279, 326-335. doi: 10.1016/j. jconrel.2018.04.037

Choi, D., Montermini, L., Jeong, H., Sharma, S., Meehan, B., and Rak, J. (2019). Mapping Subpopulations of Cancer Cell-Derived Extracellular Vesicles and Particles by Nano-Flow Cytometry. ACS Nano 13, 10499-10511. doi: 10.1021/ acsnano. 9 b04480

Christianson, H. C., Svensson, K. J., van Kuppevelt, T. H., Li, J. P., and Belting, M. (2013). Cancer cell exosomes depend on cell-surface heparan sulfate proteoglycans for their internalization and functional activity. Proc. Natl. Acad. Sci. U.S.A. 110, 17380-17385. doi: 10.1073/pnas.1304266110

Claassen, I., Meylis, J., van der Ley, P., Peeters, C., Brons, H., Robert, J., et al. (1996). Production, characterization and control of a Neisseria meningitidis hexavalent class 1 outer membrane protein containing vesicle vaccine. Vaccine 14, 1001-1008. doi: 10.1016/0264-410x(96)00020-5

Clancy, J. W., Schmidtmann, M., and D'Souza-Schorey, C. (2021). The ins and outs of microvesicles. FASEB Bioadv. 3, 399-406. doi: 10.1096/fba.2020-00127

Claridge, B., Rai, A., Fang, H., Matsumoto, A., Luo, J., McMullen, J. R., et al. (2021). Proteome characterisation of extracellular vesicles isolated from heart. Proteomics 2021:e2100026.

Coakley, G., McCaskill, J. L., Borger, J. G., Simbari, F., Robertson, E., Millar, M., et al. (2017). Extracellular Vesicles from a Helminth Parasite Suppress Macrophage Activation and Constitute an Effective Vaccine for Protective Immunity. Cell Rep. 19, 1545-1557. doi: 10.1016/j.celrep.2017.05.001

Cocozza, F., Nevo, N., Piovesana, E., Lahaye, X., Buchrieser, J., Schwartz, O., et al. (2020). Extracellular vesicles containing ACE2 efficiently prevent infection by SARS-CoV-2 Spike protein-containing virus. J. Extracell Vesicles 10:e12050. doi: 10.1002/jev2.12050

Colao, I. L., Corteling, R., Bracewell, D., and Wall, I. (2018). Manufacturing Exosomes: A Promising Therapeutic Platform. Trends Mol. Med. 24, 242-256.

Commisso, C., Davidson, S. M., Soydaner-Azeloglu, R. G., Parker, S. J., Kamphorst, J. J., Hackett, S., et al. (2013). Macropinocytosis of protein is an amino acid supply route in Ras-transformed cells. Nature 497, 633-637. doi: 10.1038/ nature 12138

Consortium, E.-T., Van Deun, J., Mestdagh, P., Agostinis, P., Akay, O., Anand, S., et al. (2017). EV-TRACK: transparent reporting and centralizing knowledge in extracellular vesicle research. Nat. Methods 14, 228-232. doi: 10.1038/nmeth. 4185

Cordonnier, M., Nardin, C., Chanteloup, G., Derangere, V., Algros, M. P., Arnould, L., et al. (2020). Tracking the evolution of circulating exosomal-PD-L1 to monitor melanoma patients. J. Extracell Vesicles 9:1710899. doi: 10.1080/ 20013078.2019.1710899

Cosenza, S., Ruiz, M., Toupet, K., Jorgensen, C., and Noel, D. (2017). Mesenchymal stem cells derived exosomes and microparticles protect cartilage and bone from degradation in osteoarthritis. Sci. Rep. 7:16214. doi: 10.1038/s41598-01715376-8

Cossetti, C., Iraci, N., Mercer, T. R., Leonardi, T., Alpi, E., Drago, D., et al. (2014). Extracellular vesicles from neural stem cells transfer IFN-gamma via Ifngrl to 
activate Stat1 signaling in target cells. Mol. Cell 56, 193-204. doi: 10.1016/j. molcel.2014.08.020

Costa-Silva, B., Aiello, N. M., Ocean, A. J., Singh, S., Zhang, H., Thakur, B. K., et al. (2015). Pancreatic cancer exosomes initiate pre-metastatic niche formation in the liver. Nat. Cell Biol. 17, 816-826.

Curley, N., Levy, D., Do, M. A., Brown, A., Stickney, Z., Marriott, G., et al. (2020). Sequential deletion of CD63 identifies topologically distinct scaffolds for surface engineering of exosomes in living human cells. Nanoscale 12, 12014-12026. doi: $10.1039 / \mathrm{d} 0 \mathrm{nr} 00362 \mathrm{j}$

Cvjetkovic, A., Jang, S. C., Konecna, B., Hoog, J. L., Sihlbom, C., Lasser, C., et al. (2016). Detailed Analysis of Protein Topology of Extracellular VesiclesEvidence of Unconventional Membrane Protein Orientation. Sci. Rep. 6:36338. doi: $10.1038 /$ srep36338

Daassi, D., Mahoney, K. M., and Freeman, G. J. (2020). The importance of exosomal PDL1 in tumour immune evasion. Nat. Rev. Immunol. 20, 209-215.

Dad, H. A., Gu, T. W., Zhu, A. Q., Huang, L. Q., and Peng, L. H. (2021). Plant Exosome-like Nanovesicles: Emerging Therapeutics and Drug Delivery Nanoplatforms. Mol. Ther. 29, 13-31. doi: 10.1016/j.ymthe.2020. 11.030

Dalirfardouei, R., Gholoobi, A., Vahabian, M., Mahdipour, E., and Afzaljavan, F. (2021). Therapeutic role of extracellular vesicles derived from stem cells in cutaneous wound models: A systematic review. Life Sci. 273:119271. doi: 10.1016/j.lfs.2021.119271

Dasgupta, S. K., Abdel-Monem, H., Niravath, P., Le, A., Bellera, R. V., Langlois, K., et al. (2009). Lactadherin and clearance of platelet-derived microvesicles. Blood 113, 1332-1339. doi: 10.1182/blood-2008-07-167148

Dasgupta, S. K., Le, A., Chavakis, T., Rumbaut, R. E., and Thiagarajan, P. (2012). Developmental endothelial locus-1 (Del-1) mediates clearance of platelet microparticles by the endothelium. Circulation 125, 1664-1672. doi: 10.1161/ CIRCULATIONAHA.111.068833

Davis, M. E., Chen, Z. G., and Shin, D. M. (2008). Nanoparticle therapeutics: an emerging treatment modality for cancer. Nat. Rev. Drug Discov. 7, 771-782.

de Couto, G., Gallet, R., Cambier, L., Jaghatspanyan, E., Makkar, N., Dawkins, J. F., et al. (2017). Exosomal MicroRNA Transfer Into Macrophages Mediates Cellular Postconditioning. Circulation 136, 200-214.

de Jong, O. G., Verhaar, M. C., Chen, Y., Vader, P., Gremmels, H., Posthuma, G., et al. (2012). Cellular stress conditions are reflected in the protein and RNA content of endothelial cell-derived exosomes. J. Extracell Vesicles 1:18396. doi: $10.3402 /$ jev.v1i0.18396

de Kleijn, E. D., de Groot, R., Lafeber, A. B., Labadie, J., van Limpt, C. J., Visser, J., et al. (2001). Prevention of meningococcal serogroup B infections in children: a protein-based vaccine induces immunologic memory. J. Infect. Dis. 184, 98-102.

Dehghani, M., Gulvin, S. M., Flax, J., and Gaborski, T. R. (2020). Systematic Evaluation of PKH Labelling on Extracellular Vesicle Size by Nanoparticle Tracking Analysis. Sci. Rep. 10:9533. doi: 10.1038/s41598-020-664 34-7

Della Rosa, G., Ruggeri, C., and Aloisi, A. (2021). From Exosome Glycobiology to Exosome Glycotechnology, the Role of Natural Occurring Polysaccharides. Polysaccharides 2, 311-338.

Desdin-Mico, G., and Mittelbrunn, M. (2017). Role of exosomes in the protection of cellular homeostasis. Cell Adh. Migr. 11, 127-134.

Di Blasi, R., Marbiah, M. M., Siciliano, V., Polizzi, K., and Ceroni, F. (2021). A call for caution in analysing mammalian co-transfection experiments and implications of resource competition in data misinterpretation. Nat. Commun. 12:2545. doi: 10.1038/s41467-021-22795-9

Dinkla, S., van Cranenbroek, B., van der Heijden, W. A., He, X., Wallbrecher, R., Dumitriu, I. E., et al. (2016). Platelet microparticles inhibit IL-17 production by regulatory T cells through P-selectin. Blood 127, 1976-1986. doi: 10.1182/ blood-2015-04-640300

Doeppner, T. R., Herz, J., Gorgens, A., Schlechter, J., Ludwig, A. K., Radtke, S., et al. (2015). Extracellular Vesicles Improve Post-Stroke Neuroregeneration and Prevent Postischemic Immunosuppression. Stem Cells Transl. Med. 4, 1131-1143. doi: 10.5966/sctm.2015-0078

Dooley, K., McConnell, R. E., Xu, K., Lewis, N. D., Haupt, S., Youniss, M. R., et al. (2021). A versatile platform for generating engineered extracellular vesicles with defined therapeutic properties. Mol. Ther. 29, 1729-1743. doi: 10.1016/j.ymthe. 2021.01.020
Dos Santos, A., Balayan, A., Funderburgh, M. L., Ngo, J., Funderburgh, J. L., and Deng, S. X. (2019). Differentiation Capacity of Human Mesenchymal Stem Cells into Keratocyte Lineage. Invest. Ophthalmol. Vis. Sci. 60, 3013-3023.

Dykman, L. A., and Khlebtsov, N. G. (2011). Gold nanoparticles in biology and medicine: recent advances and prospects. Acta Naturae 3, 34-55.

Eitan, E., Zhang, S., Witwer, K. W., and Mattson, M. P. (2015). Extracellular vesicle-depleted fetal bovine and human sera have reduced capacity to support cell growth. J. Extracell. Vesicles 4:26373. doi: 10.3402/jev.v4.26373

El-Khateeb, E., Vasilogianni, A. M., Alrubia, S., Al-Majdoub, Z. M., Couto, N., Howard, M., et al. (2019). Quantitative mass spectrometry-based proteomics in the era of model-informed drug development: Applications in translational pharmacology and recommendations for best practice. Pharmacol. Ther. 203:107397. doi: 10.1016/j.pharmthera.2019.107397

Emmanouilidi, A., Paladin, D., Greening, D. W., and Falasca, M. (2019). Oncogenic and Non-Malignant Pancreatic Exosome Cargo Reveal Distinct Expression of Oncogenic and Prognostic Factors Involved in Tumor Invasion and Metastasis. Proteomics 19:e1800158. doi: 10.1002/pmic.201800158

Escude Martinez de Castilla, P., Tong, L., Huang, C., Sofias, A. M., Pastorin, G., Chen, X., et al. (2021). Extracellular vesicles as a drug delivery system: A systematic review of preclinical studies. Adv. Drug Deliv. Rev. 175:113801.

Escudier, B., Dorval, T., Chaput, N., Andre, F., Caby, M. P., Novault, S., et al. (2005). Vaccination of metastatic melanoma patients with autologous dendritic cell (DC) derived-exosomes: results of thefirst phase I clinical trial. J. Transl. Med. 3:10. doi: 10.1186/1479-5876-3-10

Fadok, V. A., Bratton, D. L., Rose, D. M., Pearson, A., Ezekewitz, R. A., and Henson, P. M. (2000). A receptor for phosphatidylserine-specific clearance of apoptotic cells. Nature 405, 85-90.

Fan, S. J., Kroeger, B., Marie, P. P., Bridges, E. M., Mason, J. D., McCormick, K., et al. (2020). Glutamine deprivation alters the origin and function of cancer cell exosomes. EMBO J. 39:e103009. doi: 10.15252/embj.2019103009

Fan, W., Tian, X. D., Huang, E., and Zhang, J. J. (2013). Exosomes from CIITAtransfected CT26 cells enhance anti- tumor effects. Asian Pac. J. Cancer Prev. 14, 987-991. doi: 10.7314/apjcp.2013.14.2.987

Fang, S., Tian, H., Li, X., Jin, D., Li, X., Kong, J., et al. (2017). Clinical application of a microfluidic chip for immunocapture and quantification of circulating exosomes to assist breast cancer diagnosis and molecular classification. PLoS One 12:e0175050. doi: 10.1371/journal.pone.0175050

Fathali, H., Dunevall, J., Majdi, S., and Cans, A. S. (2017). Extracellular Osmotic Stress Reduces the Vesicle Size while Keeping a Constant Neurotransmitter Concentration. ACS Chem. Neurosci. 8, 368-375. doi: 10.1021/acschemneuro. 6b00350

Feng, C., Xiong, Z., Wang, C., Xiao, W., Xiao, H., Xie, K., et al. (2021). Folic acidmodified Exosome-PH20 enhances the efficiency of therapy via modulation of the tumor microenvironment and directly inhibits tumor cell metastasis. Bioact. Mater. 6, 963-974. doi: 10.1016/j.bioactmat.2020.09.014

Feng, Z., Hensley, L., McKnight, K. L., Hu, F., Madden, V., Ping, L., et al. (2013). A pathogenic picornavirus acquires an envelope by hijacking cellular membranes. Nature 496, 367-371.

Fernando, M. R., Jiang, C., Krzyzanowski, G. D., and Ryan, W. L. (2017). New evidence that a large proportion of human blood plasma cell-free DNA is localized in exosomes. PLoS One 12:e0183915. doi: 10.1371/journal.pone. 0183915

Figueroa, J. M., Skog, J., Akers, J., Li, H., Komotar, R., Jensen, R., et al. (2017). Detection of wild-type EGFR amplification and EGFRvIII mutation in CSFderived extracellular vesicles of glioblastoma patients. Neuro Oncol. 19, 14941502. doi: 10.1093/neuonc/nox085

Flaherty, S. E. III, Grijalva, A., Xu, X., Ables, E., Nomani, A., and Ferrante, A. W. Jr. (2019). A lipase-independent pathway of lipid release and immune modulation by adipocytes. Science 363, 989-993. doi: 10.1126/science.aaw2586

Friman, T., Chernobrovkin, A., Martinez Molina, D., and Arnold, L. (2021). CETSA MS Profiling for a Comparative Assessment of FDAApproved Antivirals Repurposed for COVID-19 Therapy Identifies TRIP13 as a Remdesivir Off-Target. SLAS Discov. 26, 336-344. doi: 10.1177/2472555220973597

Fuhrmann, G., Serio, A., Mazo, M., Nair, R., and Stevens, M. M. (2015). Active loading into extracellular vesicles significantly improves the cellular uptake and photodynamic effect of porphyrins. J. Control. Release 205, 35-44. doi: 10.1016/j.jconrel.2014.11.029 
Fujita, Y., Kadota, T., Araya, J., Ochiya, T., and Kuwano, K. (2018). Clinical Application of Mesenchymal Stem Cell-Derived Extracellular Vesicle-Based Therapeutics for Inflammatory Lung Diseases. J. Clin. Med. 7:355. doi: 10.3390/ jcm7100355

Galieva, L. R., James, V., Mukhamedshina, Y. O., and Rizvanov, A. A. (2019). Therapeutic Potential of Extracellular Vesicles for the Treatment of Nerve Disorders. Front. Neurosci. 13:163. doi: 10.3389/fnins.2019.00163

Gandham, S., Su, X., Wood, J., Nocera, A. L., Alli, S. C., Milane, L., et al. (2020). Technologies and Standardization in Research on Extracellular Vesicles. Trends Biotechnol. 38, 1066-1098.

Gangadaran, P., and Ahn, B. C. (2020). Extracellular Vesicle- and Extracellular Vesicle Mimetics-Based Drug Delivery Systems: New Perspectives, Challenges, and Clinical Developments. Pharmaceutics 12:442. doi: 10.3390/pharmaceutics12050442

Gao, G., Li, C., Zhu, J., Wang, Y., Huang, Y., Zhao, S., et al. (2020). Glutaminase 1 Regulates Neuroinflammation After Cerebral Ischemia Through Enhancing Microglial Activation and Pro-Inflammatory Exosome Release. Front. Immunol. 11:161. doi: 10.3389/fimmu.2020.00161

Gao, G., Zhao, S., Xia, X., Li, C., Li, C., Ji, C., et al. (2019). Glutaminase C Regulates Microglial Activation and Pro-inflammatory Exosome Release: Relevance to the Pathogenesis of Alzheimer's Disease. Front. Cell Neurosci. 13:264. doi: 10.3389/ fncel.2019.00264

Gao, J., Wang, S., and Wang, Z. (2017). High yield, scalable and remotely drugloaded neutrophil-derived extracellular vesicles (EVs) for anti-inflammation therapy. Biomaterials 135, 62-73. doi: 10.1016/j.biomaterials.2017.05.003

Garaeva, L., Kamyshinsky, R., Kil, Y., Varfolomeeva, E., Verlov, N., Komarova, E., et al. (2021). Delivery of functional exogenous proteins by plant-derived vesicles to human cells in vitro. Sci. Rep. 11:6489. doi: 10.1038/s41598-021-85833-y

Garcia, N. A., Moncayo-Arlandi, J., Sepulveda, P., and Diez-Juan, A. (2016). Cardiomyocyte exosomes regulate glycolytic flux in endothelium by direct transfer of GLUT transporters and glycolytic enzymes. Cardiovasc. Res. 109, 397-408. doi: 10.1093/cvr/cvv260

Garcia-Manrique, P., Matos, M., Gutierrez, G., Pazos, C., and Blanco-Lopez, M. C. (2018). Therapeutic biomaterials based on extracellular vesicles: classification of bio-engineering and mimetic preparation routes. J. Extracell. Vesicles 7:1422676. doi: $10.1080 / 20013078.2017 .1422676$

Geeurickx, E., Lippens, L., Rappu, P., De Geest, B. G., De Wever, O., and Hendrix, A. (2021). Recombinant extracellular vesicles as biological reference material for method development, data normalization and assessment of (pre-)analytical variables. Nat. Protoc. 16, 603-633. doi: 10.1038/s41596-020-0 0446-5

Geeurickx, E., Tulkens, J., Dhondt, B., Van Deun, J., Lippens, L., Vergauwen, G., et al. (2019). The generation and use of recombinant extracellular vesicles as biological reference material. Nat. Commun. 10:3288.

Gehrmann, U., Naslund, T. I., Hiltbrunner, S., Larssen, P., and Gabrielsson, S. (2014). Harnessing the exosome-induced immune response for cancer immunotherapy. Semin. Cancer Biol. 28, 58-67. doi: 10.1016/j.semcancer.2014. 05.003

Gezsi, A., Kovacs, A., Visnovitz, T., and Buzas, E. I. (2019). Systems biology approaches to investigating the roles of extracellular vesicles in human diseases. Exp. Mol. Med. 51, 1-11.

Gimona, M., Pachler, K., Laner-Plamberger, S., Schallmoser, K., and Rohde, E. (2017). Manufacturing of Human Extracellular Vesicle-Based Therapeutics for Clinical Use. Int. J. Mol. Sci. 18:1190.

Gomez-Ferrer, M., Villanueva-Badenas, E., Sanchez-Sanchez, R., Sanchez-Lopez, C. M., Baquero, M. C., Sepulveda, P., et al. (2021). HIF-1alpha and Pro-Inflammatory Signaling Improves the Immunomodulatory Activity of MSC-Derived Extracellular Vesicles. Int. J. Mol. Sci. 22:3416. doi: 10.3390/ ijms 22073416

Goodman, R. R., and Davies, J. E. (2020). Mesenchymal stromal cells and their derivatives-putative therapeutics in the management of autoimmune pancreatitis. FEBS Open Bio 10, 969-978. doi: 10.1002/2211-5463. 12866

Gordon, S. R., Maute, R. L., Dulken, B. W., Hutter, G., George, B. M., McCracken, M. N., et al. (2017). PD-1 expression by tumour-associated macrophages inhibits phagocytosis and tumour immunity. Nature 545, 495-499.

Gorringe, A. R., and Pajon, R. (2012). Bexsero: a multicomponent vaccine for prevention of meningococcal disease. Hum. Vaccin Immunother. 8, 174-183.
Grange, C., Tapparo, M., Bruno, S., Chatterjee, D., Quesenberry, P. J., Tetta, C., et al. (2014). Biodistribution of mesenchymal stem cell-derived extracellular vesicles in a model of acute kidney injury monitored by optical imaging. Int. J. Mol. Med. 33, 1055-1063. doi: 10.3892/ijmm.2014.1663

Grangier, A., Branchu, J., Volatron, J., Piffoux, M., Gazeau, F., Wilhelm, C., et al. (2021). Technological advances towards extracellular vesicles mass production. Adv. Drug Deliv. Rev. 2021:113843. doi: 10.1016/j.addr.2021.113843

Grapp, M., Wrede, A., Schweizer, M., Huwel, S., Galla, H. J., Snaidero, N., et al. (2013). Choroid plexus transcytosis and exosome shuttling deliver folate into brain parenchyma. Nat. Commun. 4:2123. doi: 10.1038/ncomms3123

Greening, D. W., and Simpson, R. J. (2018). Understanding extracellular vesicle diversity - current status. Expert Rev. Proteom. 15, 887-910.

Greening, D. W., Xu, R., Gopal, S. K., Rai, A., and Simpson, R. J. (2017). Proteomic insights into extracellular vesicle biology - defining exosomes and shed microvesicles. Expert Rev. Proteomics 14, 69-95.

Greening, D. W., Xu, R., Ji, H., Tauro, B. J., and Simpson, R. J. (2015). A protocol for exosome isolation and characterization: evaluation of ultracentrifugation, density-gradient separation, and immunoaffinity capture methods. Methods Mol. Biol. 1295, 179-209. doi: 10.1007/978-1-4939-2550-6_15

Grossen, P., Portmann, M., Koller, E., Duschmale, M., Minz, T., Sewing, S., et al. (2021). Evaluation of bovine milk extracellular vesicles for the delivery of locked nucleic acid antisense oligonucleotides. Eur. J. Pharm. Biopharm. 158, 198-210. doi: 10.1016/j.ejpb.2020.11.012

Gu, H., Liu, Z., Li, Y., Xie, Y., Yao, J., Zhu, Y., et al. (2018). SerumDerived Extracellular Vesicles Protect Against Acute Myocardial Infarction by Regulating miR-21/PDCD4 Signaling Pathway. Front. Physiol. 9:348. doi: 10.3389/fphys.2018.00348

Gu, W., Bobrin, V. A., Chen, S. R., Wang, Z., Schoning, J. P., Gu, Y., et al. (2019). Biodistribution of PNIPAM-Coated Nanostructures Synthesized by the TDMT Method. Biomacromolecules 20, 625-634. doi: 10.1021/acs.biomac.8b01196

Gu, Y. Y., Yu, J., Zhang, J. F., and Wang, C. (2019). Suppressing the secretion of exosomal miR-19b by gw 4869 could regulate oxaliplatin sensitivity in colorectal cancer. Neoplasma 66, 39-45. doi: 10.4149/neo_2018_180306N155

Gujrati, V., Kim, S., Kim, S. H., Min, J. J., Choy, H. E., Kim, S. C., et al. (2014). Bioengineered bacterial outer membrane vesicles as cell-specific drug-delivery vehicles for cancer therapy. ACS Nano 8, 1525-1537. doi: 10.1021/nn405724x

Guo, S., Shen, S., Wang, J., Wang, H., Li, M., Liu, Y., et al. (2015). Detection of highrisk atherosclerotic plaques with ultrasound molecular imaging of glycoprotein IIb/IIIa receptor on activated platelets. Theranostics 5, 418-430.

Gupta, D., Liang, X., Pavlova, S., Wiklander, O. P. B., Corso, G., Zhao, Y., et al. (2020). Quantification of extracellular vesicles in vitro and in vivo using sensitive bioluminescence imaging. J. Extracell. Vesicles 9:1800222. doi: 10. 1080/20013078.2020.1800222

Gurnani, K., Kennedy, J., Sad, S., Sprott, G. D., and Krishnan, L. (2004). Phosphatidylserine receptor-mediated recognition of archaeosome adjuvant promotes endocytosis and MHC class I cross-presentation of the entrapped antigen by phagosome-to-cytosol transport and classical processing. J. Immunol. 173, 566-578. doi: 10.4049/jimmunol.173.1.566

Gurung, S., Greening, D. W., Catt, S., Salamonsen, L., and Evans, J. (2020). Exosomes and soluble secretome from hormone-treated endometrial epithelial cells direct embryo implantation. Mol. Hum. Reprod. 26, 510-520. doi: 10.1093/ molehr/gaaa034

Gyorgy, B., Sage, C., Indzhykulian, A. A., Scheffer, D. I., Brisson, A. R., Tan, S., et al. (2017). Rescue of Hearing by Gene Delivery to Inner-Ear Hair Cells Using Exosome-Associated AAV. Mol. Ther. 25, 379-391. doi: 10.1016/j.ymthe.2016. 12.010

Ha, D., Yang, N., and Nadithe, V. (2016). Exosomes as therapeutic drug carriers and delivery vehicles across biological membranes: current perspectives and future challenges. Acta Pharm. Sin. B 6, 287-296. doi: 10.1016/j.apsb.2016. 02.001

Hall, J., Prabhakar, S., Balaj, L., Lai, C. P., Cerione, R. A., and Breakefield, X. O. (2016). Delivery of Therapeutic Proteins via Extracellular Vesicles: Review and Potential Treatments for Parkinson's Disease, Glioma, and Schwannoma. Cell Mol. Neurobiol. 36, 417-427. doi: 10.1007/s10571-015-0309-0

Han, H. D., Lee, A., Song, C. K., Hwang, T., Seong, H., Lee, C. O., et al. (2006). In vivo distribution and antitumor activity of heparin-stabilized doxorubicinloaded liposomes. Int. J. Pharm. 313, 181-188. doi: 10.1016/j.ijpharm.2006.02. 007 
Han, Q., Xie, Q. R., Li, F., Cheng, Y., Wu, T., Zhang, Y., et al. (2021). Targeted inhibition of SIRT6 via engineered exosomes impairs tumorigenesis and metastasis in prostate cancer. Theranostics 11, 6526-6541. doi: 10.7150/thno. 53886

Han, Y., Ren, J., Bai, Y., Pei, X., and Han, Y. (2019). Exosomes from hypoxia-treated human adipose-derived mesenchymal stem cells enhance angiogenesis through VEGF/VEGF-R. Int. J. Biochem. Cell Biol. 109, 59-68.

Haney, M. J., Klyachko, N. L., Harrison, E. B., Zhao, Y., Kabanov, A. V., and Batrakova, E. V. (2019). TPP1 Delivery to Lysosomes with Extracellular Vesicles and their Enhanced Brain Distribution in the Animal Model of Batten Disease. Adv. Healthc. Mater. 8:e1801271. doi: 10.1002/adhm.201801271

Haney, M. J., Klyachko, N. L., Zhao, Y., Gupta, R., Plotnikova, E. G., He, Z., et al. (2015). Exosomes as drug delivery vehicles for Parkinson's disease therapy. J. Control Release 207, 18-30.

Haney, M. J., Zhao, Y., Jin, Y. S., Li, S. M., Bago, J. R., Klyachko, N. L., et al. (2020). Macrophage-Derived Extracellular Vesicles as Drug Delivery Systems for Triple Negative Breast Cancer (TNBC) Therapy. J. Neuroimmune Pharmacol. 15, 487-500. doi: 10.1007/s11481-019-09884-9

Hassett, K. J., Benenato, K. E., Jacquinet, E., Lee, A., Woods, A., Yuzhakov, O., et al. (2019). Optimization of Lipid Nanoparticles for Intramuscular Administration of mRNA Vaccines. Mol. Ther. Nucleic Acids 15, 1-11.

Haun, J. B., and Hammer, D. A. (2008). Quantifying nanoparticle adhesion mediated by specific molecular interactions. Langmuir 24, 8821-8832.

Haun, J. B., Pepper, L. R., Boder, E. T., and Hammer, D. A. (2011). Using engineered single-chain antibodies to correlate molecular binding properties and nanoparticle adhesion dynamics. Langmuir 27, 13701-13712. doi: 10.1021/ la202926m

He, H., Pham-Huy, L. A., Dramou, P., Xiao, D., Zuo, P., and Pham-Huy, C. (2013). Carbon nanotubes: applications in pharmacy and medicine. Biomed. Res. Int. 2013:578290.

Herrmann, I. K., Wood, M. J. A., and Fuhrmann, G. (2021). Extracellular vesicles as a next-generation drug delivery platform. Nat. Nanotechnol. 16, 748-759.

Hong, Y., Kim, Y. K., Kim, G. B., Nam, G. H., Kim, S. A., Park, Y., et al. (2019). Degradation of tumour stromal hyaluronan by small extracellular vesicle-PH20 stimulates CD103(+) dendritic cells and in combination with PD-L1 blockade boosts anti-tumour immunity. J. Extracell. Vesicles 8:1670893. doi: 10.1080/ 20013078.2019.1670893

Horodecka, K., and Duchler, M. (2021). CRISPR/Cas9: Principle, Applications, and Delivery through Extracellular Vesicles. Int. J. Mol. Sci. 22:6072.

Horst, A. K., Kumashie, K. G., Neumann, K., Diehl, L., and Tiegs, G. (2021). Antigen presentation, autoantibody production, and therapeutic targets in autoimmune liver disease. Cell Mol. Immunol. 18, 92-111.

Hoshino, A., Costa-Silva, B., Shen, T. L., Rodrigues, G., Hashimoto, A., Tesic Mark, M., et al. (2015). Tumour exosome integrins determine organotropic metastasis. Nature 527, 329-335.

Hoshino, A., Kim, H. S., Bojmar, L., Gyan, K. E., Cioffi, M., Hernandez, J., et al. (2020). Extracellular Vesicle and Particle Biomarkers Define Multiple Human Cancers. Cell 182, 1044-1061e1018.

Howard, M., Zern, B. J., Anselmo, A. C., Shuvaev, V. V., Mitragotri, S., and Muzykantov, V. (2014). Vascular targeting of nanocarriers: perplexing aspects of the seemingly straightforward paradigm. ACS Nano 8, 4100-4132. doi: 10. $1021 / \mathrm{nn} 500136 \mathrm{z}$

Hsu, J., Hodgins, J. J., Marathe, M., Nicolai, C. J., Bourgeois-Daigneault, M. C., Trevino, T. N., et al. (2018). Contribution of NK cells to immunotherapy mediated by PD-1/PD-L1 blockade. J. Clin. Invest. 128, 46544668 .

Hu, C. M., Zhang, L., Aryal, S., Cheung, C., Fang, R. H., and Zhang, L. (2011). Erythrocyte membrane-camouflaged polymeric nanoparticles as a biomimetic delivery platform. Proc. Natl. Acad. Sci. U.S.A. 108, 10980-10985.

Hu, J., Chen, X., Li, P., Lu, X., Yan, J., Tan, H., et al. (2021). Exosomes derived from human amniotic fluid mesenchymal stem cells alleviate cardiac fibrosis via enhancing angiogenesis in vivo and in vitro. Cardiovasc. Diagn. Ther. 11, 348-361. doi: $10.21037 /$ cdt-20-1032

Hu, S., Li, Z., Shen, D., Zhu, D., Huang, K., Su, T., et al. (2021). Exosome-eluting stents for vascular healing after ischaemic injury. Nat. Biomed. Eng. [Preprint].

Huang, H. J., Tsai, Y. L., Lin, S. H., and Hsu, S. H. (2019). Smart polymers for cell therapy and precision medicine. J. Biomed. Sci. 26:73.
Huber, D. L. (2005). Synthesis, properties, and applications of iron nanoparticles. Small 1, 482-501.

Ikeda, G., Santoso, M. R., Tada, Y., Li, A. M., Vaskova, E., Jung, J. H., et al. (2021). Mitochondria-Rich Extracellular Vesicles From Autologous Stem CellDerived Cardiomyocytes Restore Energetics of Ischemic Myocardium. J. Am. Coll. Cardiol. 77, 1073-1088. doi: 10.1016/j.jacc.2020.12.060

Imai, T., Takahashi, Y., Nishikawa, M., Kato, K., Morishita, M., Yamashita, T., et al. (2015). Macrophage-dependent clearance of systemically administered B16BL6-derived exosomes from the blood circulation in mice. J. Extracell. Vesicles 4:26238. doi: 10.3402/jev.v4.26238

Islam, M. N., Das, S. R., Emin, M. T., Wei, M., Sun, L., Westphalen, K., et al. (2012). Mitochondrial transfer from bone-marrow-derived stromal cells to pulmonary alveoli protects against acute lung injury. Nat. Med. 18, 759-765.

Iupac (2018). Terminology of bioanalytical methods (IUPAC Recommendations 2018). Chem. Int. 40:34.

Jafari, D., Shajari, S., Jafari, R., Mardi, N., Gomari, H., Ganji, F., et al. (2020). Designer Exosomes: A New Platform for Biotechnology Therapeutics. BioDrugs 34, 567-586. doi: 10.1007/s40259-020-00434-x

Jafarinia, M., Alsahebfosoul, F., Salehi, H., Eskandari, N., Azimzadeh, M., Mahmoodi, M., et al. (2020). Therapeutic effects of extracellular vesicles from human adipose-derived mesenchymal stem cells on chronic experimental autoimmune encephalomyelitis. J. Cell Physiol. 235, 8779-8790. doi: 10.1002/ jcp. 29721

Jang, S. C., Economides, K. D., Moniz, R. J., Sia, C. L., Lewis, N., McCoy, C., et al. (2021). ExoSTING, an extracellular vesicle loaded with STING agonists, promotes tumor immune surveillance. Commun. Biol. 4:497. doi: 10.1038/ s42003-021-02004-5

Jang, S. C., Kim, O. Y., Yoon, C. M., Choi, D. S., Roh, T. Y., Park, J., et al. (2013). Bioinspired exosome-mimetic nanovesicles for targeted delivery of chemotherapeutics to malignant tumors. ACS Nano 7, 7698-7710. doi: 10.1021/ nn402232g

Jeppesen, D. K., Fenix, A. M., Franklin, J. L., Higginbotham, J. N., Zhang, Q., Zimmerman, L. J., et al. (2019). Reassessment of Exosome Composition. Cell $177,428-445 \mathrm{e} 418$.

Jeyaram, A., and Jay, S. M. (2017). Preservation and Storage Stability of Extracellular Vesicles for Therapeutic Applications. AAPS J. 20:1.

Jhan, Y. Y., Prasca-Chamorro, D., Palou Zuniga, G., Moore, D. M., Arun Kumar, S., Gaharwar, A. K., et al. (2020). Engineered extracellular vesicles with synthetic lipids via membrane fusion to establish efficient gene delivery. Int. J. Pharm. 573:118802. doi: 10.1016/j.ijpharm.2019.118802

Jia, S., Wang, R., Wu, K., Jiang, H., and Du, Z. (2019). Elucidation of the Mechanism of Action for Metal Based Anticancer Drugs by Mass Spectrometry-Based Quantitative Proteomics. Molecules 24:581. doi: 10.3390/ molecules24030581

Jia, Y., Lu, T., Chen, Q., Pu, X., Ji, L., Yang, J., et al. (2021). Exosomes secreted from sonic hedgehog-modified bone mesenchymal stem cells facilitate the repair of rat spinal cord injuries. Acta Neurochir. [Preprint]. doi: 10.1007/s00701-02104829-9

Jiang, Y., Wang, L., Zhang, P., Liu, X., Di, H., Yang, J., et al. (2020). Chemoenzymatic Labeling of Extracellular Vesicles for Visualizing Their Cellular Internalization in Real Time. Anal. Chem. 92, 2103-2111. doi: 10.1021/ acs.analchem.9b04608

Jin, Z., Ren, J., and Qi, S. (2020). Human bone mesenchymal stem cells-derived exosomes overexpressing microRNA-26a-5p alleviate osteoarthritis via downregulation of PTGS2. Int. Immunopharmacol. 78:105946. doi: 10.1016/j.intimp. 2019.105946

Jo, W., Jeong, D., Kim, J., Cho, S., Jang, S. C., Han, C., et al. (2014a). Microfluidic fabrication of cell-derived nanovesicles as endogenous RNA carriers. Lab. Chip $14,1261-1269$

Jo, W., Kim, J., Yoon, J., Jeong, D., Cho, S., Jeong, H., et al. (2014b). Large-scale generation of cell-derived nanovesicles. Nanoscale 6, 12056-12064.

Johnson, J., Wu, Y. W., Blyth, C., Lichtfuss, G., Goubran, H., and Burnouf, T. (2021). Prospective Therapeutic Applications of Platelet Extracellular Vesicles. Trends Biotechnol. 39, 598-612. doi: 10.1016/j.tibtech.2020.10.004

Joshi, B. S., and Zuhorn, I. S. (2021). Heparan sulfate proteoglycan-mediated dynamin-dependent transport of neural stem cell exosomes in an in vitro blood-brain barrier model. Eur. .J Neurosci. 53, 706-719. doi: 10.1111/ejn. 14974 
Jung, Y. J., Kim, H. K., Cho, Y., Choi, J. S., Woo, C. H., Lee, K. S., et al. (2020). Cell reprogramming using extracellular vesicles from differentiating stem cells into white/beige adipocytes. Sci. Adv. 6:eaay6721. doi: 10.1126/sciadv.aay6721

Kahmini, F. R., and Shahgaldi, S. (2020). Therapeutic potential of mesenchymal stem cell-derived extracellular vesicles as novel cell-free therapy for treatment of autoimmune disorders. Exp. Mol. Pathol. 2020:104566. doi: 10.1016/j.yexmp. 2020.104566

Kalani, A., Chaturvedi, P., Kamat, P. K., Maldonado, C., Bauer, P., Joshua, I. G., et al. (2016). Curcumin-loaded embryonic stem cell exosomes restored neurovascular unit following ischemia-reperfusion injury. Int. J. Biochem. Cell Biol. 79, 360-369. doi: 10.1016/j.biocel.2016.09.002

Kalluri, R., and LeBleu, V. S. (2020). The biology, function, and biomedical applications of exosomes. Science 367:eaau6977.

Kamerkar, S., LeBleu, V. S., Sugimoto, H., Yang, S., Ruivo, C. F., Melo, S. A., et al. (2017). Exosomes facilitate therapeutic targeting of oncogenic KRAS in pancreatic cancer. Nature 546, 498-503. doi: 10.1038/nature22341

Karimi, N., Cvjetkovic, A., Jang, S. C., Crescitelli, R., Hosseinpour Feizi, M. A., Nieuwland, R., et al. (2018). Detailed analysis of the plasma extracellular vesicle proteome after separation from lipoproteins. Cell Mol. Life Sci. 75, 2873-2886. doi: 10.1007/s00018-018-2773-4

Kaur, S., Singh, S. P., Elkahloun, A. G., Wu, W., Abu-Asab, M. S., and Roberts, D. D. (2014). CD47-dependent immunomodulatory and angiogenic activities of extracellular vesicles produced by T cells. Matrix Biol. 37, 49-59. doi: 10.1016/j. matbio.2014.05.007

Kennedy, T. L., Russell, A. J., and Riley, P. (2020). Experimental limitations of extracellular vesicle-based therapies for the treatment of myocardial infarction. Trends Cardiovasc. Med. [Preprint]. doi: 10.1016/j.tcm.2020. 08.003

Kidd, S., Spaeth, E., Dembinski, J. L., Dietrich, M., Watson, K., Klopp, A., et al. (2009). Direct evidence of mesenchymal stem cell tropism for tumor and wounding microenvironments using in vivo bioluminescent imaging. Stem Cells 27, 2614-2623. doi: 10.1002/stem.187

Kim, D. K., Lee, S., Kim, M., Jeong, Y., and Lee, S. (2021). Exosomecoated silk fibroin 3D-scaffold for inducing osteogenic differentiation of bone marrow derived mesenchymal stem cells. Chem. Engine. J. 406: 127080.

Kim, H. Y., Kumar, H., Jo, M. J., Kim, J., Yoon, J. K., Lee, J. R., et al. (2018). Therapeutic Efficacy-Potentiated and Diseased Organ-Targeting Nanovesicles Derived from Mesenchymal Stem Cells for Spinal Cord Injury Treatment. Nano Lett. 18, 4965-4975. doi: 10.1021/acs.nanolett.8b01816

Kim, H., Kim, D., Nam, H., Moon, S., Kwon, Y. J., and Lee, J. B. (2020). Engineered extracellular vesicles and their mimetics for clinical translation. Methods 177, $80-94$.

Kim, M. S., Haney, M. J., Zhao, Y., Mahajan, V., Deygen, I., Klyachko, N. L., et al. (2016). Development of exosome-encapsulated paclitaxel to overcome MDR in cancer cells. Nanomedicine 12, 655-664. doi: 10.1016/j.nano.2015.10.012

Kim, M. S., Haney, M. J., Zhao, Y., Yuan, D., Deygen, I., Klyachko, N. L., et al. (2018). Engineering macrophage-derived exosomes for targeted paclitaxel delivery to pulmonary metastases: in vitro and in vivo evaluations. Nanomedicine 14, 195-204. doi: 10.1016/j.nano.2017. 09.011

Kim, R., Lee, S., Lee, J., Kim, M., Kim, W. J., Lee, H. W., et al. (2018). Exosomes derived from microRNA-584 transfected mesenchymal stem cells: novel alternative therapeutic vehicles for cancer therapy. BMB Rep. 51, 406-411. doi: 10.5483/bmbrep.2018.51.8.105

Kobayashi, M., Sawada, K., Miyamoto, M., Shimizu, A., Yamamoto, M., Kinose, Y., et al. (2020). Exploring the potential of engineered exosomes as delivery systems for tumor-suppressor microRNA replacement therapy in ovarian cancer. Biochem. Biophys. Res. Commun. 527, 153-161. doi: 10.1016/j.bbrc. 2020.04.076

Kojima, R., Bojar, D., Rizzi, G., Hamri, G. C., El-Baba, M. D., Saxena, P., et al. (2018). Designer exosomes produced by implanted cells intracerebrally deliver therapeutic cargo for Parkinson's disease treatment. Nat. Commun. 9:1305. doi: 10.1038/s41467-018-03733-8

Kompa, A. R., Greening, D. W., Kong, A. M., McMillan, P. J., Fang, H., Saxena, R., et al. (2021). Sustained subcutaneous delivery of secretome of human cardiac stem cells promotes cardiac repair following myocardial infarction. Cardiovasc. Res. 117, 918-929.
Kooijmans, S. A. A., de Jong, O. G., and Schiffelers, R. M. (2021). Exploring interactions between extracellular vesicles and cells for innovative drug delivery system design. Adv. Drug Deliv. Rev. 173, 252-278.

Kooijmans, S. A. A., Fliervoet, L. A. L., van der Meel, R., Fens, M., Heijnen, H. F. G., van Bergen En Henegouwen, P. M. P., et al. (2016). PEGylated and targeted extracellular vesicles display enhanced cell specificity and circulation time. J. Control. Release 224, 77-85. doi: 10.1016/j.jconrel.2016.01.009

Kordelas, L., Rebmann, V., Ludwig, A. K., Radtke, S., Ruesing, J., Doeppner, T. R., et al. (2014). MSC-derived exosomes: a novel tool to treat therapy-refractory graft-versus-host disease. Leukemia 28, 970-973. doi: 10.1038/leu.2014.41

Kotoucek, J., Hubatka, F., Masek, J., Kulich, P., Velinska, K., Bezdekova, J., et al. (2020). Preparation of nanoliposomes by microfluidic mixing in herring-bone channel and the role of membrane fluidity in liposomes formation. Sci. Rep. 10:5595. doi: 10.1038/s41598-020-62500-2

Kowal, J., Arras, G., Colombo, M., Jouve, M., Morath, J. P., Primdal-Bengtson, B., et al. (2016). Proteomic comparison defines novel markers to characterize heterogeneous populations of extracellular vesicle subtypes. Proc. Natl. Acad. Sci. U.S.A. 113, E968-E977. doi: 10.1073/pnas.1521230113

Kruh-Garcia, N. A., Wolfe, L. M., Chaisson, L. H., Worodria, W. O., Nahid, P., Schorey, J. S., et al. (2014). Detection of Mycobacterium tuberculosis peptides in the exosomes of patients with active and latent M. tuberculosis infection using MRM-MS. PLoS One 9:e103811. doi: 10.1371/journal.pone.0103811

Kugeratski, F. G., Hodge, K., Lilla, S., McAndrews, K. M., Zhou, X., Hwang, R. F., et al. (2021). Quantitative proteomics identifies the core proteome of exosomes with syntenin-1 as the highest abundant protein and a putative universal biomarker. Nat. Cell Biol. 23, 631-641. doi: 10.1038/s41556-021-00693-y

Kuhn, T., Koch, M., and Fuhrmann, G. (2020). Probiomimetics-Novel Lactobacillus-Mimicking Microparticles Show Anti-Inflammatory and Barrier-Protecting Effects in Gastrointestinal Models. Small 16:e2003158. doi: $10.1002 /$ smll.202003158

Kusuma, G. D., Barabadi, M., Tan, J. L., Morton, D. A. V., Frith, J. E., and Lim, R. (2018). To Protect and to Preserve: Novel Preservation Strategies for Extracellular Vesicles. Front. Pharmacol. 9:1199. doi: 10.3389/fphar.2018.01199

Kwon, Y. J. (2020). Extracellular vesicles (EVs): Comprehensive packages with promises and complications for clinical translation and commercialization. Methods 177:1. doi: 10.1016/j.ymeth.2020.03.001

Lai, C. P., Mardini, O., Ericsson, M., Prabhakar, S., Maguire, C., Chen, J. W., et al. (2014). Dynamic biodistribution of extracellular vesicles in vivo using a multimodal imaging reporter. ACS Nano 8, 483-494. doi: 10.1021/nn404945r

Lambshead, J. W., Meagher, L., Goodwin, J., Labonne, T., Ng, E., Elefanty, A., et al. (2018). Long-Term Maintenance of Human Pluripotent Stem Cells on cRGDfK-Presenting Synthetic Surfaces. Sci. Rep. 8:701. doi: 10.1038/s41598018-19209-0

Lamparski, H. G., Metha-Damani, A., Yao, J. Y., Patel, S., Hsu, D. H., Ruegg, C., et al. (2002). Production and characterization of clinical grade exosomes derived from dendritic cells. J. Immunol. Methods 270, 211-226. doi: 10.1016/s00221759(02)00330-7

Lara, P., Chan, A. B., Cruz, L. J., Quest, A. F. G., and Kogan, M. J. (2020). Exploiting the Natural Properties of Extracellular Vesicles in Targeted Delivery towards Specific Cells and Tissues. Pharmaceutics 12:1022. doi: 10.3390/ pharmaceutics12111022

Laso-Garcia, F., Ramos-Cejudo, J., Carrillo-Salinas, F. J., Otero-Ortega, L., Feliu, A., Gomez-de Frutos, M., et al. (2018). Therapeutic potential of extracellular vesicles derived from human mesenchymal stem cells in a model of progressive multiple sclerosis. PLoS One 13:e0202590. doi: 10.1371/journal.pone.0202590

Lazaro-Ibanez, E., Faruqu, F. N., Saleh, A. F., Silva, A. M., Tzu-Wen Wang, J., Rak, J., et al. (2021). Selection of Fluorescent, Bioluminescent, and Radioactive Tracers to Accurately Reflect Extracellular Vesicle Biodistribution in Vivo. ACS Nano 15, 3212-3227. doi: 10.1021/acsnano.0c09873

Le Saux, S., Aarrass, H., Lai-Kee-Him, J., Bron, P., Armengaud, J., Miotello, G., et al. (2020). Post-production modifications of murine mesenchymal stem cell (mMSC) derived extracellular vesicles (EVs) and impact on their cellular interaction. Biomaterials 231:119675. doi: 10.1016/j.biomaterials.2019. 119675

Lee, E. Y., Park, K. S., Yoon, Y. J., Lee, J., Moon, H. G., Jang, S. C., et al. (2012). Therapeutic effects of autologous tumor-derived nanovesicles on melanoma growth and metastasis. PLoS One 7:e33330. doi: 10.1371/journal.pone.003 3330 
Leftin, A., Molugu, T. R., Job, C., Beyer, K., and Brown, M. F. (2014). Area per lipid and cholesterol interactions in membranes from separated local-field (13)C NMR spectroscopy. Biophys J. 107, 2274-2286. doi: 10.1016/j.bpj.2014. 07.044

Lehrich, B. M., Liang, Y., and Fiandaca, M. S. (2021). Foetal bovine serum influence on in vitro extracellular vesicle analyses. J. Extracell. Vesicles 10:e12061. doi: 10.1002/jev2.12061

Lener, T., Gimona, M., Aigner, L., Borger, V., Buzas, E., Camussi, G., et al. (2015). Applying extracellular vesicles based therapeutics in clinical trials - an ISEV position paper. J. Extracell. Vesicles 4:30087. doi: 10.3402/jev.v4.30087

Lewis, N. D., Sia, C. L., Kirwin, K., Haupt, S., Mahimkar, G., Zi, T., et al. (2021). Exosome Surface Display of IL12 Results in Tumor-Retained Pharmacology with Superior Potency and Limited Systemic Exposure Compared with Recombinant IL12. Mol. Cancer Ther. 20, 523-534. doi: 10.1158/1535-7163. MCT-20-0484

Li, C., Deng, C., Zhou, T., Hu, J., Dai, B., Yi, F., et al. (2021a). MicroRNA-370 carried by M2 macrophage-derived exosomes alleviates asthma progression through inhibiting the FGF1/MAPK/STAT1 axis. Int. J. Biol. Sci. 17, 1795-1807.

Li, D., Zhang, P., Yao, X., Li, H., Shen, H., Li, X., et al. (2018). Exosomes Derived From miR-133b-Modified Mesenchymal Stem Cells Promote Recovery After Spinal Cord Injury. Front. Neurosci. 12:845. doi: 10.3389/fnins.2018.00845

Li, G. Q., Fang, Y. X., Liu, Y., Meng, F. R., Wu, X., Zhang, C. W., et al. (2021b). MicroRNA-21 from bone marrow mesenchymal stem cell-derived extracellular vesicles targets TET1 to suppress KLF4 and alleviate rheumatoid arthritis. Ther. Adv. Chronic. Dis. 12:20406223211007369. doi: 10.1177/20406223211007369

Li, J., Lee, Y., Johansson, H. J., Mager, I., Vader, P., Nordin, J. Z., et al. (2015). Serum-free culture alters the quantity and protein composition of neuroblastoma-derived extracellular vesicles. J. Extracell. Vesicles 4:26883. doi: 10.3402/jev.v4.26883

Li, J., Zhang, Y., Liu, Y., Dai, X., Li, W., Cai, X., et al. (2013). Microvesicle-mediated transfer of microRNA-150 from monocytes to endothelial cells promotes angiogenesis. J. Biol. Chem. 288, 23586-23596. doi: 10.1074/jbc.M113.489302

Li, L., Lu, S., Liang, X., Cao, B., Wang, S., Jiang, J., et al. (2019). gammadeltaTDEs: An Efficient Delivery System for miR-138 with Anti-tumoral and Immunostimulatory Roles on Oral Squamous Cell Carcinoma. Mol. Ther. Nucleic Acids 14, 101-113. doi: 10.1016/j.omtn.2018.11.009

Li, L., Zhang, Y., Mu, J., Chen, J., Zhang, C., Cao, H., et al. (2020). Transplantation of Human Mesenchymal Stem-Cell-Derived Exosomes Immobilized in an Adhesive Hydrogel for Effective Treatment of Spinal Cord Injury. Nano Lett. 20, 4298-4305. doi: 10.1021/acs.nanolett.0c00929

Li, Q., Song, Y., Wang, Q., Chen, J., Gao, J., Tan, H., et al. (2021c). Engineering extracellular vesicles with platelet membranes fusion enhanced targeted therapeutic angiogenesis in a mouse model of myocardial ischemia reperfusion. Theranostics 11, 3916-3931. doi: 10.7150/thno.52496

Li, Q., Xu, Y., Lv, K., Wang, Y., Zhong, Z., Xiao, C., et al. (2021d). Small extracellular vesicles containing miR-486-5p promote angiogenesis after myocardial infarction in mice and nonhuman primates. Sci. Transl. Med. 13:eabb0202. doi: 10.1126/scitranslmed.abb0202

Li, X., Corbett, A. L., Taatizadeh, E., Tasnim, N., Little, J. P., Garnis, C., et al. (2019). Challenges and opportunities in exosome research-Perspectives from biology, engineering, and cancer therapy. APL Bioeng. 3:011503. doi: 10.1063/1.5087122

Li, Y. J., Wu, J. Y., Wang, J. M., Hu, X. B., Cai, J. X., and Xiang, D. X. (2020). Gemcitabine loaded autologous exosomes for effective and safe chemotherapy of pancreatic cancer. Acta Biomater. 101, 519-530. doi: 10.1016/j.actbio.2019. 10.022

Liang, G., Zhu, Y., Ali, D. J., Tian, T., Xu, H., Si, K., et al. (2020). Engineered exosomes for targeted co-delivery of miR-21 inhibitor and chemotherapeutics to reverse drug resistance in colon cancer. J. Nanobiotechnol. 18:10. doi: 10. 1186/s12951-019-0563-2

Liang, X., Zhang, L., Wang, S., Han, Q., and Zhao, R. C. (2016). Exosomes secreted by mesenchymal stem cells promote endothelial cell angiogenesis by transferring miR-125a. J. Cell Sci. 129, 2182-2189. doi: 10.1242/jcs.170373

Liang, Y., Duan, L., Lu, J., and Xia, J. (2021). Engineering exosomes for targeted drug delivery. Theranostics 11, 3183-3195.

Lievens, D., Zernecke, A., Seijkens, T., Soehnlein, O., Beckers, L., Munnix, I. C., et al. (2010). Platelet CD40L mediates thrombotic and inflammatory processes in atherosclerosis. Blood 116, 4317-4327.
Lim, G. T., You, D. G., Han, H. S., Lee, H., Shin, S., Oh, B. H., et al. (2021). Bioorthogonally surface-edited extracellular vesicles based on metabolic glycoengineering for CD44-mediated targeting of inflammatory diseases. J. Extracell. Vesicles 10:e12077. doi: 10.1002/jev2.12077

Lima, L. G., Ham, S., Shin, H., Chai, E. P. Z., Lek, E. S. H., Lobb, R. J., et al. (2021). Tumor microenvironmental cytokines bound to cancer exosomes determine uptake by cytokine receptor-expressing cells and biodistribution. Nat. Commun. 12:3543. doi: 10.1038/s41467-021-23946-8

Lin, Y., Wu, J., Gu, W., Huang, Y., Tong, Z., Huang, L., et al. (2018). ExosomeLiposome Hybrid Nanoparticles Deliver CRISPR/Cas9 System in MSCs. Adv. Sci. 5:1700611. doi: 10.1002/advs.201700611

Lindemann, R. A. (1989). Roles of interferon and cellular adhesion molecules in bacterial activation of human natural killer cells. Infect. Immun. 57, 1702-1706.

Liu, C., Quan, P., and Fang, L. (2016). Effect of drug physicochemical properties on drug release and their relationship with drug skin permeation behaviors in hydroxyl pressure sensitive adhesive. Eur. J. Pharm. Sci. 93, 437-446. doi: 10.1016/j.ejps.2016.08.048

Liu, H., Gao, W., Yuan, J., Wu, C., Yao, K., Zhang, L., et al. (2016). Exosomes derived from dendritic cells improve cardiac function via activation of CD4(+) T lymphocytes after myocardial infarction. J. Mol. Cell Cardiol. 91, 123-133. doi: 10.1016/j.yjmcc.2015.12.028

Liu, X., Zhang, M., Liu, H., Zhu, R., He, H., Zhou, Y., et al. (2021). Bone marrow mesenchymal stem cell-derived exosomes attenuate cerebral ischemia-reperfusion injury-induced neuroinflammation and pyroptosis by modulating microglia M1/M2 phenotypes. Exp. Neurol. 341:113700. doi: 10. 1016/j.expneurol.2021.113700

Lobb, R. J., Becker, M., Wen, S. W., Wong, C. S., Wiegmans, A. P., Leimgruber, A., et al. (2015). Optimized exosome isolation protocol for cell culture supernatant and human plasma. J. Extracell. Vesicles 4:27031. doi: 10.3402/jev.v4.27031

Lobb, R. J., Hastie, M. L., Norris, E. L., van Amerongen, R., Gorman, J. J., and Moller, A. (2017). Oncogenic transformation of lung cells results in distinct exosome protein profile similar to the cell of origin. Proteomics 17:201600432. doi: 10.1002/pmic.201600432

Lou, P., Liu, S., Xu, X., Pan, C., Lu, Y., and Liu, J. (2021). Extracellular vesiclebased therapeutics for the regeneration of chronic wounds: current knowledge and future perspectives. Acta Biomater. 119, 42-56. doi: 10.1016/j.actbio.2020. 11.001

Low, L. A., Mummery, C., Berridge, B. R., Austin, C. P., and Tagle, D. A. (2021). Organs-on-chips: into the next decade. Nat. Rev. Drug Discov. 20, $345-361$.

Luan, X., Sansanaphongpricha, K., Myers, I., Chen, H., Yuan, H., and Sun, D. (2017). Engineering exosomes as refined biological nanoplatforms for drug delivery. Acta Pharmacol. Sin. 38, 754-763. doi: 10.1038/aps.2017.12

Luga, V., Zhang, L., Viloria-Petit, A. M., Ogunjimi, A. A., Inanlou, M. R., Chiu, E., et al. (2012). Exosomes mediate stromal mobilization of autocrine Wnt-PCP signaling in breast cancer cell migration. Cell 151, 1542-1556. doi: 10.1016/j. cell.2012.11.024

Luk, B. T., Fang, R. H., Hu, C. M., Copp, J. A., Thamphiwatana, S., Dehaini, D., et al. (2016). Safe and Immunocompatible Nanocarriers Cloaked in RBC Membranes for Drug Delivery to Treat Solid Tumors. Theranostics 6, 1004-1011. doi: 10. 7150/thno.14471

Lukomska, B., Stanaszek, L., Zuba-Surma, E., Legosz, P., Sarzynska, S., and Drela, K. (2019). Challenges and Controversies in Human Mesenchymal Stem Cell Therapy. Stem Cells Int. 2019:9628536.

Luo, N., Li, J., Chen, Y., Xu, Y., Wei, Y., Lu, J., et al. (2021). Hepatic stellate cell reprogramming via exosome-mediated CRISPR/dCas9-VP64 delivery. Drug Deliv. 28, 10-18. doi: 10.1080/10717544.2020.1850917

Ma, Q., Fan, Q., Xu, J., Bai, J., Han, X., Dong, Z., et al. (2020). Calming Cytokine Storm in Pneumonia by Targeted Delivery of TPCA-1 Using Platelet-Derived Extracellular Vesicles. Matter 3, 287-301. doi: 10.1016/j.matt.2020.05.017

Mach, F., Schonbeck, U., Sukhova, G. K., Bourcier, T., Bonnefoy, J. Y., Pober, J. S., et al. (1997). Functional CD40 ligand is expressed on human vascular endothelial cells, smooth muscle cells, and macrophages: implications for CD40-CD40 ligand signaling in atherosclerosis. Proc. Natl. Acad. Sci. U.S.A. 94, 1931-1936.

MacParland, S. A., Tsoi, K. M., Ouyang, B., Ma, X. Z., Manuel, J., Fawaz, A., et al. (2017). Phenotype Determines Nanoparticle Uptake by Human Macrophages 
from Liver and Blood. ACS Nano 11, 2428-2443. doi: 10.1021/acsnano.6b0 6245

Mahaweni, N. M., Kaijen-Lambers, M. E., Dekkers, J., Aerts, J. G., and Hegmans, J. P. (2013). Tumour-derived exosomes as antigen delivery carriers in dendritic cell-based immunotherapy for malignant mesothelioma. J. Extracell. Vesicles 2013:22492. doi: 10.3402/jev.v2i0.22492

Makridakis, M., Kontostathi, G., Petra, E., Stroggilos, R., Lygirou, V., Filip, S., et al. (2020). Multiplexed MRM-based protein quantification of putative prognostic biomarkers for chronic kidney disease progression in plasma. Sci. Rep. 10:4815. doi: 10.1038/s41598-020-61496-z

Mao, F., Wu, Y., Tang, X., Kang, J., Zhang, B., Yan, Y., et al. (2017). Exosomes Derived from Human Umbilical Cord Mesenchymal Stem Cells Relieve Inflammatory Bowel Disease in Mice. Biomed. Res. Int. 2017:5356760.

Mardpour, S., Ghanian, M. H., Sadeghi-Abandansari, H., Mardpour, S., Nazari, A., Shekari, F., et al. (2019). Hydrogel-Mediated Sustained Systemic Delivery of Mesenchymal Stem Cell-Derived Extracellular Vesicles Improves Hepatic Regeneration in Chronic Liver Failure. ACS Appl. Mater. Interf. 11, 3742137433. doi: $10.1021 /$ acsami.9b10126

Martinez-Greene, J. A., Hernandez-Ortega, K., Quiroz-Baez, R., Resendis-Antonio, O., Pichardo-Casas, I., Sinclair, D. A., et al. (2021). Quantitative proteomic analysis of extracellular vesicle subgroups isolated by an optimized method combining polymer-based precipitation and size exclusion chromatography. J. Extracell. Vesicles 10:e12087. doi: 10.1002/jev2.12087

Martin-Jaular, L., Nevo, N., Schessner, J. P., Tkach, M., Jouve, M., Dingli, F., et al. (2021). Unbiased proteomic profiling of host cell extracellular vesicle composition and dynamics upon HIV-1 infection. EMBO J. 40:e105492. doi: 10.15252/embj.2020105492

Martins, A. M., Ramos, C. C., Freitas, D., and Reis, C. A. (2021). Glycosylation of Cancer Extracellular Vesicles: Capture Strategies, Functional Roles and Potential Clinical Applications. Cells 10:109. doi: 10.3390/cells10010109

Mathieu, M., Martin-Jaular, L., Lavieu, G., and Thery, C. (2019). Specificities of secretion and uptake of exosomes and other extracellular vesicles for cell-to-cell communication. Nat. Cell Biol. 21, 9-17.

Mattera, V. S., Pereyra Gerber, P., Glisoni, R., Ostrowski, M., Verstraeten, S. V., Pasquini, J. M., et al. (2020). Extracellular vesicles containing the transferrin receptor as nanocarriers of apotransferrin. J. Neurochem. 155, 327-338. doi: 10.1111/jnc. 15019

Melo, S. A., Luecke, L. B., Kahlert, C., Fernandez, A. F., Gammon, S. T., Kaye, J., et al. (2015). Glypican-1 identifies cancer exosomes and detects early pancreatic cancer. Nature 523, 177-182.

Melocchi, A., Uboldi, M., Cerea, M., Foppoli, A., Maroni, A., Moutaharrik, S., et al. (2021). Shape memory materials and 4D printing in pharmaceutics. Adv. Drug Deliv. Rev. 173, 216-237.

Mendt, M., Kamerkar, S., Sugimoto, H., McAndrews, K. M., Wu, C. C., Gagea, M., et al. (2018). Generation and testing of clinical-grade exosomes for pancreatic cancer. JCI Insight 3:e99263. doi: 10.1172/jci.insight.99263

Meng, W., He, C., Hao, Y., Wang, L., Li, L., and Zhu, G. (2020). Prospects and challenges of extracellular vesicle-based drug delivery system: considering cell source. Drug Deliv. 27, 585-598. doi: 10.1080/10717544.2020.1748758

Meng, Y., Asghari, M., Aslan, M. K., Yilmaz, A., Mateescu, B., Stavrakis, S., et al. (2021). Microfluidics for extracellular vesicle separation and mimetic synthesis: Recent advances and future perspectives. Chem. Enginee. J. 404:126110.

Mentkowski, K. I., and Lang, J. K. (2019). Exosomes Engineered to Express a Cardiomyocyte Binding Peptide Demonstrate Improved Cardiac Retention in Vivo. Sci. Rep. 9:10041. doi: 10.1038/s41598-019-46 407-1

Mentkowski, K. I., Snitzer, J. D., Rusnak, S., and Lang, J. K. (2018). Therapeutic Potential of Engineered Extracellular Vesicles. AAPS J. 20:50.

Merino-Gonzalez, C., Zuniga, F. A., Escudero, C., Ormazabal, V., Reyes, C., Nova-Lamperti, E., et al. (2016). Mesenchymal Stem Cell-Derived Extracellular Vesicles Promote Angiogenesis: Potencial Clinical Application. Front. Physiol. 7:24. doi: 10.3389/fphys.2016.00024

Miksa, M., Wu, R., Dong, W., Komura, H., Amin, D., Ji, Y., et al. (2009). Immature dendritic cell-derived exosomes rescue septic animals via milk fat globule epidermal growth factor-factor VIII [corrected]. J. Immunol. 183, 5983-5990. doi: $10.4049 /$ jimmunol.0802994
Millan, C., Prause, L., Vallmajo-Martin, Q., Hensky, N., and Eberli, D. (2021). Extracellular Vesicles from 3D Engineered Microtissues Harbor DiseaseRelated Cargo Absent in EVs from 2D Cultures. Adv. Healthc. Mater. 2021:e2002067. doi: 10.1002/adhm.202002067

Mitchell, J. P., Court, J., Mason, M. D., Tabi, Z., and Clayton, A. (2008). Increased exosome production from tumour cell cultures using the Integra CELLine Culture System. J. Immunol. Methods 335, 98-105. doi: 10.1016/j.jim.2008.03. 001

Mitchell, M. J., Billingsley, M. M., Haley, R. M., Wechsler, M. E., Peppas, N. A., and Langer, R. (2021). Engineering precision nanoparticles for drug delivery. Nat. Rev. Drug Discov. 20, 101-124.

Mitchell, R., Mellows, B., Sheard, J., Antonioli, M., Kretz, O., Chambers, D., et al. (2019). Secretome of adipose-derived mesenchymal stem cells promotes skeletal muscle regeneration through synergistic action of extracellular vesicle cargo and soluble proteins. Stem Cell Res. Ther. 10:116. doi: 10.1186/s13287-019-1213-1

Mitrani, M. I., Bellio, M. A., Sagel, A., Saylor, M., Kapp, W., VanOsdol, K., et al. (2021). Case Report: Administration of Amniotic Fluid-Derived Nanoparticles in Three Severely Ill COVID-19 Patients. Front. Med. 8:583842. doi: 10.3389/ fmed.2021.583842

Mittelbrunn, M., Gutierrez-Vazquez, C., Villarroya-Beltri, C., Gonzalez, S., Sanchez-Cabo, F., Gonzalez, M. A., et al. (2011). Unidirectional transfer of microRNA-loaded exosomes from T cells to antigen-presenting cells. Nat. Commun. 2:282. doi: 10.1038/ncomms1285

Molinaro, R., Corbo, C., Martinez, J. O., Taraballi, F., Evangelopoulos, M., Minardi, S., et al. (2016). Biomimetic proteolipid vesicles for targeting inflamed tissues. Nat. Mater. 15, 1037-1046. doi: 10.1038/nmat4644

Morse, M. A., Garst, J., Osada, T., Khan, S., Hobeika, A., Clay, T. M., et al. (2005). A phase I study of dexosome immunotherapy in patients with advanced non-small cell lung cancer. J. Transl. Med. 3:9. doi: 10.1186/1479-5876-3-9

Munagala, R., Aqil, F., Jeyabalan, J., Kandimalla, R., Wallen, M., Tyagi, N., et al. (2021). Exosome-mediated delivery of RNA and DNA for gene therapy. Cancer Lett. 505, 58-72.

Murphy, D. E., de Jong, O. G., Brouwer, M., Wood, M. J., Lavieu, G., Schiffelers, R. M., et al. (2019). Extracellular vesicle-based therapeutics: natural versus engineered targeting and trafficking. Exp. Mol. Med. 51, 1-12. doi: 10.1038/ s12276-019-0223-5

Nabet, B. Y., Qiu, Y., Shabason, J. E., Wu, T. J., Yoon, T., Kim, B. C., et al. (2017). Exosome RNA Unshielding Couples Stromal Activation to Pattern Recognition Receptor Signaling in Cancer. Cell 170, 352-366e313. doi: 10.1016/j.cell.2017. 06.031

Nagelkerke, A., Ojansivu, M., van der Koog, L., Whittaker, T. E., Cunnane, E. M., Silva, A. M., et al. (2021). Extracellular vesicles for tissue repair and regeneration: Evidence, challenges and opportunities. Adv. Drug Deliv. Rev. 175:113775.

Nakamizo, A., Marini, F., Amano, T., Khan, A., Studeny, M., Gumin, J., et al. (2005). Human bone marrow-derived mesenchymal stem cells in the treatment of gliomas. Cancer Res. 65, 3307-3318.

Narita, M., Kanda, T., Abe, T., Uchiyama, T., Iwafuchi, M., Zheng, Z., et al. (2015). Immune responses in patients with esophageal cancer treated with SART1 peptide-pulsed dendritic cell vaccine. Int. J. Oncol. 46, 1699-1709. doi: 10.3892/ ijo.2015.2846

Nasiri Kenari, A., Cheng, L., and Hill, A. F. (2020). Methods for loading therapeutics into extracellular vesicles and generating extracellular vesicles mimetic-nanovesicles. Methods 177, 103-113.

Nasiri Kenari, A., Kastaniegaard, K., Greening, D. W., Shambrook, M., Stensballe, A., Cheng, L., et al. (2019). Proteomic and Post-Translational Modification Profiling of Exosome-Mimetic Nanovesicles Compared to Exosomes. Proteomics 19:e1800161. doi: 10.1002/pmic.201800161

Nazarenko, I., Rana, S., Baumann, A., McAlear, J., Hellwig, A., Trendelenburg, M., et al. (2010). Cell surface tetraspanin Tspan8 contributes to molecular pathways of exosome-induced endothelial cell activation. Cancer Res. 70, 1668-1678. doi: 10.1158/0008-5472.CAN-09-2470

Nazimek, K., and Bryniarski, K. (2020). Perspectives in Manipulating EVs for Therapeutic Applications: Focus on Cancer Treatment. Int. J. Mol. Sci. 21:4623.

Needham, D., and Nunn, R. S. (1990). Elastic deformation and failure of lipid bilayer membranes containing cholesterol. Biophys. J. 58, 997-1009. doi: 10. 1016/S0006-3495(90)82444-9 
Nele, V., Holme, M. N., Kauscher, U., Thomas, M. R., Doutch, J. J., and Stevens, M. M. (2019). Effect of Formulation Method, Lipid Composition, and PEGylation on Vesicle Lamellarity: A Small-Angle Neutron Scattering Study. Langmuir 35, 6064-6074. doi: 10.1021/acs.langmuir.8b0 4256

Nelson, B. C., Maragh, S., Ghiran, I. C., Jones, J. C., DeRose, P. C., Elsheikh, E., et al. (2020). Measurement and standardization challenges for extracellular vesicle therapeutic delivery vectors. Nanomedicine 15, 2149-2170.

Nguyen, S. L., Ahn, S. H., Greenberg, J. W., Collaer, B. W., Agnew, D. W., Arora, R., et al. (2021). Integrins mediate placental extracellular vesicle trafficking to lung and liver in vivo. Sci. Rep. 11:4217. doi: 10.1038/s41598-021-82752-w

Nguyen, V. V. T., Witwer, K. W., Verhaar, M. C., Strunk, D., and van Balkom, B. W. M. (2020). Functional assays to assess the therapeutic potential of extracellular vesicles. J. Extracell. Vesicles 10:e12033.

Niada, S., Giannasi, C., Gomarasca, M., Stanco, D., Casati, S., and Brini, A. T. (2019). Adipose-derived stromal cell secretome reduces TNFalpha-induced hypertrophy and catabolic markers in primary human articular chondrocytes. Stem Cell Res. 38:101463. doi: 10.1016/j.scr.2019.101463

Niemela, P., Hyvonen, M. T., and Vattulainen, I. (2004). Structure and dynamics of sphingomyelin bilayer: insight gained through systematic comparison to phosphatidylcholine. Biophys. J. 87, 2976-2989. doi: 10.1529/biophysj.104. 048702

Nieuwland, R., Falcon-Perez, J. M., Thery, C., and Witwer, K. W. (2020). Rigor and standardization of extracellular vesicle research: Paving the road towards robustness. J. Extracell. Vesicles 10:e12037. doi: 10.1002/jev2.12037

Nikfarjam, S., Rezaie, J., Zolbanin, N. M., and Jafari, R. (2020). Mesenchymal stem cell derived-exosomes: a modern approach in translational medicine. J. Transl. Med. 18:449. doi: 10.1186/s12967-020-02622-3

Niu, W., Xiao, Q., Wang, X., Zhu, J., Li, J., Liang, X., et al. (2021). A Biomimetic Drug Delivery System by Integrating Grapefruit Extracellular Vesicles and Doxorubicin-Loaded Heparin-Based Nanoparticles for Glioma Therapy. Nano Lett. 21, 1484-1492. doi: 10.1021/acs.nanolett.0c04753

No Author (2010). Mechanism matters. Nat. Med. 16:347.

Obregon, C., Rothen-Rutishauser, B., Gerber, P., Gehr, P., and Nicod, L. P. (2009). Active uptake of dendritic cell-derived exovesicles by epithelial cells induces the release of inflammatory mediators through a TNF-alphamediated pathway. Am. J. Pathol. 175, 696-705. doi: 10.2353/ajpath.2009.08 0716

O’Brien, K., Breyne, K., Ughetto, S., Laurent, L. C., and Breakefield, X. O. (2020). RNA delivery by extracellular vesicles in mammalian cells and its applications. Nat. Rev. Mol. Cell Biol. 21, 585-606.

O’Farrell, N., Houlton, A., and Horrocks, B. R. (2006). Silicon nanoparticles: applications in cell biology and medicine. Int. J. Nanomed. 1, 451-472.

Oh, K., Kim, S. R., Kim, D. K., Seo, M. W., Lee, C., Lee, H. M., et al. (2015). In Vivo Differentiation of Therapeutic Insulin-Producing Cells from Bone Marrow Cells via Extracellular Vesicle-Mimetic Nanovesicles. ACS Nano 9, 11718-11727. doi: 10.1021/acsnano.5b02997

Ohno, S., Takanashi, M., Sudo, K., Ueda, S., Ishikawa, A., Matsuyama, N., et al. (2013). Systemically injected exosomes targeted to EGFR deliver antitumor microRNA to breast cancer cells. Mol. Ther. 21, 185-191. doi: 10.1038/mt.2012. 180

Oksvold, M. P., Kullmann, A., Forfang, L., Kierulf, B., Li, M., Brech, A., et al. (2014). Expression of B-cell surface antigens in subpopulations of exosomes released from B-cell lymphoma cells. Clin. Ther. 36, 847-862e841. doi: 10.1016/ j.clinthera.2014.05.010

Ono, R., Yasuhiko, Y., Aisaki, K. I., Kitajima, S., Kanno, J., and Hirabayashi, Y. (2019). Exosome-mediated horizontal gene transfer occurs in double-strand break repair during genome editing. Commun. Biol. 2:57. doi: 10.1038/s42003019-0300-2

Otero-Ortega, L., Laso-Garcia, F., Gomez-de Frutos, M. D., Rodriguez-Frutos, B., Pascual-Guerra, J., Fuentes, B., et al. (2017). White Matter Repair After Extracellular Vesicles Administration in an Experimental Animal Model of Subcortical Stroke. Sci. Rep. 7:44433.

Ou, Y. H., Liang, J., Czarny, B., Wacker, M. G., Yu, V., Wang, J. W., et al. (2021). Extracellular Vesicle (EV) biohybrid systems for cancer therapy: Recent advances and future perspectives. Semin. Cancer Biol. [Preprint]. doi: 10.1016/ j.semcancer.2021.02.006
Ouyang, T., Liu, X., Ouyang, H., and Ren, L. (2018). Recent trends in click chemistry as a promising technology for virus-related research. Virus Res. 256, 21-28. doi: 10.1016/j.virusres.2018.08.003

Ozturk, S., Elcin, A. E., Koca, A., and Elcin, Y. M. (2021). Therapeutic Applications of Stem Cells and Extracellular Vesicles in Emergency Care: Futuristic Perspectives. Stem Cell Rev. Rep. 17, 390-410. doi: 10.1007/s12015-02010029-2

Paganini, C., Capasso Palmiero, U., Pocsfalvi, G., Touzet, N., Bongiovanni, A., and Arosio, P. (2019). Scalable Production and Isolation of Extracellular Vesicles: Available Sources and Lessons from Current Industrial Bioprocesses. Biotechnol. J. 14:e1800528. doi: 10.1002/biot.201800528

Palmulli, R., and van Niel, G. (2018). To be or not to be secreted as exosomes, a balance finely tuned by the mechanisms of biogenesis. Essays Biochem. 62, 177-191. doi: 10.1042/EBC20170076

Palviainen, M., Saari, H., Karkkainen, O., Pekkinen, J., Auriola, S., Yliperttula, M., et al. (2019). Metabolic signature of extracellular vesicles depends on the cell culture conditions. J. Extracell. Vesicles 8:1596669.

Park, K. S., Sun, X., Aikins, M. E., and Moon, J. J. (2021). Non-viral COVID-19 vaccine delivery systems. Adv. Drug Deliv. Rev. 169, 137-151.

Parolini, I., Federici, C., Raggi, C., Lugini, L., Palleschi, S., De Milito, A., et al. (2009). Microenvironmental $\mathrm{pH}$ is a key factor for exosome traffic in tumor cells. J. Biol. Chem. 284, 34211-34222. doi: 10.1074/jbc.M109.041152

Patel, D. B., Gray, K. M., Santharam, Y., Lamichhane, T. N., Stroka, K. M., and Jay, S. M. (2017). Impact of cell culture parameters on production and vascularization bioactivity of mesenchymal stem cell-derived extracellular vesicles. Bioeng. Transl. Med. 2, 170-179. doi: 10.1002/btm2.10065

Patel, S., Ashwanikumar, N., Robinson, E., DuRoss, A., Sun, C., Murphy-Benenato, K. E., et al. (2017). Boosting Intracellular Delivery of Lipid NanoparticleEncapsulated mRNA. Nano Lett. 17, 5711-5718. doi: 10.1021/acs.nanolett. $7 \mathrm{~b} 02664$

Pawlowski, C. L., Li, W., Sun, M., Ravichandran, K., Hickman, D., Kos, C., et al. (2017). Platelet microparticle-inspired clot-responsive nanomedicine for targeted fibrinolysis. Biomaterials 128, 94-108. doi: 10.1016/j.biomaterials.2017. 03.012

Peer, D., Karp, J. M., Hong, S., Farokhzad, O. C., Margalit, R., and Langer, R. (2007). Nanocarriers as an emerging platform for cancer therapy. Nat. Nanotechnol. 2, 751-760.

Pegtel, D. M., Cosmopoulos, K., Thorley-Lawson, D. A., van Eijndhoven, M. A., Hopmans, E. S., Lindenberg, J. L., et al. (2010). Functional delivery of viral miRNAs via exosomes. Proc. Natl. Acad. Sci. U.S.A. 107, 6328-6333.

Peinado, H., Aleckovic, M., Lavotshkin, S., Matei, I., Costa-Silva, B., MorenoBueno, G., et al. (2012). Melanoma exosomes educate bone marrow progenitor cells toward a pro-metastatic phenotype through MET. Nat. Med. 18, 883-891.

Petersen, S. H., Odintsova, E., Haigh, T. A., Rickinson, A. B., Taylor, G. S., and Berditchevski, F. (2011). The role of tetraspanin CD63 in antigen presentation via MHC class II. Eur. J. Immunol. 41, 2556-2561. doi: 10.1002/eji.201141438

Pham, C. V., Midge, S., Barua, H., Zhang, Y., Ngoc-Gia Nguyen, T., Barrero, R. A., et al. (2021). Bovine extracellular vesicles contaminate human extracellular vesicles produced in cell culture conditioned medium when 'exosome-depleted serum' is utilised. Arch. Biochem. Biophys. 708:108963. doi: 10.1016/j.abb.2021. 108963

Phinney, D. G., Di Giuseppe, M., Njah, J., Sala, E., Shiva, S., St Croix, C. M., et al. (2015). Mesenchymal stem cells use extracellular vesicles to outsource mitophagy and shuttle microRNAs. Nat. Commun. 6:8472. doi: 10.1038/ ncomms 9472

Pinheiro, A., Silva, A. M., Teixeira, J. H., Goncalves, R. M., Almeida, M. I., Barbosa, M. A., et al. (2018). Extracellular vesicles: intelligent delivery strategies for therapeutic applications. J. Control Release 289, 56-69.

Pirisinu, M., Pham, T. C., Zhang, D. X., Hong, T. N., Nguyen, L. T., and Le, M. T. (2020). Extracellular vesicles as natural therapeutic agents and innate drug delivery systems for cancer treatment: Recent advances, current obstacles, and challenges for clinical translation. Semin. Cancer Biol. [Preprint]. doi: 10.1016/ j.semcancer.2020.08.007

Plotnikov, E. Y., Khryapenkova, T. G., Galkina, S. I., Sukhikh, G. T., and Zorov, D. B. (2010). Cytoplasm and organelle transfer between mesenchymal multipotent stromal cells and renal tubular cells in co-culture. Exp. Cell Res. 316, 2447-2455. doi: 10.1016/j.yexcr.2010.06.009 
Plotnikov, E. Y., Khryapenkova, T. G., Vasileva, A. K., Marey, M. V., Galkina, S. I., Isaev, N. K., et al. (2008). Cell-to-cell cross-talk between mesenchymal stem cells and cardiomyocytes in co-culture. J. Cell Mol. Med. 12, 1622-1631. doi: 10.1111/j.1582-4934.2007.00205.x

Polak, K., Greze, N., Lachat, M., Merle, D., Chiumento, S., Bertrand-Gaday, C., et al. (2020). Extracellular vesicle-based vaccine platform displaying native viral envelope proteins elicits a robust anti-SARS-CoV-2 response in mice. bioRxiv. [Preprint].

Powell, J. R., Cook, J., Wang, Y., Peck, R., and Weiner, D. (2021). Drug Dosing Recommendations for All Patients: A Roadmap for Change. Clin. Pharmacol. Ther. 109, 65-72. doi: 10.1002/cpt.1923

Purushothaman, A., Bandari, S. K., Liu, J., Mobley, J. A., Brown, E. E., and Sanderson, R. D. (2016). Fibronectin on the Surface of Myeloma Cell-derived Exosomes Mediates Exosome-Cell Interactions. J. Biol. Chem. 291, 1652-1663. doi: 10.1074/jbc.M115.686295

Puzar Dominkus, P., Stenovec, M., Sitar, S., Lasic, E., Zorec, R., Plemenitas, A., et al. (2018). PKH26 labeling of extracellular vesicles: Characterization and cellular internalization of contaminating PKH26 nanoparticles. Biochim. Biophys. Acta Biomembr. 1860, 1350-1361. doi: 10.1016/j.bbamem.2018.03.013

Quah, B. J., and O’Neill, H. C. (2007). Mycoplasma contaminants present in exosome preparations induce polyclonal B cell responses. J. Leukoc. Biol. 82, 1070-1082. doi: 10.1189/jlb.0507277

Rai, A., Greening, D. W., Xu, R., Chen, M., Suwakulsiri, W., and Simpson, R. J. (2021). Secreted midbody remnants are a class of extracellular vesicles molecularly distinct from exosomes and microparticles. Commun. Biol. 4:400. doi: 10.1038/s42003-021-01882-z

Rana, S., Claas, C., Kretz, C. C., Nazarenko, I., and Zoeller, M. (2011). Activationinduced internalization differs for the tetraspanins CD9 and Tspan8: Impact on tumor cell motility. Int. J. Biochem. Cell Biol. 43, 106-119. doi: 10.1016/j.biocel. 2010.10.002

Rani, S., Ryan, A. E., Griffin, M. D., and Ritter, T. (2015). Mesenchymal Stem Cellderived Extracellular Vesicles: Toward Cell-free Therapeutic Applications. Mol. Ther. 23, 812-823.

Rankin-Turner, S., Vader, P., O’Driscoll, L., Giebel, B., Heaney, L. M., and Davies, O. G. (2021). A call for the standardised reporting of factors affecting the exogenous loading of extracellular vesicles with therapeutic cargos. Adv. Drug Deliv. Rev. 173, 479-491. doi: 10.1016/j.addr.2021.04.012

Rao, L., Bu, L. L., Xu, J. H., Cai, B., Yu, G. T., Yu, X., et al. (2015). Red Blood Cell Membrane as a Biomimetic Nanocoating for Prolonged Circulation Time and Reduced Accelerated Blood Clearance. Small 11, 6225-6236. doi: 10.1002/smll. 201502388

Rao, L., Xia, S., Xu, W., Tian, R., Yu, G., Gu, C., et al. (2020). Decoy nanoparticles protect against COVID-19 by concurrently adsorbing viruses and inflammatory cytokines. Proc. Natl. Acad. Sci. U.S.A. 117, 27141-27147. doi: 10.1073/pnas. 2014352117

Rao, Q., Zuo, B., Lu, Z., Gao, X., You, A., Wu, C., et al. (2016). Tumor-derived exosomes elicit tumor suppression in murine hepatocellular carcinoma models and humans in vitro. Hepatology 64, 456-472. doi: 10.1002/hep. 28549

Rappazzo, C. G., Watkins, H. C., Guarino, C. M., Chau, A., Lopez, J. L., DeLisa, M. P., et al. (2016). Recombinant M2e outer membrane vesicle vaccines protect against lethal influenza A challenge in BALB/c mice. Vaccine 34, 1252-1258.

Ratajczak, J., Miekus, K., Kucia, M., Zhang, J., Reca, R., Dvorak, P., et al. (2006). Embryonic stem cell-derived microvesicles reprogram hematopoietic progenitors: evidence for horizontal transfer of mRNA and protein delivery. Leukemia 20, 847-856. doi: 10.1038/sj.leu.2404132

Rayamajhi, S., and Aryal, S. (2020). Surface functionalization strategies of extracellular vesicles. J. Mater. Chem. B 8, 4552-4569.

Rayamajhi, S., Nguyen, T. D. T., Marasini, R., and Aryal, S. (2019). Macrophagederived exosome-mimetic hybrid vesicles for tumor targeted drug delivery. Acta Biomater. 94, 482-494. doi: 10.1016/j.actbio.2019.05.054

Reiner, A. T., Witwer, K. W., Van Balkom, B. W., De Beer, J., Brodie, C., Corteling, R. L., et al. (2017). Concise review: developing best-practice models for the therapeutic use of extracellular vesicles. Stem Cells Translat. Med. 6, 1730-1739. doi: 10.1002/sctm.17-0055

Rezaei, R., Baghaei, K., Hashemi, S. M., Zali, M. R., Ghanbarian, H., and Amani, D. (2021). Tumor-Derived Exosomes Enriched by miRNA-124 Promote Antitumor Immune Response in CT-26 Tumor-Bearing Mice. Front. Med. 8:619939. doi: 10.3389/fmed.2021.619939
Richter, M., Vader, P., and Fuhrmann, G. (2021). Approaches to surface engineering of extracellular vesicles. Adv. Drug Deliv. Rev. 173, 416-426.

Robbins, P. D., and Morelli, A. E. (2014). Regulation of immune responses by extracellular vesicles. Nat. Rev. Immunol. 14, 195-208.

Roberts, T. C., Langer, R., and Wood, M. J. A. (2020). Advances in oligonucleotide drug delivery. Nat. Rev. Drug Discov. 19, 673-694.

Rocha, S., Carvalho, J., Oliveira, P., Voglstaetter, M., Schvartz, D., Thomsen, A. R., et al. (2019). 3D Cellular Architecture Affects MicroRNA and Protein Cargo of Extracellular Vesicles. Adv. Sci. 6:1800948. doi: 10.1002/advs.201800948

Rodrigues, G., Hoshino, A., Kenific, C. M., Matei, I. R., Steiner, L., Freitas, D., et al. (2019). Tumour exosomal CEMIP protein promotes cancer cell colonization in brain metastasis. Nat. Cell Biol. 21, 1403-1412. doi: 10.1038/s41556-019-0404-4

Rodriguez, P. L., Harada, T., Christian, D. A., Pantano, D. A., Tsai, R. K., and Discher, D. E. (2013). Minimal "Self" peptides that inhibit phagocytic clearance and enhance delivery of nanoparticles. Science 339, 971-975. doi: 10.1126/ science. 1229568

Roefs, M. T., Sluijter, J. P. G., and Vader, P. (2020). Extracellular Vesicle-Associated Proteins in Tissue Repair. Trends Cell Biol. 30, 990-1013.

Rohde, E., Pachler, K., and Gimona, M. (2019). Manufacturing and characterization of extracellular vesicles from umbilical cord-derived mesenchymal stromal cells for clinical testing. Cytotherapy 21, 581-592. doi: 10.1016/j.jcyt.2018.12.006

Ronaldson-Bouchard, K., and Vunjak-Novakovic, G. (2018). Organs-on-a-Chip: A Fast Track for Engineered Human Tissues in Drug Development. Cell Stem Cell 22, 310-324. doi: 10.1016/j.stem.2018.02.011

Rong, Y., Liu, W., Wang, J., Fan, J., Luo, Y., Li, L., et al. (2019). Neural stem cellderived small extracellular vesicles attenuate apoptosis and neuroinflammation after traumatic spinal cord injury by activating autophagy. Cell Death Dis. 10:340. doi: 10.1038/s41419-019-1571-8

Rontogianni, S., Synadaki, E., Li, B., Liefaard, M. C., Lips, E. H., Wesseling, J., et al. (2019). Proteomic profiling of extracellular vesicles allows for human breast cancer subtyping. Commun. Biol. 2:325. doi: 10.1038/s42003-019-0570-8

Russell, A. E., Sneider, A., Witwer, K. W., Bergese, P., Bhattacharyya, S. N., Cocks, A., et al. (2019). Biological membranes in EV biogenesis, stability, uptake, and cargo transfer: an ISEV position paper arising from the ISEV membranes and EVs workshop. J. Extracell. Vesicles 8:1684862. doi: 10.1080/20013078.2019. 1684862

Saari, H., Lazaro-Ibanez, E., Viitala, T., Vuorimaa-Laukkanen, E., Siljander, P., and Yliperttula, M. (2015). Microvesicle- and exosome-mediated drug delivery enhances the cytotoxicity of Paclitaxel in autologous prostate cancer cells. J. Control Release 220, 727-737. doi: 10.1016/j.jconrel.2015.09.031

Sabanovic, B., Piva, F., Cecati, M., and Giulietti, M. (2021). Promising Extracellular Vesicle-Based Vaccines against Viruses, Including SARS-CoV-2. Biology 10:94. doi: 10.3390/biology10020094

Saeedimasine, M., Montanino, A., Kleiven, S., and Villa, A. (2019). Role of lipid composition on the structural and mechanical features of axonal membranes: a molecular simulation study. Sci. Rep. 9:8000. doi: 10.1038/s41598-019-44318-9

Sahoo, S., Adamiak, M., Mathiyalagan, P., Kenneweg, F., Kafert-Kasting, S., and Thum, T. (2021). Therapeutic and Diagnostic Translation of Extracellular Vesicles in Cardiovascular Diseases: Roadmap to the Clinic. Circulation 143, 1426-1449.

Salmond, N., and Williams, K. C. (2021). Isolation and characterization of extracellular vesicles for clinical applications in cancer - time for standardization? Nanoscale Adv. 3, 1830-1852.

Saludas, L., Oliveira, C. C., Roncal, C., Ruiz-Villalba, A., Prosper, F., Garbayo, E., et al. (2021). Extracellular Vesicle-Based Therapeutics for Heart Repair. Nanomaterials 11:570. doi: 10.3390/nano11030570

Sarugaser, R., Hanoun, L., Keating, A., Stanford, W. L., and Davies, J. E. (2009). Human mesenchymal stem cells self-renew and differentiate according to a deterministic hierarchy. PLoS One 4:e6498. doi: 10.1371/journal.pone.000 6498

Sasaki, M., Abe, R., Fujita, Y., Ando, S., Inokuma, D., and Shimizu, H. (2008). Mesenchymal stem cells are recruited into wounded skin and contribute to wound repair by transdifferentiation into multiple skin cell type. J. Immunol. 180, 2581-2587. doi: 10.4049/jimmunol.180.4. 2581

Sato, Y. T., Umezaki, K., Sawada, S., Mukai, S. A., Sasaki, Y., Harada, N., et al. (2016). Engineering hybrid exosomes by membrane fusion with liposomes. Sci. Rep. 6:21933. 
Shafiq, A., Suwakulsiri, W., Rai, A., Chen, M., Greening, D. W., Zhu, H. J., et al. (2021). Transglutaminase-2, RNA-binding proteins and mitochondrial proteins selectively traffic to MDCK cell-derived microvesicles following H-Ras-induced epithelial-mesenchymal transition. Proteomics 2021:e2000221. doi: 10.1002/ pmic.202000221

Shah, V. M., Nguyen, D. X., Patel, P., Cote, B., Al-Fatease, A., Pham, Y., et al. (2019). Liposomes produced by microfluidics and extrusion: A comparison for scale-up purposes. Nanomedicine 18, 146-156. doi: 10.1016/j.nano.2019.02.019

Shao, H., Im, H., Castro, C. M., Breakefield, X., Weissleder, R., and Lee, H. (2018). New Technologies for Analysis of Extracellular Vesicles. Chem. Rev. 118, 1917-1950.

Sharma, J., Hampton, J. M., Valiente, G. R., Wada, T., Steigelman, H., Young, M. C., et al. (2017). Therapeutic development of mesenchymal stem cells or their extracellular vesicles to inhibit autoimmune-mediated inflammatory processes in systemic lupus erythematosus. Front. Immunol. 8:526. doi: 10.3389/fimmu. 2017.00526

Sharma, P., Diergaarde, B., Ferrone, S., Kirkwood, J. M., and Whiteside, T. L. (2020). Melanoma cell-derived exosomes in plasma of melanoma patients suppress functions of immune effector cells. Sci. Rep. 10:92. doi: 10.1038/ s41598-019-56542-4

Shehata, M. M., Mostafa, A., Teubner, L., Mahmoud, S. H., Kandeil, A., Elshesheny, R., et al. (2019). Bacterial Outer Membrane Vesicles (OMVs)-based Dual Vaccine for Influenza A H1N1 Virus and MERS-CoV. Vaccines 7:46. doi: 10. 3390/vaccines7020046

Shi, A., Li, J., Qiu, X., Sabbah, M., Boroumand, S., Huang, T. C., et al. (2021). TGFbeta loaded exosome enhances ischemic wound healing in vitro and in vivo. Theranostics 11, 6616-6631. doi: 10.7150/thno.57701

Shi, B., Wang, Y., Zhao, R., Long, X., Deng, W., and Wang, Z. (2018). Bone marrow mesenchymal stem cell-derived exosomal miR-21 protects C-kit+ cardiac stem cells from oxidative injury through the PTEN/PI3K/Akt axis. PLoS One 13:e0191616. doi: 10.1371/journal.pone.0191616

Shi, C., Ulke-Lemee, A., Deng, J., Batulan, Z., and O'Brien, E. R. (2019). Characterization of heat shock protein 27 in extracellular vesicles: a potential anti-inflammatory therapy. FASEB J. 33, 1617-1630.

Shi, X., Cheng, Q., and Zhang, Y. (2020). Reprogramming extracellular vesicles with engineered proteins. Methods 177, 95-102.

Shtam, T. A., Kovalev, R. A., Varfolomeeva, E. Y., Makarov, E. M., Kil, Y. V., and Filatov, M. V. (2013). Exosomes are natural carriers of exogenous siRNA to human cells in vitro. Cell Commun. Signal 11:88.

Shukla, L., Yuan, Y., Shayan, R., Greening, D. W., and Karnezis, T. (2020). Fat Therapeutics: The Clinical Capacity of Adipose-Derived Stem Cells and Exosomes for Human Disease and Tissue Regeneration. Front. Pharmacol. 11:158. doi: 10.3389/fphar.2020.00158

Siddique, H. R. (2016). CRSPR/CAS9 Technology: A Revolutionary Molecular Scissors for Genome Editing and Genetic Research. MOJ Cell Sci. Rep. 3:46.

Skog, J., Wurdinger, T., van Rijn, S., Meijer, D. H., Gainche, L., Sena-Esteves, M., et al. (2008). Glioblastoma microvesicles transport RNA and proteins that promote tumour growth and provide diagnostic biomarkers. Nat. Cell Biol. 10, 1470-1476. doi: 10.1038/ncb1800

Skotland, T., Hessvik, N. P., Sandvig, K., and Llorente, A. (2019). Exosomal lipid composition and the role of ether lipids and phosphoinositides in exosome biology. J. Lipid Res. 60, 9-18. doi: 10.1194/jlr.R084343

Sluijter, J. P. G., Davidson, S. M., Boulanger, C. M., Buzas, E. I., de Kleijn, D. P. V., Engel, F. B., et al. (2018). Extracellular vesicles in diagnostics and therapy of the ischaemic heart: Position Paper from the Working Group on Cellular Biology of the Heart of the European Society of Cardiology. Cardiovasc. Res. 114, 19-34. doi: $10.1093 / \mathrm{cvr} / \mathrm{cvx} 211$

Smith, P., Quinn, P. J., and Lorenz, C. D. (2020). Two Coexisting Membrane Structures Are Defined by Lateral and Transbilayer Interactions between Sphingomyelin and Cholesterol. Langmuir 36, 9786-9799. doi: 10.1021/acs. langmuir.0c01237

Smyth, T., Kullberg, M., Malik, N., Smith-Jones, P., Graner, M. W., and Anchordoquy, T. J. (2015). Biodistribution and delivery efficiency of unmodified tumor-derived exosomes. J. Control Release 199, 145-155. doi: 10.1016/j.jconrel.2014.12.013

Smyth, T., Petrova, K., Payton, N. M., Persaud, I., Redzic, J. S., Graner, M. W., et al. (2014). Surface functionalization of exosomes using click chemistry. Bioconjug. Chem. 25, 1777-1784.
Sobo-Vujanovic, A., Munich, S., and Vujanovic, N. L. (2014). Dendritic-cell exosomes cross-present Toll-like receptor-ligands and activate bystander dendritic cells. Cell Immunol. 289, 119-127. doi: 10.1016/j.cellimm.2014. 03.016

Song, Y., Dou, H., Li, X., Zhao, X., Li, Y., Liu, D., et al. (2017). Exosomal miR-146a Contributes to the Enhanced Therapeutic Efficacy of Interleukin-1beta-Primed Mesenchymal Stem Cells Against Sepsis. Stem Cells 35, 1208-1221. doi: 10.1002/ stem.2564

Song, Y., Huang, Z., Liu, X., Pang, Z., Chen, J., Yang, H., et al. (2019). Platelet membrane-coated nanoparticle-mediated targeting delivery of Rapamycin blocks atherosclerotic plaque development and stabilizes plaque in apolipoprotein E-deficient $(\operatorname{ApoE}(-/-))$ mice. Nanomedicine 15, 13-24. doi: 10.1016/j.nano.2018.08.002

Spees, J. L., Olson, S. D., Whitney, M. J., and Prockop, D. J. (2006). Mitochondrial transfer between cells can rescue aerobic respiration. Proc. Natl. Acad. Sci. U.S.A. 103, 1283-1288.

Spellicy, S. E., Kaiser, E. E., Bowler, M. M., Jurgielewicz, B. J., Webb, R. L., West, F. D., et al. (2020). Neural Stem Cell Extracellular Vesicles Disrupt Midline Shift Predictive Outcomes in Porcine Ischemic Stroke Model. Transl. Stroke Res. 11, 776-788. doi: 10.1007/s12975-019-00753-4

Sterzenbach, U., Putz, U., Low, L. H., Silke, J., Tan, S. S., and Howitt, J. (2017). Engineered Exosomes as Vehicles for Biologically Active Proteins. Mol. Ther. $25,1269-1278$.

Suharta, S., Barlian, A., Hidajah, A. C., Notobroto, H. B., Ana, I. D., Indariani, S., et al. (2021). Plant-derived exosome-like nanoparticles: A concise review on its extraction methods, content, bioactivities, and potential as functional food ingredient. J. Food Sci. [Preprint]. doi: 10.1111/1750-3841.15787

Suk, J. S., Xu, Q., Kim, N., Hanes, J., and Ensign, L. M. (2016). PEGylation as a strategy for improving nanoparticle-based drug and gene delivery. Adv. Drug Deliv. Rev. 99, 28-51.

Sung, B. H., von Lersner, A., Guerrero, J., Krystofiak, E. S., Inman, D., Pelletier, R., et al. (2020). A live cell reporter of exosome secretion and uptake reveals pathfinding behavior of migrating cells. Nat. Commun. 11:2092. doi: 10.1038/ s41467-020-15747-2

Surman, M., Drozdz, A., Stepien, E., and Przybylo, M. (2019). Extracellular Vesicles as Drug Delivery Systems - Methods of Production and Potential Therapeutic Applications. Curr. Pharm. Des. 25, 132-154.

Swingle, K. L., Hamilton, A. G., and Mitchell, M. J. (2021). Lipid NanoparticleMediated Delivery of mRNA Therapeutics and Vaccines. Trends Mol. Med. 27, 616-617.

Takahashi, A., Okada, R., Nagao, K., Kawamata, Y., Hanyu, A., Yoshimoto, S., et al. (2017). Exosomes maintain cellular homeostasis by excreting harmful DNA from cells. Nat. Commun. 8:15287.

Takahashi, Y., Nishikawa, M., Shinotsuka, H., Matsui, Y., Ohara, S., Imai, T., et al. (2013). Visualization and in vivo tracking of the exosomes of murine melanoma B16-BL6 cells in mice after intravenous injection. J. Biotechnol. 165, 77-84. doi: 10.1016/j.jbiotec.2013.03.013

Takayama, Y., Kusamori, K., and Nishikawa, M. (2019). Click Chemistry as a Tool for Cell Engineering and Drug Delivery. Molecules 24:172.

Takenaka, T., Nakai, S., Katayama, M., Hirano, M., Ueno, N., Noguchi, K., et al. (2019). Effects of gefitinib treatment on cellular uptake of extracellular vesicles in EGFR-mutant non-small cell lung cancer cells. Int. J. Pharm. 572:118762. doi: 10.1016/j.ijpharm.2019.118762

Takov, K., Yellon, D. M., and Davidson, S. M. (2017). Confounding factors in vesicle uptake studies using fluorescent lipophilic membrane dyes. J. Extracell. Vesicles 6:1388731. doi: 10.1080/20013078.2017.1388731

Tan, J. L., Lau, S. N., Leaw, B., Nguyen, H. P. T., Salamonsen, L. A., Saad, M. I., et al. (2018). Amnion Epithelial Cell-Derived Exosomes Restrict Lung Injury and Enhance Endogenous Lung Repair. Stem Cells Transl. Med. 7, 180-196. doi: 10.1002/sctm.17-0185

Tang, T. T., Lv, L. L., Wang, B., Cao, J. Y., Feng, Y., Li, Z. L., et al. (2019). Employing Macrophage-Derived Microvesicle for Kidney-Targeted Delivery of Dexamethasone: An Efficient Therapeutic Strategy against Renal Inflammation and Fibrosis. Theranostics 9, 4740-4755. doi: 10.7150/thno. 33520

Tang, Y., Wang, X., Li, J., Nie, Y., Liao, G., Yu, Y., et al. (2019). Overcoming the Reticuloendothelial System Barrier to Drug Delivery with a "Don't-Eat-Us" Strategy. ACS Nano 13, 13015-13026. doi: 10.1021/acsnano.9b05679 
Tauro, B. J., Mathias, R. A., Greening, D. W., Gopal, S. K., Ji, H., Kapp, E. A., et al. (2013). Oncogenic H-ras reprograms Madin-Darby canine kidney (MDCK) cell-derived exosomal proteins following epithelial-mesenchymal transition. Mol Cell Proteom. 12, 2148-2159. doi: 10.1074/mcp.M112.02 7086

Tawil, N., Bassawon, R., Meehan, B., Nehme, A., Montermini, L., Gayden, T., et al. (2021). Glioblastoma cell populations with distinct oncogenic programs release podoplanin as procoagulant extracellular vesicles. Blood Adv. 5, 1682-1694. doi: 10.1182/bloodadvances.2020002998

Thery, C., Witwer, K. W., Aikawa, E., Alcaraz, M. J., Anderson, J. D., Andriantsitohaina, R., et al. (2018). Minimal information for studies of extracellular vesicles 2018 (MISEV2018): a position statement of the International Society for Extracellular Vesicles and update of the MISEV2014 guidelines. J. Extracell. Vesicles 7:1535750. doi: 10.1080/20013078.2018.1535750

Thomou, T., Mori, M. A., Dreyfuss, J. M., Konishi, M., Sakaguchi, M., Wolfrum, C., et al. (2017). Adipose-derived circulating miRNAs regulate gene expression in other tissues. Nature 542, 450-455.

Thone, M. N., and Kwon, Y. J. (2020). Extracellular blebs: Artificially-induced extracellular vesicles for facile production and clinical translation. Methods 177, 135-145.

Tian, T., Zhang, H. X., He, C. P., Fan, S., Zhu, Y. L., Qi, C., et al. (2018). Surface functionalized exosomes as targeted drug delivery vehicles for cerebral ischemia therapy. Biomaterials 150, 137-149. doi: 10.1016/j.biomaterials.2017.10.012

Tian, Y., Li, S., Song, J., Ji, T., Zhu, M., Anderson, G. J., et al. (2014). A doxorubicin delivery platform using engineered natural membrane vesicle exosomes for targeted tumor therapy. Biomaterials 35, 2383-2390. doi: 10.1016/ j.biomaterials.2013.11.083

Tietjen, G. T., Gong, Z., Chen, C. H., Vargas, E., Crooks, J. E., Cao, K. D., et al. (2014). Molecular mechanism for differential recognition of membrane phosphatidylserine by the immune regulatory receptor Tim4. Proc. Natl. Acad. Sci. U.S.A. 111, E1463-E1472. doi: 10.1073/pnas.1320174111

Toh, W. S., Lai, R. C., Zhang, B., and Lim, S. K. (2018). MSC exosome works through a protein-based mechanism of action. Biochem. Soc. Trans. 46, 843853. doi: $10.1042 /$ BST20180079

Tong, M., Stanley, J. L., Chen, Q., James, J. L., Stone, P. R., and Chamley, L. W. (2017). Placental Nano-vesicles Target to Specific Organs and Modulate Vascular Tone In Vivo. Hum. Reprod. 32, 2188-2198. doi: 10.1093/humrep/ $\operatorname{dex} 310$

Trivedi, M., Talekar, M., Shah, P., Ouyang, Q., and Amiji, M. (2016). Modification of tumor cell exosome content by transfection with wt-p53 and microRNA-125b expressing plasmid DNA and its effect on macrophage polarization. Oncogenesis 5:e250. doi: 10.1038/oncsis.2016.52

Ullah, M., Kodam, S. P., Mu, Q., and Akbar, A. (2021). Microbubbles versus Extracellular Vesicles as Therapeutic Cargo for Targeting Drug Delivery. ACS Nano 15, 3612-3620. doi: 10.1021/acsnano.0c10689

Units of Enzyme Activity (1979). Recommendations 1978. Eur. J. Biochem. 97, 319-320.

Urbanelli, L., Buratta, S., Tancini, B., Sagini, K., Delo, F., Porcellati, S., et al. (2019). The Role of Extracellular Vesicles in Viral Infection and Transmission. Vaccines 7:102.

Usman, W. M., Pham, T. C., Kwok, Y. Y., Vu, L. T., Ma, V., Peng, B., et al. (2018). Efficient RNA drug delivery using red blood cell extracellular vesicles. Nat. Commun. 9:2359. doi: 10.1038/s41467-018-04791-8

Vachon, E., Martin, R., Kwok, V., Cherepanov, V., Chow, C. W., Doerschuk, C. M., et al. (2007). CD44-mediated phagocytosis induces inside-out activation of complement receptor-3 in murine macrophages. Blood 110, 4492-4502. doi: 10.1182/blood-2007-02-076539

Vader, P., Mol, E. A., Pasterkamp, G., and Schiffelers, R. M. (2016). Extracellular vesicles for drug delivery. Adv. Drug Deliv. Rev. 106, 148-156.

Valadi, H., Ekstrom, K., Bossios, A., Sjostrand, M., Lee, J. J., and Lotvall, J. O. (2007). Exosome-mediated transfer of mRNAs and microRNAs is a novel mechanism of genetic exchange between cells. Nat. Cell Biol. 9, 654-659. doi: 10.1038/ncb1596 van Balkom, B. W. M., Gremmels, H., Giebel, B., and Lim, S. K. (2019). Proteomic Signature of Mesenchymal Stromal Cell-Derived Small Extracellular Vesicles. Proteomics 19:e1800163.

van Dongen, H. M., Masoumi, N., Witwer, K. W., and Pegtel, D. M. (2016). Extracellular Vesicles Exploit Viral Entry Routes for Cargo Delivery. Microbiol. Mol. Biol. Rev. 80, 369-386. doi: 10.1128/MMBR.00063-15 van Niel, G., D’Angelo, G., and Raposo, G. (2018). Shedding light on the cell biology of extracellular vesicles. Nat. Rev. Mol. Cell Biol. 19, 213-228.

Vandergriff, A., Huang, K., Shen, D., Hu, S., Hensley, M. T., Caranasos, T. G., et al. (2018). Targeting regenerative exosomes to myocardial infarction using cardiac homing peptide. Theranostics 8:1869. doi: 10.7150/thno.20524

Varga, Z., van der Pol, E., Palmai, M., Garcia-Diez, R., Gollwitzer, C., Krumrey, M., et al. (2018). Hollow organosilica beads as reference particles for optical detection of extracellular vesicles. J. Thromb. Haemost. [Preprint]. doi: 10.1111/ jth.14193

Vargason, A. M., Anselmo, A. C., and Mitragotri, S. (2021). The evolution of commercial drug delivery technologies. Nat. Biomed. Eng. [Preprint].

Viaud, S., Ploix, S., Lapierre, V., Thery, C., Commere, P. H., Tramalloni, D., et al. (2011). Updated technology to produce highly immunogenic dendritic cell-derived exosomes of clinical grade: a critical role of interferon-gamma. J. Immunother. 34, 65-75. doi: 10.1097/CJI.0b013e3181fe535b

Villarroya-Beltri, C., Gutierrez-Vazquez, C., Sanchez-Cabo, F., Perez-Hernandez, D., Vazquez, J., Martin-Cofreces, N., et al. (2013). Sumoylated hnRNPA2B1 controls the sorting of miRNAs into exosomes through binding to specific motifs. Nat. Commun. 4:2980. doi: 10.1038/ncomms3980

Vinas, J. L., Spence, M., Gutsol, A., Knoll, W., Burger, D., Zimpelmann, J., et al. (2018). Receptor-Ligand Interaction Mediates Targeting of Endothelial Colony Forming Cell-derived Exosomes to the Kidney after Ischemic Injury. Sci. Rep. 8:16320. doi: 10.1038/s41598-018-34557-7

Wahlund, C. J. E., Gucluler, G., Hiltbrunner, S., Veerman, R. E., Naslund, T. I., and Gabrielsson, S. (2017). Exosomes from antigen-pulsed dendritic cells induce stronger antigen-specific immune responses than microvesicles in vivo. Sci. Rep. 7:17095. doi: 10.1038/s41598-017-16609-6

Wan, Y., Wang, L., Zhu, C., Zheng, Q., Wang, G., Tong, J., et al. (2018). AptamerConjugated Extracellular Nanovesicles for Targeted Drug Delivery. Cancer Res. 78, 798-808. doi: 10.1158/0008-5472.CAN-17-2880

Wang, B., Yao, K., Huuskes, B. M., Shen, H. H., Zhuang, J., Godson, C., et al. (2016). Mesenchymal Stem Cells Deliver Exogenous MicroRNA-let7c via Exosomes to Attenuate Renal Fibrosis. Mol. Ther. 24, 1290-1301. doi: 10.1038/mt.2016.90

Wang, J., Bonacquisti, E. E., Brown, A. D., and Nguyen, J. (2020). Boosting the Biogenesis and Secretion of Mesenchymal Stem Cell-Derived Exosomes. Cells 9:660.

Wang, Q., and $\mathrm{Lu}$, Q. (2017). Plasma membrane-derived extracellular microvesicles mediate non-canonical intercellular NOTCH signaling. Nat. Commun. 8:709. doi: 10.1038/s41467-017-00767-2

Wang, Q., Yu, J., Kadungure, T., Beyene, J., Zhang, H., and Lu, Q. (2018). ARMMs as a versatile platform for intracellular delivery of macromolecules. Nat. Commun. 9:960. doi: 10.1038/s41467-018-03390-x

Wang, X., Chen, Y., Zhao, Z., Meng, Q., Yu, Y., Sun, J., et al. (2018). Engineered Exosomes With Ischemic Myocardium-Targeting Peptide for Targeted Therapy in Myocardial Infarction. J. Am. Heart Assoc. 7:e008737. doi: 10.1161/JAHA. 118.008737

Wang, Y., Yao, J., Cai, L., Liu, T., Wang, X., Zhang, Y., et al. (2020). Bone-Targeted Extracellular Vesicles from Mesenchymal Stem Cells for Osteoporosis Therapy. Int. J. Nanomed. 15, 7967-7977. doi: 10.2147/IJN.S263756

Wang, Y., Yu, D., Liu, Z., Zhou, F., Dai, J., Wu, B., et al. (2017). Exosomes from embryonic mesenchymal stem cells alleviate osteoarthritis through balancing synthesis and degradation of cartilage extracellular matrix. Stem Cell Res. Ther. 8:189. doi: 10.1186/s13287-017-0632-0

Watkins, H. C., Rappazzo, C. G., Higgins, J. S., Sun, X., Brock, N., Chau, A., et al. (2017). Safe Recombinant Outer Membrane Vesicles that Display M2e Elicit Heterologous Influenza Protection. Mol. Ther. 25, 989-1002. doi: 10.1016/j. ymthe.2017.01.010

Webb, R. L., Kaiser, E. E., Jurgielewicz, B. J., Spellicy, S., Scoville, S. L., Thompson, T. A., et al. (2018a). Human Neural Stem Cell Extracellular Vesicles Improve Recovery in a Porcine Model of Ischemic Stroke. Stroke 49, 1248-1256. doi: 10.1161/STROKEAHA.117.020353

Webb, R. L., Kaiser, E. E., Scoville, S. L., Thompson, T. A., Fatima, S., Pandya, C., et al. (2018b). Human Neural Stem Cell Extracellular Vesicles Improve Tissue and Functional Recovery in the Murine Thromboembolic Stroke Model. Transl. Stroke Res. 9, 530-539. doi: 10.1007/s12975-017-0599-2

Wei, G., Jie, Y., Haibo, L., Chaoneng, W., Dong, H., Jianbing, Z., et al. (2017). Dendritic cells derived exosomes migration to spleen and induction of inflammation are regulated by CCR7. Sci. Rep. 7:42996. doi: 10.1038/srep42996 
Wei, Y., Quan, L., Zhou, C., and Zhan, Q. (2018). Factors relating to the biodistribution \& clearance of nanoparticles \& their effects on in vivo application. Nanomedicine 13, 1495-1512.

Welsh, J. A., van der Pol, E., Bettin, B. A., Carter, D. R. F., Hendrix, A., Lenassi, M., et al. (2020). Towards defining reference materials for measuring extracellular vesicle refractive index, epitope abundance, size and concentration. J. Extracell. Vesicles 9:1816641. doi: 10.1080/20013078.2020.18 16641

Welton, J. L., Loveless, S., Stone, T., von Ruhland, C., Robertson, N. P., and Clayton, A. (2017). Cerebrospinal fluid extracellular vesicle enrichment for protein biomarker discovery in neurological disease; multiple sclerosis. J. Extracell. Vesicles 6:1369805. doi: 10.1080/20013078.2017.1369805

Wen, Z., Mai, Z., Zhu, X., Wu, T., Chen, Y., Geng, D., et al. (2020). Mesenchymal stem cell-derived exosomes ameliorate cardiomyocyte apoptosis in hypoxic conditions through microRNA144 by targeting the PTEN/AKT pathway. Stem Cell Res. Ther. 11:36. doi: 10.1186/s13287-020-1563-8

Whitford, W., and Guterstam, P. (2019). Exosome manufacturing status. Fut. Med. Chem. 11, 1225-1236.

Wiklander, O. P. B., Brennan, M. A., Lotvall, J., Breakefield, X. O., and El Andaloussi, S. (2019). Advances in therapeutic applications of extracellular vesicles. Sci. Transl. Med. 11:eaav8521.

Wiklander, O. P., Nordin, J. Z., O’Loughlin, A., Gustafsson, Y., Corso, G., Mager, I., et al. (2015). Extracellular vesicle in vivo biodistribution is determined by cell source, route of administration and targeting. J. Extracell. Vesicles 4:26316. doi: 10.3402/jev.v4.26316

Williams, A. M., Dennahy, I. S., Bhatti, U. F., Halaweish, I., Xiong, Y., Chang, P., et al. (2019). Mesenchymal Stem Cell-Derived Exosomes Provide Neuroprotection and Improve Long-Term Neurologic Outcomes in a Swine Model of Traumatic Brain Injury and Hemorrhagic Shock. J. Neurotrauma 36, 54-60. doi: 10.1089/neu.2018.5711

Williams, C., Pazos, R., Royo, F., Gonzalez, E., Roura-Ferrer, M., Martinez, A., et al. (2019). Assessing the role of surface glycans of extracellular vesicles on cellular uptake. Sci. Rep. 9:11920. doi: 10.1038/s41598-019-48499-1

Williams, C., Royo, F., Aizpurua-Olaizola, O., Pazos, R., Boons, G. J., Reichardt, N. C., et al. (2018). Glycosylation of extracellular vesicles: current knowledge, tools and clinical perspectives. J. Extracell. Vesicles 7:1442985. doi: 10.1080/ 20013078.2018.1442985

Willis, G. R., Kourembanas, S., and Mitsialis, S. A. (2017). Toward Exosome-Based Therapeutics: Isolation, Heterogeneity, and Fit-for-Purpose Potency. Front. Cardiovasc. Med. 4:63. doi: 10.3389/fcrm.2017.00063

Willis, G. R., Mitsialis, S. A., and Kourembanas, S. (2018). "Good things come in small packages": application of exosome-based therapeutics in neonatal lung injury. Pediatr. Res. 83, 298-307. doi: 10.1038/pr.2017.256

Willms, E., Johansson, H. J., Mager, I., Lee, Y., Blomberg, K. E., Sadik, M., et al. (2016). Cells release subpopulations of exosomes with distinct molecular and biological properties. Sci. Rep. 6:22519.

Witwer, K. W., and Wolfram, J. (2021). Extracellular vesicles versus synthetic nanoparticles for drug delivery. Nat. Rev. Mater. 6, 103-106.

Witwer, K. W., Van Balkom, B. W. M., Bruno, S., Choo, A., Dominici, M., Gimona, M., et al. (2019). Defining mesenchymal stromal cell (MSC)-derived small extracellular vesicles for therapeutic applications. J. Extracell. Vesicles 8:1609206.

Wu, A. Y., Sung, Y. C., Chen, Y. J., Chou, S. T., Guo, V., Chien, J. C., et al. (2020). Multiresolution Imaging Using Bioluminescence Resonance Energy Transfer Identifies Distinct Biodistribution Profiles of Extracellular Vesicles and Exomeres with Redirected Tropism. Adv. Sci. 7:2001467. doi: 10.1002/advs. 202001467

Wu, J. Y., Li, Y. J., Hu, X. B., Huang, S., and Xiang, D. X. (2021). Preservation of small extracellular vesicles for functional analysis and therapeutic applications: a comparative evaluation of storage conditions. Drug Deliv. 28, 162-170. doi: 10.1080/10717544.2020.1869866

Wu, J., Kuang, L., Chen, C., Yang, J., Zeng, W. N., Li, T., et al. (2019). miR100-5p-abundant exosomes derived from infrapatellar fat pad MSCs protect articular cartilage and ameliorate gait abnormalities via inhibition of mTOR in osteoarthritis. Biomaterials 206, 87-100. doi: 10.1016/j.biomaterials.2019.03. 022

Xiao, G. Y., Cheng, C. C., Chiang, Y. S., Cheng, W. T., Liu, I. H., and Wu, S. C. (2016). Exosomal miR-10a derived from amniotic fluid stem cells preserves ovarian follicles after chemotherapy. Sci. Rep. 6:23120. doi: 10.1038/srep 23120

Xiao, J., Pan, Y., Li, X. H., Yang, X. Y., Feng, Y. L., Tan, H. H., et al. (2016). Cardiac progenitor cell-derived exosomes prevent cardiomyocytes apoptosis through exosomal miR-21 by targeting PDCD4. Cell Death Dis. 7:e2277. doi: 10.1038/cddis.2016.181

Xin, H., Wang, F., Li, Y., Lu, Q. E., Cheung, W. L., Zhang, Y., et al. (2017). Secondary Release of Exosomes From Astrocytes Contributes to the Increase in Neural Plasticity and Improvement of Functional Recovery After Stroke in Rats Treated With Exosomes Harvested From MicroRNA 133b-Overexpressing Multipotent Mesenchymal Stromal Cells. Cell Transplant. 26, 243-257. doi: 10.3727/096368916X693031

Xitong, D., and Xiaorong, Z. (2016). Targeted therapeutic delivery using engineered exosomes and its applications in cardiovascular diseases. Gene 575, 377-384.

$\mathrm{Xu}, \mathrm{H}$., Jia, S., and Xu, H. (2019). Potential therapeutic applications of exosomes in different autoimmune diseases. Clin. Immunol. 205, 116-124.

Xu, H., Liao, C., Zuo, P., Liu, Z., and Ye, B. C. (2018). Magnetic-Based Microfluidic Device for On-Chip Isolation and Detection of Tumor-Derived Exosomes. Anal. Chem. 90, 13451-13458. doi: 10.1021/acs.analchem.8b0 3272

Xu, K., Liu, Q., Wu, K., Liu, L., Zhao, M., Yang, H., et al. (2020). Extracellular vesicles as potential biomarkers and therapeutic approaches in autoimmune diseases. J. Translat. Med. 18, 1-8.

Xu, R., Greening, D. W., Chen, M., Rai, A., Ji, H., Takahashi, N., et al. (2019). Surfaceome of Exosomes Secreted from the Colorectal Cancer Cell Line SW480: Peripheral and Integral Membrane Proteins Analyzed by Proteolysis and TX114. Proteomics 19:e1700453. doi: 10.1002/pmic.20170 0453

Xu, R., Greening, D. W., Zhu, H. J., Takahashi, N., and Simpson, R. J. (2016). Extracellular vesicle isolation and characterization: toward clinical application. J. Clin. Invest. 126, 1152-1162.

Xue, C., Shen, Y., Li, X., Li, B., Zhao, S., Gu, J., et al. (2018). Exosomes Derived from Hypoxia-Treated Human Adipose Mesenchymal Stem Cells Enhance Angiogenesis Through the PKA Signaling Pathway. Stem Cells Dev. 27, 456465. doi: $10.1089 /$ scd.2017.0296

Xunian, Z., and Kalluri, R. (2020). Biology and therapeutic potential of mesenchymal stem cell-derived exosomes. Cancer Sci. 111, 3100-3110.

Yang, J., Liu, X. X., Fan, H., Tang, Q., Shou, Z. X., Zuo, D. M., et al. (2015). Extracellular Vesicles Derived from Bone Marrow Mesenchymal Stem Cells Protect against Experimental Colitis via Attenuating Colon Inflammation, Oxidative Stress and Apoptosis. PLoS One 10:e140551. doi: 10.1371/journal. pone.0140551

Yang, S., Sun, I. C., Hwang, H. S., Shim, M. K., Yoon, H. Y., and Kim, K. (2021). Rediscovery of nanoparticle-based therapeutics: boosting immunogenic cell death for potential application in cancer immunotherapy. J. Mater. Chem. B 9, 3983-4001. doi: 10.1039/d1tb00 $397 f$

Yang, Z., Shi, J., Xie, J., Wang, Y., Sun, J., Liu, T., et al. (2020). Large-scale generation of functional mRNA-encapsulating exosomes via cellular nanoporation. Nat. Biomed. Eng. 4, 69-83.

Yao, J., Huang, K., Zhu, D., Chen, T., Jiang, Y., Zhang, J., et al. (2021). A Minimally Invasive Exosome Spray Repairs Heart after Myocardial Infarction. ACS Nano. [Preprint]. doi: 10.1021/acsnano.1c00628

Yao, X., Lyu, P., Yoo, K., Yadav, M. K., Singh, R., Atala, A., et al. (2021). Engineered extracellular vesicles as versatile ribonucleoprotein delivery vehicles for efficient and safe CRISPR genome editing. J. Extracell. Vesicles 10:e12076. doi: 10.1002/ jev2.12076

Ye, Y., Zhang, X., Xie, F., Xu, B., Xie, P., Yang, T., et al. (2020). An engineered exosome for delivering sgRNA:Cas9 ribonucleoprotein complex and genome editing in recipient cells. Biomater. Sci. 8, 2966-2976. doi: 10.1039/d0bm00 $427 \mathrm{~h}$

Yim, N., Ryu, S. W., Choi, K., Lee, K. R., Lee, S., Choi, H., et al. (2016). Exosome engineering for efficient intracellular delivery of soluble proteins using optically reversible protein-protein interaction module. Nat. Commun. 7:12277. doi: 10. 1038/ncomms12277

Yin, K., Wang, S., and Zhao, R. C. (2019). Exosomes from mesenchymal stem/stromal cells: a new therapeutic paradigm. Biomark. Res. 7:8. doi: 10.1186/ s40364-019-0159-x 
Yin, Z., Fan, J., Xu, J., Wu, F., Li, Y., Zhou, M., et al. (2020). Immunoregulatory Roles of Extracellular Vesicles and Associated Therapeutic Applications in Lung Cancer. Front. Immunol. 11:2024. doi: 10.3389/fimmu.2020.02024

Yoon, J., Jo, W., Jeong, D., Kim, J., Jeong, H., and Park, J. (2015). Generation of nanovesicles with sliced cellular membrane fragments for exogenous material delivery. Biomaterials 59, 12-20. doi: 10.1016/j.biomaterials.2015.04.028

Yuan, Z., Kolluri, K. K., Gowers, K. H., and Janes, S. M. (2017). TRAIL delivery by MSC-derived extracellular vesicles is an effective anticancer therapy. J. Extracell. Vesicles 6:1265291. doi: 10.1080/20013078.2017.1265291

Yuyama, K., Sun, H., Sakai, S., Mitsutake, S., Okada, M., Tahara, H., et al. (2014). Decreased amyloid-beta pathologies by intracerebral loading of glycosphingolipid-enriched exosomes in Alzheimer model mice. J. Biol. Chem. 289, 24488-24498. doi: 10.1074/jbc.M114.577213

Zabeo, D., Cvjetkovic, A., Lasser, C., Schorb, M., Lotvall, J., and Hoog, J. L. (2017). Exosomes purified from a single cell type have diverse morphology. J. Extracell. Vesicles 6:1329476. doi: 10.1080/20013078.2017.1329476

Zaborowski, M. P., Cheah, P. S., Zhang, X., Bushko, I., Lee, K., Sammarco, A., et al. (2019). Membrane-bound Gaussia luciferase as a tool to track shedding of membrane proteins from the surface of extracellular vesicles. Sci. Rep. 9:17387. doi: 10.1038/s41598-019-53554-y

Zhang, G., Liu, Z., Ding, H., Zhou, Y., Doan, H. A., Sin, K. W. T., et al. (2017). Tumor induces muscle wasting in mice through releasing extracellular Hsp70 and Hsp90. Nat. Commun. 8:589. doi: 10.1038/s41467-017-00726-x

Zhang, L., Ouyang, P., He, G., Wang, X., Song, D., Yang, Y., et al. (2021). Exosomes from microRNA-126 overexpressing mesenchymal stem cells promote angiogenesis by targeting the PIK3R2-mediated PI3K/Akt signalling pathway. J. Cell Mol. Med. 25, 2148-2162. doi: 10.1111/jcmm.16192

Zhang, Q., Higginbotham, J. N., Jeppesen, D. K., Yang, Y. P., Li, W., McKinley, E. T., et al. (2019). Transfer of Functional Cargo in Exomeres. Cell Rep. 27, 940-954e946. doi: 10.1016/j.celrep.2019.01.009

Zhang, S., Teo, K. Y. W., Chuah, S. J., Lai, R. C., Lim, S. K., and Toh, W. S. (2019). MSC exosomes alleviate temporomandibular joint osteoarthritis by attenuating inflammation and restoring matrix homeostasis. Biomaterials 200, 35-47. doi: 10.1016/j.biomaterials.2019.02.006

Zhang, S., Wan, Z., and Kamm, R. D. (2021). Vascularized organoids on a chip: strategies for engineering organoids with functional vasculature. Lab. Chip 21, 473-488.

Zhang, Y. S., Aleman, J., Shin, S. R., Kilic, T., Kim, D., Mousavi Shaegh, S. A., et al. (2017). Multisensor-integrated organs-on-chips platform for automated and continual in situ monitoring of organoid behaviors. Proc. Natl. Acad. Sci. U.S.A. 114, E2293-E2302. doi: 10.1073/pnas.1612906114

Zhang, Y., Li, L., Yu, J., Zhu, D., Zhang, Y., Li, X., et al. (2014). Microvesiclemediated delivery of transforming growth factor betal siRNA for the suppression of tumor growth in mice. Biomaterials 35, 4390-4400. doi: 10.1016/ j.biomaterials.2014.02.003

Zhang, Y., Tan, J., Miao, Y., and Zhang, Q. (2021). The effect of extracellular vesicles on the regulation of mitochondria under hypoxia. Cell Death Dis. 12:358.

Zhao, W., Liu, L., Zhang, F., Leng, J., and Liu, Y. (2019). Shape memory polymers and their composites in biomedical applications. Mater. Sci. Eng. C Mater. Biol. Appl. 97, 864-883.

Zhao, X., Liu, Y., Jia, P., Cheng, H., Wang, C., Chen, S., et al. (2021). Chitosan hydrogel-loaded MSC-derived extracellular vesicles promote skin rejuvenation by ameliorating the senescence of dermal fibroblasts. Stem Cell Res. Ther. 12:196. doi: 10.1186/s13287-021-02262-4

Zhao, Z., Yang, Y., Zeng, Y., and He, M. (2016). A microfluidic ExoSearch chip for multiplexed exosome detection towards blood-based ovarian cancer diagnosis. Lab. Chip 16, 489-496. doi: 10.1039/c5lc01117e

Zhou, X., Xie, F., Wang, L., Zhang, L., Zhang, S., Fang, M., et al. (2020). The function and clinical application of extracellular vesicles in innate immune regulation. Cell Mol. Immunol. 17, 323-334.

Zhu, D., Fang, H., Kusuma, G. D., Schwab, R., Barabadi, M., Chan, S. T., et al. (2021a). Impact of chemically defined culture media formulations on extracellular vesicle production by amniotic epithelial cells. Proteomics 2021:e2000080. doi: 10.1002/pmic.202000080

Zhu, D., Li, Z., Huang, K., Caranasos, T. G., Rossi, J. S., and Cheng, K. (2021b). Minimally invasive delivery of therapeutic agents by hydrogel injection into the pericardial cavity for cardiac repair. Nat. Commun. 12:1412. doi: 10.1038/ s41467-021-21682-7

Zhu, L. P., Tian, T., Wang, J. Y., He, J. N., Chen, T., Pan, M., et al. (2018). Hypoxia-elicited mesenchymal stem cell-derived exosomes facilitates cardiac repair through miR-125b-mediated prevention of cell death in myocardial infarction. Theranostics 8, 6163-6177. doi: 10.7150/thno.28021

Zhu, X., Badawi, M., Pomeroy, S., Sutaria, D. S., Xie, Z., Baek, A., et al. (2017). Comprehensive toxicity and immunogenicity studies reveal minimal effects in mice following sustained dosing of extracellular vesicles derived from HEK293T cells. J. Extracell. Vesicles 6:1324730. doi: 10.1080/20013078.2017.1324730

Zipkin, M. (2019). Exosome redux. Nat. Biotechnol. 37, 1395-1400. doi: 10.1038/ s41587-019-0326-5

Zitvogel, L., Regnault, A., Lozier, A., Wolfers, J., Flament, C., Tenza, D., et al. (1998). Eradication of established murine tumors using a novel cell-free vaccine: dendritic cell-derived exosomes. Nat. Med. 4, 594-600. doi: 10.1038/nm0598594

Zuo, R., Kong, L., Wang, M., Wang, W., Xu, J., Chai, Y., et al. (2019). Exosomes derived from human $\mathrm{CD} 34(+)$ stem cells transfected with miR26a prevent glucocorticoid-induced osteonecrosis of the femoral head by promoting angiogenesis and osteogenesis. Stem Cell Res. Ther. 10:321. doi: 10.1186/s13287-019-1426-3

Conflict of Interest: The authors declare that the research was conducted in the absence of any commercial or financial relationships that could be construed as a potential conflict of interest.

Publisher's Note: All claims expressed in this article are solely those of the authors and do not necessarily represent those of their affiliated organizations, or those of the publisher, the editors and the reviewers. Any product that may be evaluated in this article, or claim that may be made by its manufacturer, is not guaranteed or endorsed by the publisher.

Copyright (c) 2021 Claridge, Lozano, Poh and Greening. This is an open-access article distributed under the terms of the Creative Commons Attribution License (CC BY). The use, distribution or reproduction in other forums is permitted, provided the original author(s) and the copyright owner(s) are credited and that the original publication in this journal is cited, in accordance with accepted academic practice. No use, distribution or reproduction is permitted which does not comply with these terms. 